\title{
Physical Activity Modulates Common Neuroplasticity Substrates in Major Depressive and Bipolar Disorder
}

\author{
Cristy Phillips \\ Department of Physical Therapy, A-State, Jonesboro, AR, USA \\ Correspondence should be addressed to Cristy Phillips; cphillips@astate.edu
}

Received 4 November 2016; Revised 10 February 2017; Accepted 16 March 2017; Published 26 April 2017

Academic Editor: Frank S. Hall

Copyright @ 2017 Cristy Phillips. This is an open access article distributed under the Creative Commons Attribution License, which permits unrestricted use, distribution, and reproduction in any medium, provided the original work is properly cited.

\begin{abstract}
Mood disorders (MDs) are chronic, recurrent mental diseases that affect millions of individuals worldwide. Although the biogenic amine model has provided some clinical utility, a need remains to better understand the interrelated mechanisms that contribute to neuroplasticity deficits in MDs and the means by which various therapeutics mitigate them. Of those therapeutics being investigated, physical activity (PA) has shown clear and consistent promise. Accordingly, the aims of this review are to (1) explicate key modulators, processes, and interactions that impinge upon multiple susceptibility points to effectuate neuroplasticity deficits in MDs; (2) explore the putative mechanisms by which PA mitigates these features; (3) review protocols used to induce the positive effects of PA in MDs; and (4) highlight implications for clinicians and researchers.
\end{abstract}

\section{Introduction}

Major depressive disorder (MDD) and bipolar disorder (BP) are chronic mood disorders (MDs) that adversely affect over 400 million persons worldwide [1]. Pathognomonic features of MDD include the persistence of one or more episodes of sadness or anhedonia in a two-week period, together with a range of cognitive and somatic symptoms (e.g., changes in appetite, sleep patterns, energy level, concentration, or physical activity and feelings of worthlessness and guilt) [2]. In BP, persons exhibit similar symptoms in the depressive phase but alternate to euphoric states during the manic phase-a state characterized by excessive activity and libido and grandiose thinking [2]. Recent attention has focused on the inability of extant treatment approaches to induce remission of symptoms in a significant number of affected persons $[3,4]$, prompting the diversification of efforts to derive more effective treatment strategies.

Fortunately, convergent evidence demonstrates that physical activity (PA) confers neuroplastic effects $[5,6]$ and may serve as an effective intervention for MDs [7-12]. Physical exercise is a subcategory of PA that connotes purposeful, planned, and structured endeavors undertaken to improve skill or physical fitness level [12]. PA alters the progression of
MD neuropathology by optimizing the levels of neurotransmitters [13], neurotrophic factors [13, 14], beta-endorphins $[15]$, cortisol $[16,17]$, and muscle-derived protein (peroxisome proliferator-activated receptor gamma coactivator $1-\alpha$ [PGC-1 $\alpha$ ]) [18]. Moreover, regular PA optimizes processes involved in neurogenesis $[19,20]$, immune function $[21,22]$, stress regulation $[23,24]$, antioxidant defense $[25,26]$, circadian rhythms [27-29], epigenetic modifications [30, 31], and the maintenance of telomere length [32-35].

Via these complex and interrelated mechanisms, PA may reduce the risk for MDs [36-38], the degree of symptoms $[10,39]$, the incidence of relapse [40, 41], and caregiver burden [42]. This evidence, along with its relatively low-risk profile and ease of implementation [43], has led to the incorporation of PA into basic clinical management protocols for MDs [44, 45]. Because it is important that clinicians and scientists understand the means by which PA can alter pathophysiological substrates, from both a self- and patienteducation perspective, the aims of this review are to (1) elucidate key substrates implicated in MD pathobiology, (2) explore the mechanisms by which PA can mitigate them, (3) examine protocols used to effectuate the positive effects of PA in MDs, and (4) highlight implications for clinicians and scientists. 


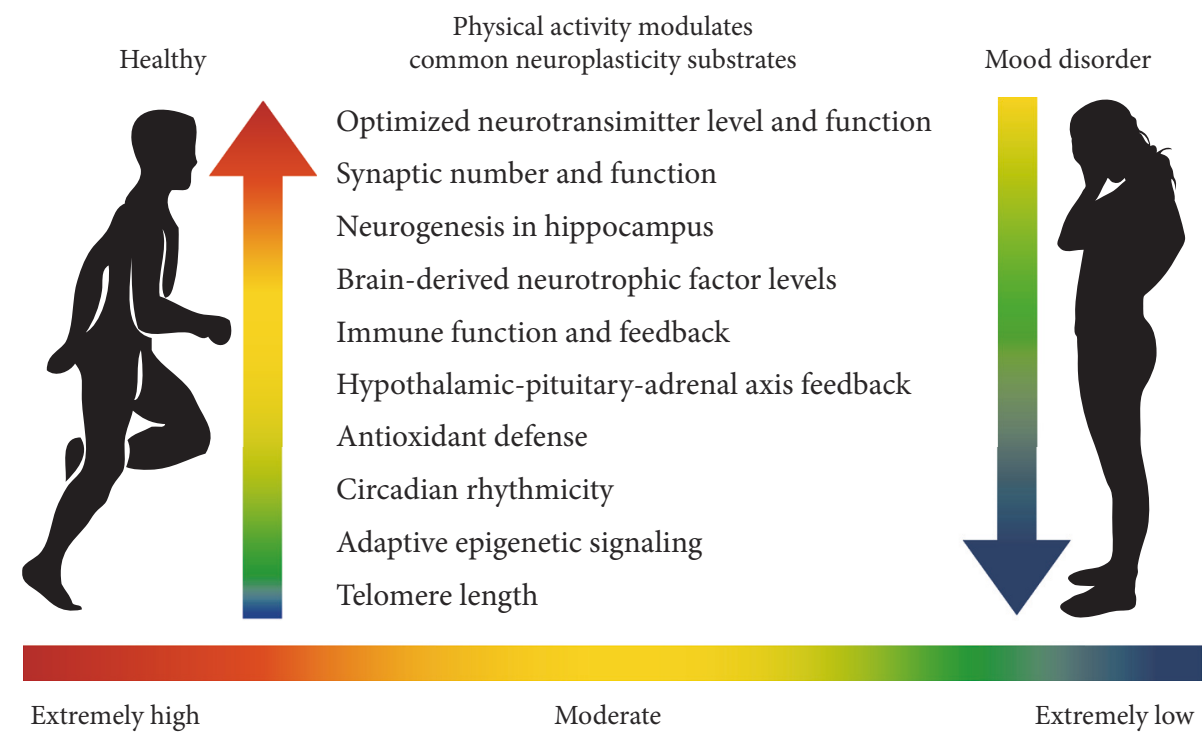

FIgure 1: Physical activity modulates common neuroplasticity substrates in the brain. Here, the effects of various levels of PA are illustrated for the person who is healthy and the person with a MD.

\section{The Neurobiology of Major Depressive and Bipolar Disorders}

Recent decades have noted dramatic progress in the neurobiological understanding and treatment of psychiatric conditions. On the one hand, psychiatrists have refined diagnostic categories based on clinical symptoms [46, 47]. On the other hand, neuroscientists have derived evidence of transdiagnostic biomarkers across psychiatric conditions [48-50], including those that modulate neuroplasticity substrates in MDs [51-54]. Early biologic theories focused upon neurotransmitters, particularly the biogenic amines [55]. Subsequent advances in technology heralded new abilities to characterize general and distinctive cellular and molecular mechanisms, genetic contributions, and structural correlates of psychiatric disease $[56,57]$. Although a complete description of these advances is beyond the scope of this article, a cursory review of MD neurobiology will be presented before focusing on neuroplasticity substrates. The reader is referred to the following excellent reviews for a more comprehensive presentation on the neurobiology of MDD [3, 58-60] and BP [61-64].

2.1. Major Depressive Disorder. Neuroimaging studies of depression and analysis of surgical lesions (that induce or reverse depressive symptoms) have revealed mood circuits $[65,66]$. Implicated in these circuits are several brain structures and regions, including the dorsal prefrontal cortex, ventral prefrontal cortex, anterior cingulate gyrus, amygdala, hippocampus, striatum, and thalamus [67-69]. Drevets et al. have emphasized the pathophysiological processes and dysfunction of multiple pathways that adversely affect mood circuits and structures $[66,70]$, including those related to genetic, epigenetic, and environmental factors. Results from a twin study suggest that the heritability of MDD is $38 \%$ [71]. Preclinical studies implicating epigenetic mechanisms have shown that maternal behavior alters the function of stress-related genes [72] and that antidepressants alter the regulation of DNA $[73,74]$. Other studies have shown that depletion in neurotransmitter levels contributes to depressive symptoms [55, 75]: slow-acting neurotransmitters (e.g., dopamine, serotonin, and norepinephrine) appear to interact with signaling proteins found inside the cell membrane in a way that allows the receiving cells to process signals from glutamate and $\gamma$-aminobutyric acid (GABA). Accordingly, therapeutic agents for MDs were derived to increase monoamine transmission acutely, either by inhibiting neuronal reuptake or by inhibiting degradation in the synaptic cleft. While this strategy has demonstrated some utility in the alleviation of symptoms, the fact that monoamine depletion fails to produce depressive symptoms in healthy individuals [76] or worsen depressive symptoms in persons with MDD [77, 78] induced a more comprehensive search for mechanisms. Subsequent work has implicated general disruption in neurogenesis [79], trophic factor level and function [80], antioxidant defense [81], hypothalamicpituitary-adrenal (HPA) axis function [82], immune regulation [83], neuroplasticity [84], and circadian rhythms $[85,86]$, changes that collectively contribute to neuronal network alterations [84, 87]. Interestingly, the patterns of disruption to neurogenesis, immune system function, and antioxidant defense in MDD are similar in many respects to the patterns of disruption that are seen in BP. Also notable is evidence that has suggested a "kindling process" wherein depressive episodes are triggered more readily over time [88] and the number of prior episodes is a better predictor of future episodes than life stress is [89].

2.2. Bipolar Disorder. The complex pathophysiology of BP is undoubtedly mediated by genetic and epigenetic factors acting in concert with environmental stressors [90] to effectuate functional and structural abnormalities in the interconnected limbic, striatal, and fronto-cortical neurotransmitter neuronal circuits [91] and in plasticity substrates [51-54]. A robust 
genetic basis for BP has been derived from familial and identical twin studies: concordance rates for BP among identical twins typically range from 40 to $70 \%$, with the estimated heritability reaching as high as $90 \%$ [92]. Notwithstanding, genome-wide studies have failed to detect single-gene contributions, supporting the premise that $\mathrm{BP}$ is a polygenic condition [92]. Strikingly, while some distinctions in genetic risks exist between $\mathrm{BP}$ and other psychiatric conditions, a high degree of genetic overlap has been reported among BP, MDD, and schizophrenia $[48,93]$. Putative interactions between genes and life stresses are thought to effectuate disruptions in homeostatic and neuroplastic mechanisms [94, 95] and increase the severity of symptoms [95]. Parallel work has demonstrated disruption of glucocorticoid signaling [96], neurogenesis [97], immune-inflammatory imbalance [98], and antioxidant defense [99], changes that contribute to increased loss of volume in brain regions vital for mood regulation and cognitive function [65]. The identification and understanding of mechanistic pathways common to BP and MDD offer an opportunity to deploy novel lifestyle interventions such as PA to target these disorders in an integrated fashion.

\section{Neuroplasticity}

The ability of the central nervous system to continuously adapt to challenges is accomplished by neuroplasticity, a process wherein neurons change and reorganize to meet the demands of the environment [100]. Neuroplasticity is dependent upon stimulus-induced synaptic activity and membrane depolarization which, in turn, induce receptor trafficking, the activation of a multiplicity of genes, and the release of neurotransmitters. The secondary messengers effectuate downstream changes in the brain that permit its resculpting. Emotional and cognitive learning, neural homeostasis, and adjustments in behavior rely on biological correlates of neural plasticity for adaptation $[53,101]$. Plastic changes in the brain can be maladaptive wherein a net loss of function occurs [102], a situation that reifies in MDs [103, 104]. On the other hand, brain plasticity can be adaptive when a gain of function occurs [105]. That is, PA can modulate common neuroplasticity substrates in the brain (as described in Figure 1) and then cognitive stimulation (e.g., cognitive behavioral therapy) can increase the likelihood of behavioral change in MDs [106].

\section{Measurement of Voluntary Physical Activity in Humans}

Voluntary PA refers to locomotor activity that is not directly required for survival or motivated by an external factor (such as searching for food, shelter, or mates; interacting with competitors; or avoiding predators) [107]. Human voluntary PA occurs in a multiplicity of ways and varies tremendously in both intensity and duration, both of which modulate its physiological consequences. Several indirect and direct assessment methods have been used to investigate the effects of voluntary PA in humans-including retrospective questionnaires, surveys, activity logs, motion sensors, heart rate monitors, calorimetry, and direct observation [108] - with different methods possessing unique strengths and weaknesses. The majority of early studies used self-reports of PA, particularly given their ease of administration, cost effectiveness, positive acceptance, and lack of intrusiveness on personal habits [109, 110]. Yet, while the administration of questionnaires at the population level has proved to be a feasible method of assessment, some evidence suggests that they are the least valid and reliable measure [107, 110-112]. In contrast, direct measures of voluntary PA assess energy expenditure [113] or actual movement [114] and are less susceptible to response and recall biases [113, 115, 116]. Notwithstanding, large-scale studies using direct measures have not been feasible in the general population [117]. Additionally, it seems plausible that long-term monitoring of PA with direct measures would sacrifice face validity by increasing intrusiveness and burden on participants $[107,116]$. The inverse relationship between the validity and feasibility of assessment methods [107] has prompted recent investigations to use direct measures and standardized interventions in smaller populations. Studies of this type are vital because direct measures provide a means to examine a cause and effect relationship between PA and neuroplasticity substrates. Accordingly, several investigations that aim to determine the neurobiological, psychological, and physiological effects of PA on humans are systematically reviewed in Table 1. Analysis of these investigations reveals that PA generally produces antidepressant effects and improves cognitive function, enhances quality of life, improves sleep, optimizes brain-derived neurotrophic factor (BDNF) levels and function in the hippocampus, and enhances fitness measures.

\section{Measurement of Voluntary Physical Activity in Animal Models}

Multiple animal studies have been conducted to ascertain the effects of PA on brain structure and function. Specifically, investigators have deployed a voluntary wheel-running model in rodents to simulate PA in humans $[118,119]$, an avenue that provides unfettered hypothesis-driven discovery. Bolstering support for the model is evidence that (1) voluntary wheel running is a self-rewarding behavior that allows rodents to choose how much to run while avoiding the stress of forced running or investigator handling $[107,120,121]$, (2) rodents show a conditioned preference to the place associated with wheel running [122] and can perform an instrumental reaction to garner access [123], (3) agerelated decrements in PA occur in both rodents and humans $[124,125]$, (4) both running wheel access in rodents and voluntary PA in humans induce changes in brain reward systems [107], and (5) voluntary wheel running and voluntary PA occur in low-energy expenditure contexts such as laboratory housing and industrialized Western society $[107,126]$.

The historical preference for voluntary wheel running as opposed to forced treadmill running has derived from the notion that forced running on motorized treadmills may cause the release of stress-linked hormones, which could 


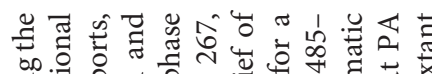

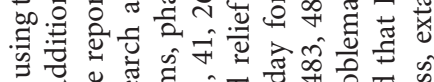

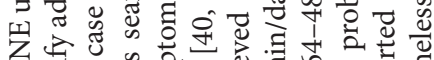

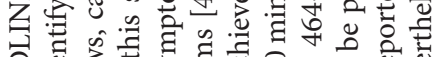

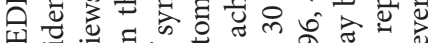

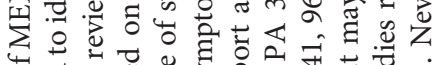

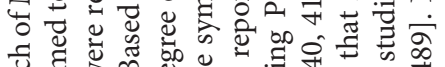

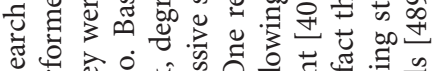

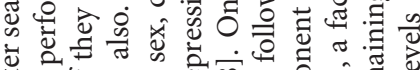

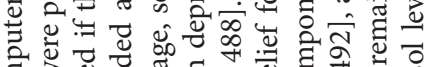

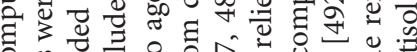

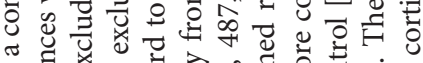
की

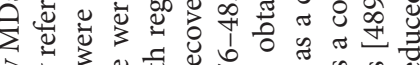

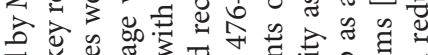

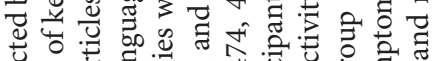

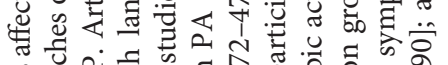

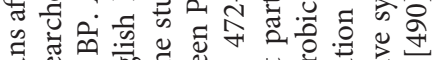

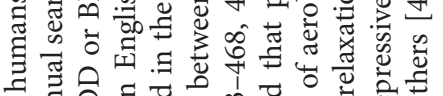

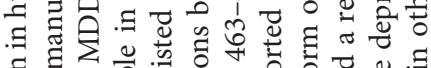

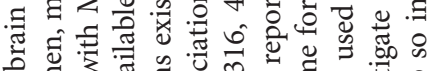

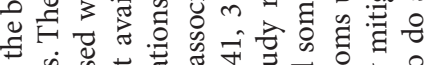

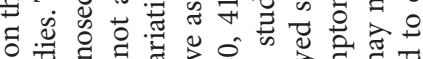
记

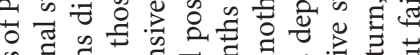
号. कै

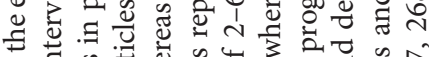

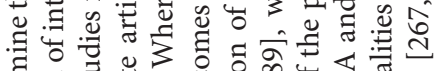

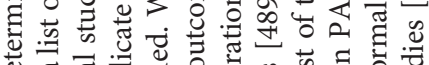

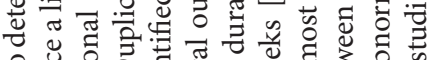

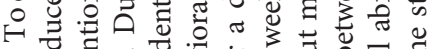

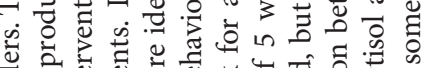
눙 诺

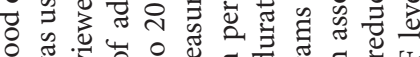

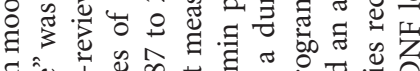

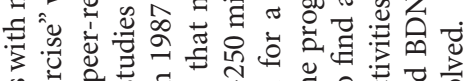

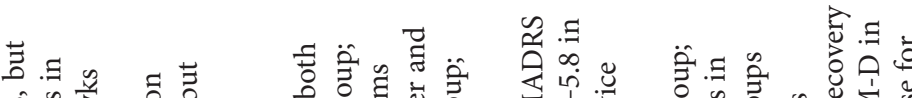

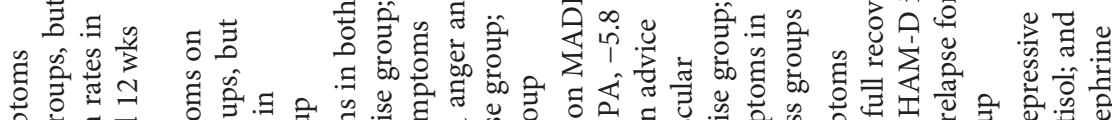

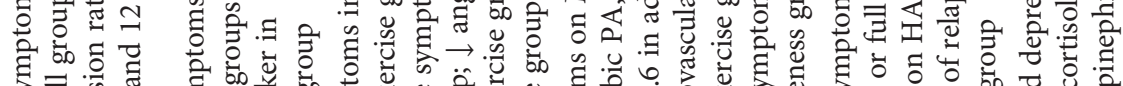

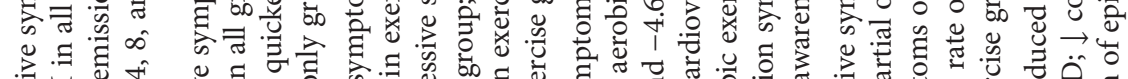

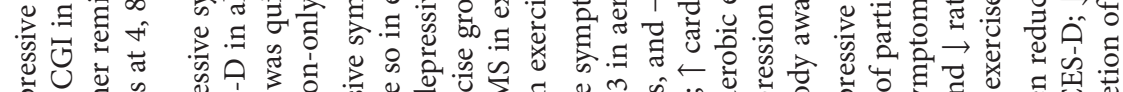

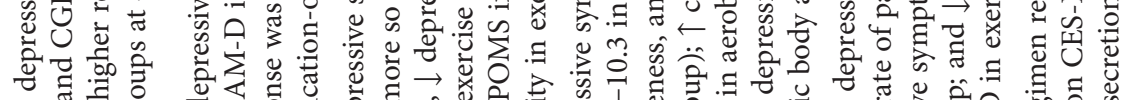

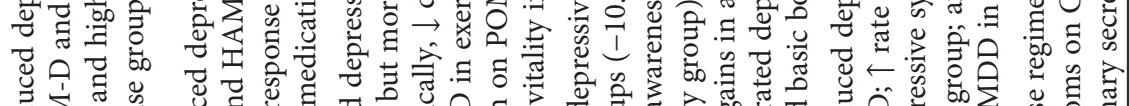

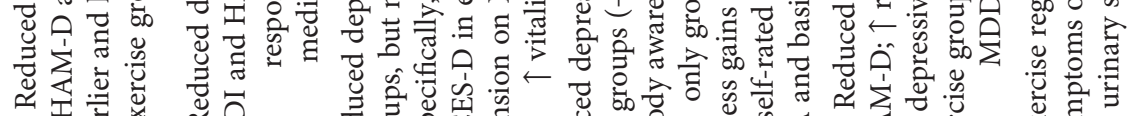

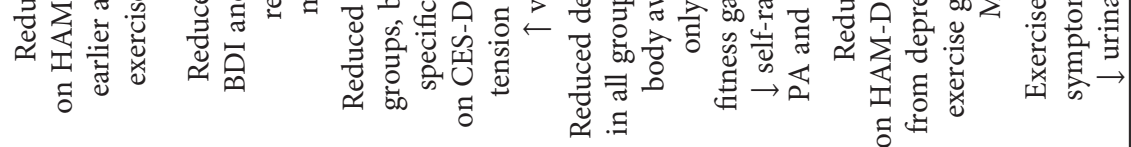

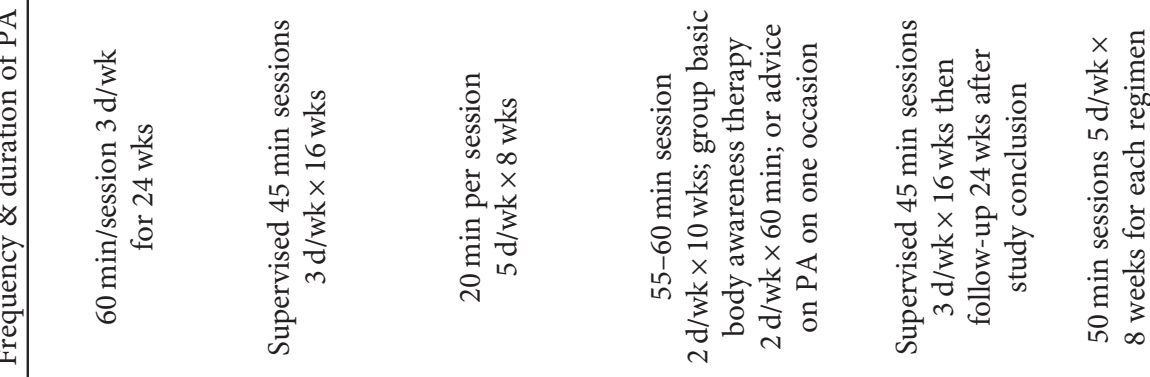
可 ơ

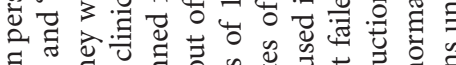
a

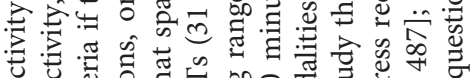

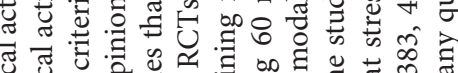

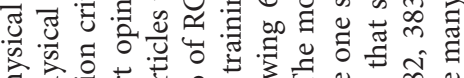

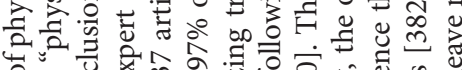

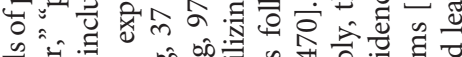

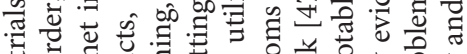

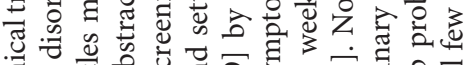

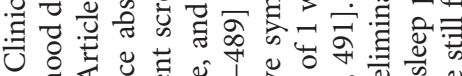

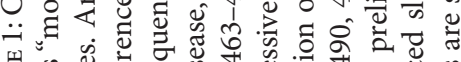

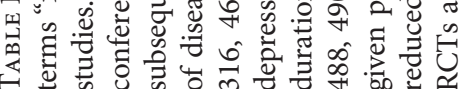

焉

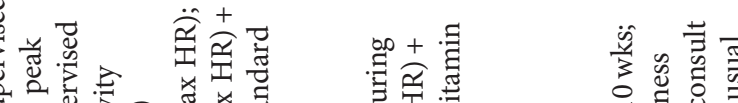

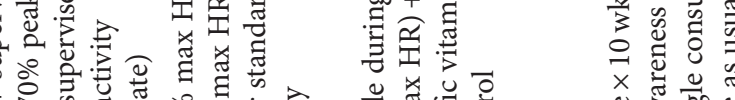

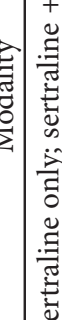

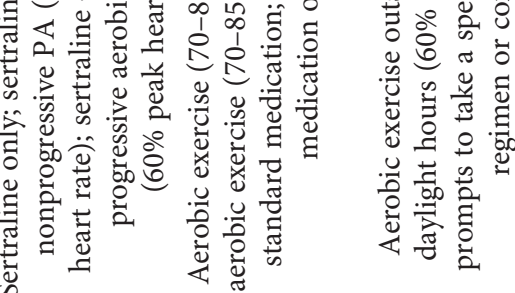

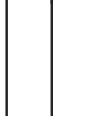

\begin{tabular}{|c|c|c|c|c|}
\hline 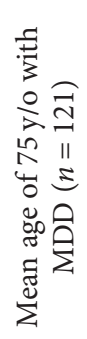 & 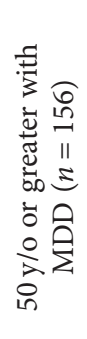 & 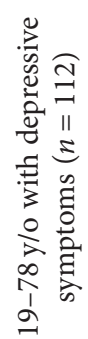 & 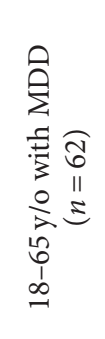 & 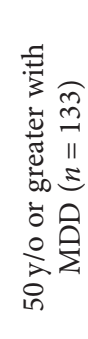 \\
\hline 鹿 & 趈 & 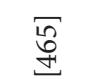 & 骂 & $\bar{\exists}$ \\
\hline
\end{tabular}




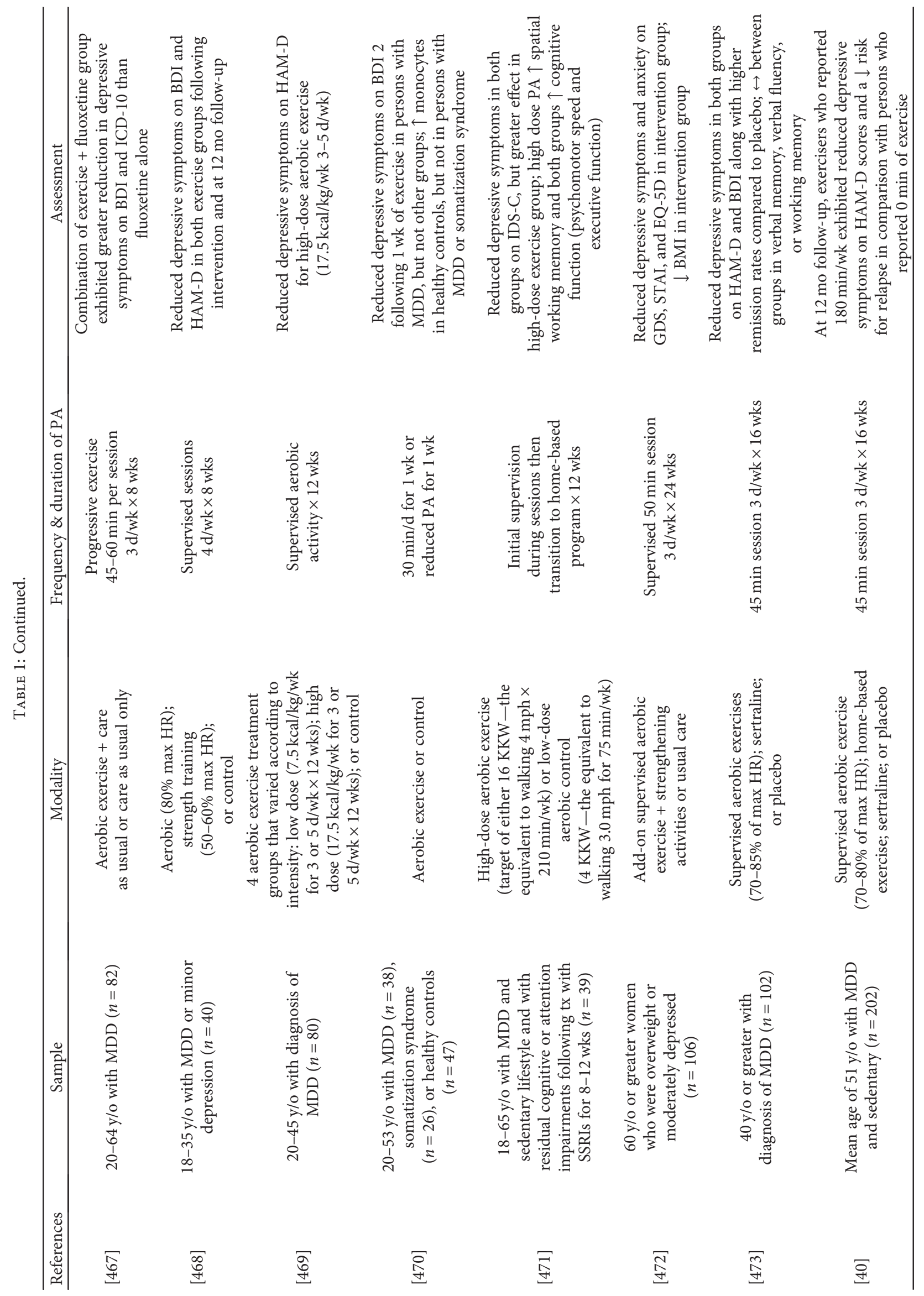




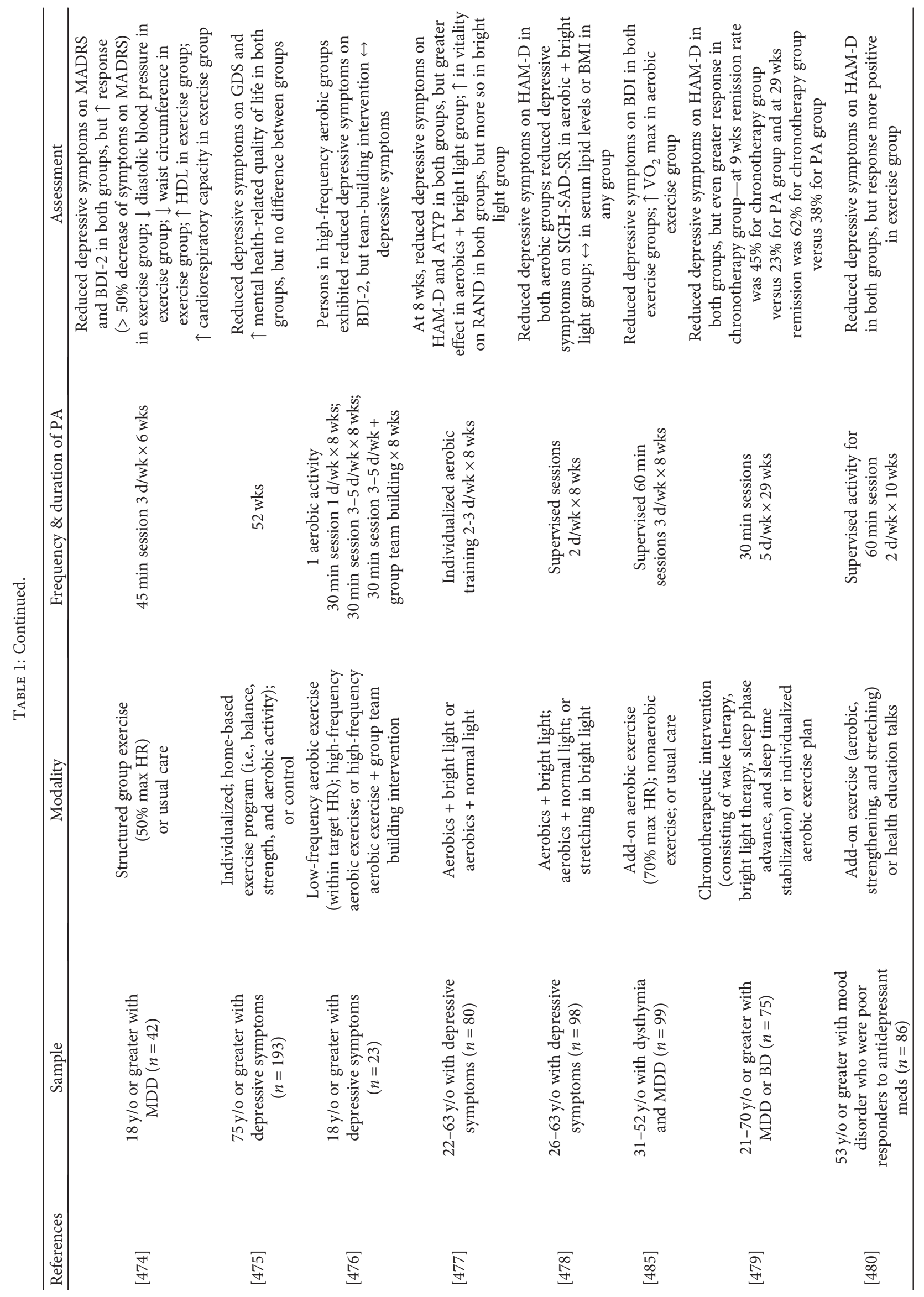




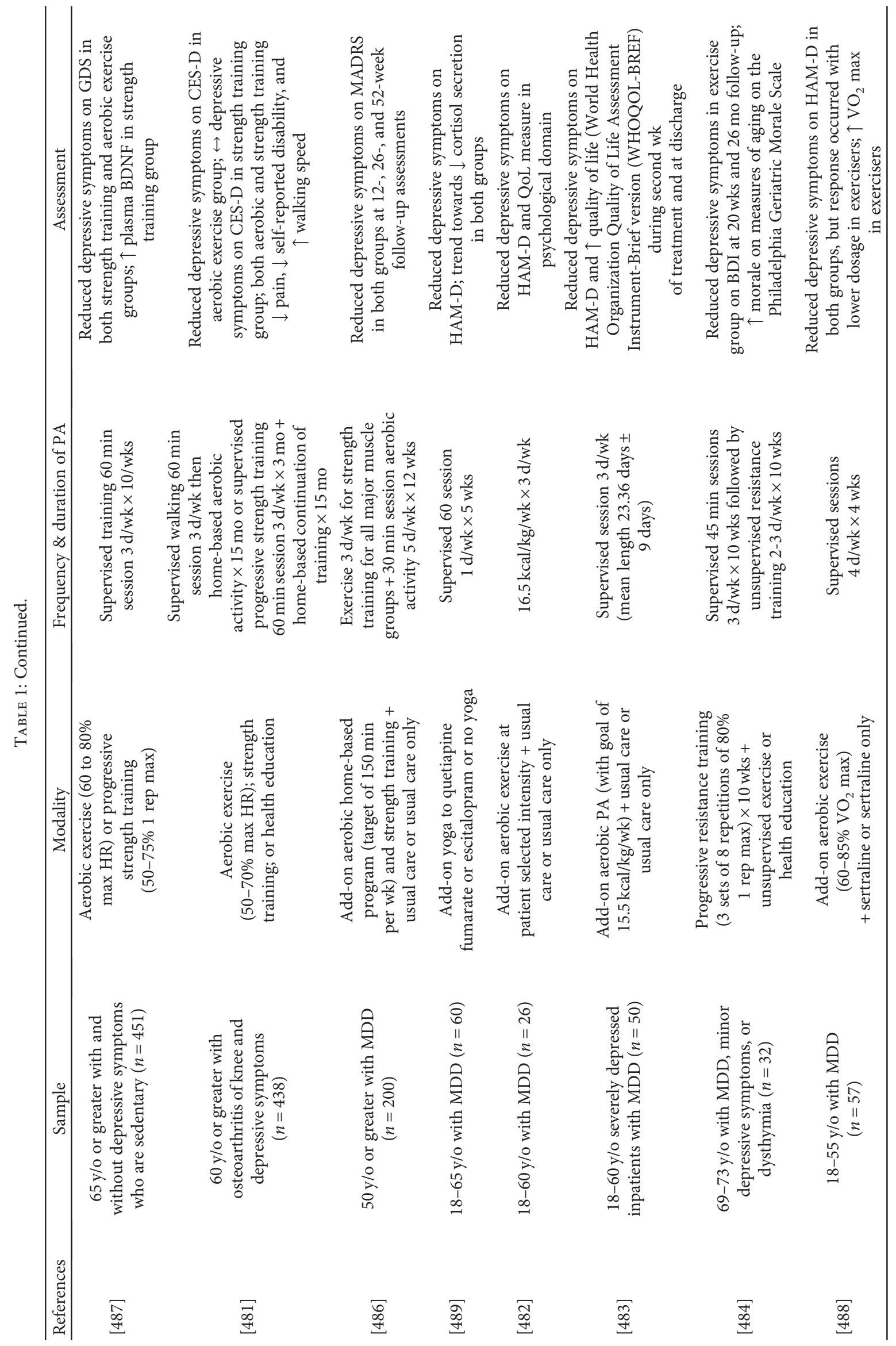




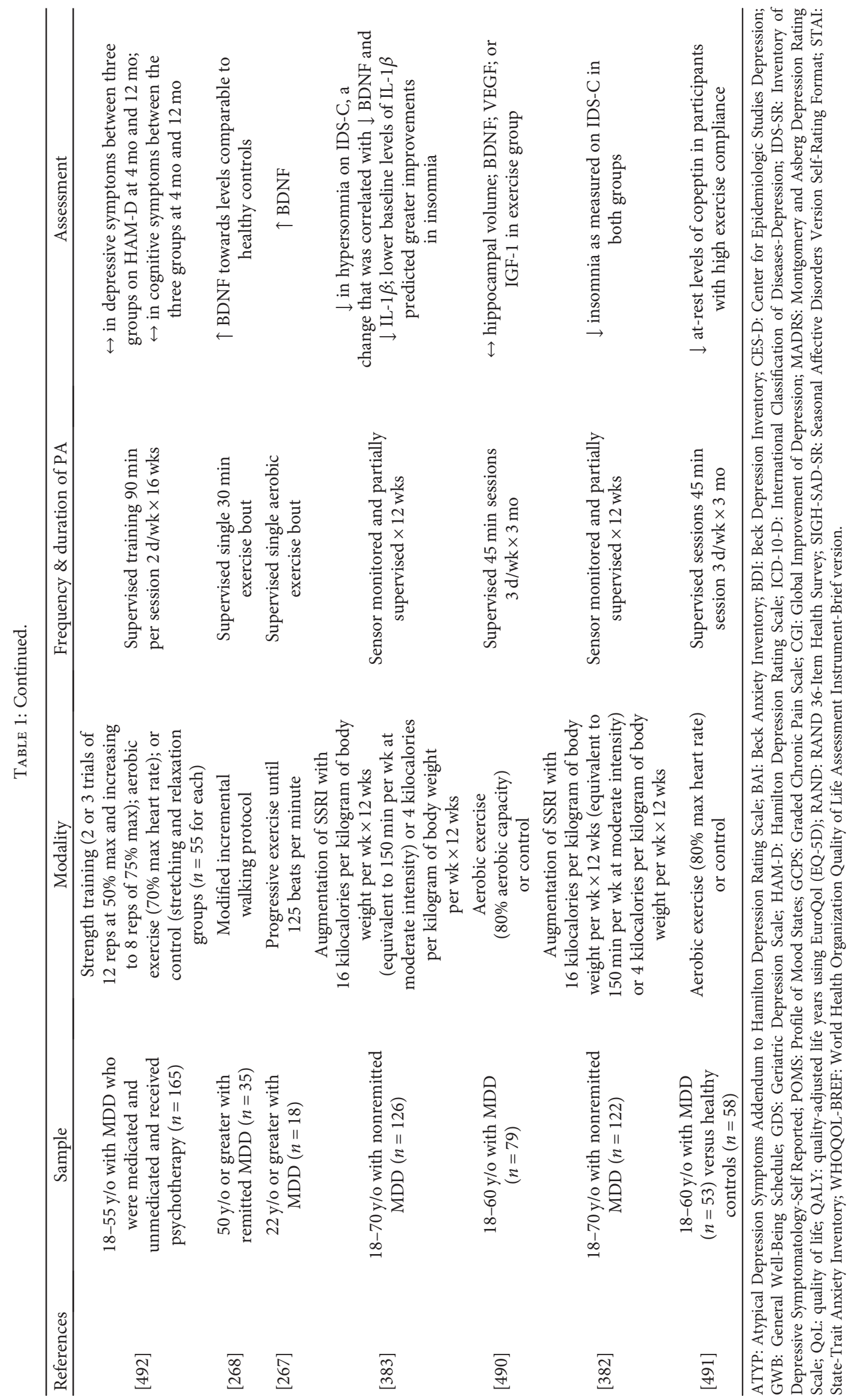


negate neuroplastic mechanisms. Bolstering this idea are preclinical and clinical studies that have shown that restriction of control during activity is deleterious [127-129], whereas the ability to exert control is beneficial for neurobiology and mental health [130]. Recently expanding on this notion, Greenwood and colleagues [131] sought to investigate the effects of forced and voluntary PA on emotional resilience. To do so, they designed a set of experiments with five exercise conditions: sedentary controls, forced treadmill training with motion initiated by foot shock, forced running on motorized wheels designed to approximate rats' voluntary running behavior, voluntary wheel running, and voluntary wheel running in an environment matched to the forced-wheel group. Then, all animals were exposed to stress-inducing conditions (restrained in Plexiglas tubes and exposed to uncontrollable tail shock), and their escape and fear responses were monitored. Interestingly, both forced and voluntary PA on running wheels prevented the behavioral consequences of stress, but forced treadmill training with foot shocks did not. The fact that wheel runners whose activity was forcibly started and stopped in naturalistic patterns (a model that mimics circuit training) also exhibited increased stress resistance [131] suggests that the ability of PA to regulate emotion and stress resilience may be modulated by the pattern of aerobic activity as long as (1) intensity, duration, and distance thresholds are sufficient; (2) the pattern of activity is naturalistic; and (3) the degree of stress is minimized [132].

While the study of affective symptoms in rodents is difficult, well-developed behavioral assays exist, as thoughtfully characterized in a review by Holmes [133]. From these studies, it has been shown that running reverses stress-related deficits and mitigates depressive and manic behavioral outcomes. Also, most of these studies report that PA increases neurogenesis in the hippocampus, reduces the length of corticosteroid exposure following stress, improves circadian rhythmicity, increases synaptic plasticity gene activity, and increases hippocampal BDNF in models of depression. A summary of preclinical studies that investigated the effects of voluntary wheel and motorized treadmill running on neurobiological, psychological, and physiological outcomes in rodents is systematically presented in Table 2.

Evidence that impairments in neural plasticity are implicated in MDs [103] and that PA modulates common neuroplasticity substrates (neurotransmitters, synaptic number and function, neurogenesis, BDNF, inflammation, stress reactivity, antioxidant defense, circadian rhythm, epigenetic modifications, and alteration of telomere length) in MDD and BP has led to numerous attempts to harness neuroplasticity to promote healing and recovery [134], particularly as it applies to psychiatric disease $[135,136]$. Fortunately, convergent evidence suggests that long-term PA is positively correlated with positive neurobiological, affective, and cognitive outcomes, as reviewed below.

\section{Neurotransmitter Levels and Function and Physical Activity}

A pathognomonic feature of MDD [55, 137] and BP [137-139] is aberrant neurotransmitter level and function, a situation that can adversely affect synaptic plasticity. It has been suggested that depressive symptoms are caused in part by a deficiency in neurotransmitter levels (serotonin, norepinephrine, and dopamine), whereas manic symptoms are caused by excess levels, a notion premised on the study of psychological and cellular actions of several psychotropic agents [140]. Both types of fluctuation are problematic given the inverted U-shaped function of neurotransmitters: moderate levels are required for optimal emotional and cognitive function [141]. Fortunately, PA can optimize the synthesis, metabolism, and release of serotonin [142-146], norepinephrine $[143,147,148]$, dopamine $[143,149,150]$, and glutamate [151-153].

In the serotonergic system, the ability of PA to restore depleted neurotransmitter levels in the cerebral cortex, hypothalamus, brainstem, and hippocampus [143, 154] occurs via three primary mechanisms. PA increases the relative proportion of free tryptophan peripherally [155], a condition which favors influx across the blood-brain barrier [156]. Also, PA modulates the activity of tryptophan hydroxylase $[157,158]$ and inactivates indoleamine 2,3-dioxygenase and tryptophan 2,3-dioxygenase, which are rate-limiting enzymes that, following stress, shunt metabolism of tryptophan towards the kynurenine pathway in lieu of the serotonin pathway $[156,159,160]$.

In the noradrenergic system, PA's neuroprotective effects stem from an adaptive response [145] wherein upregulated galanin expression hyperpolarizes noradrenergic neurons and thereby inhibits excessive norepinephrine release from the locus coeruleus [161-164]. Moreover, PA increases the conversion of cortisol to its inactivated form (cortisone) [165] to dampen an individual's reactivity to stress [166-168].

In the dopaminergic system, long-term PA optimizes dopamine metabolism [149, 169] via putative mechanisms that modulate tyrosine hydroxylase activity [170], rate of dopaminergic turnover [171], and calcium levels [172, 173]. The optimization of dopamine levels is important because dopamine levels modulate motivation and reward behavior [174]. That is, deficiencies in dopamine have been related to depression $[175,176]$, whereas excess dopamine levels have been related to mania [98].

Recently, considerable work has focused on the putative role of glutamate and the N-methyl-D-aspartate receptor (NMDAR) in the pathophysiology of MDs. Physiologic modulation of glutamate is imperative given its central role in synaptic strength and plasticity [177-179], yet alterations in plasma, serum, and cerebrospinal fluid have been reported in MDs [180]. Notably, PA enhances glutamate turnover and prevents excitotoxicity [151, 181] by improving calcium regulation [182]. The former mechanisms reciprocally interact with corticosteroid signaling and neural plasticity processes. Conversely, PA can mitigate glutamate hypofunctioning [183]. Maddock and colleagues [152] demonstrated that long-term PA increases glutamate in the anterior cingulate cortex, a significant finding given that glutamate contributes to the production of glutathione, a pervasive antioxidant in the central nervous system. Finally, PA increases the expression of NR2A and NR2B glutamatergic receptors in the hippocampus, 


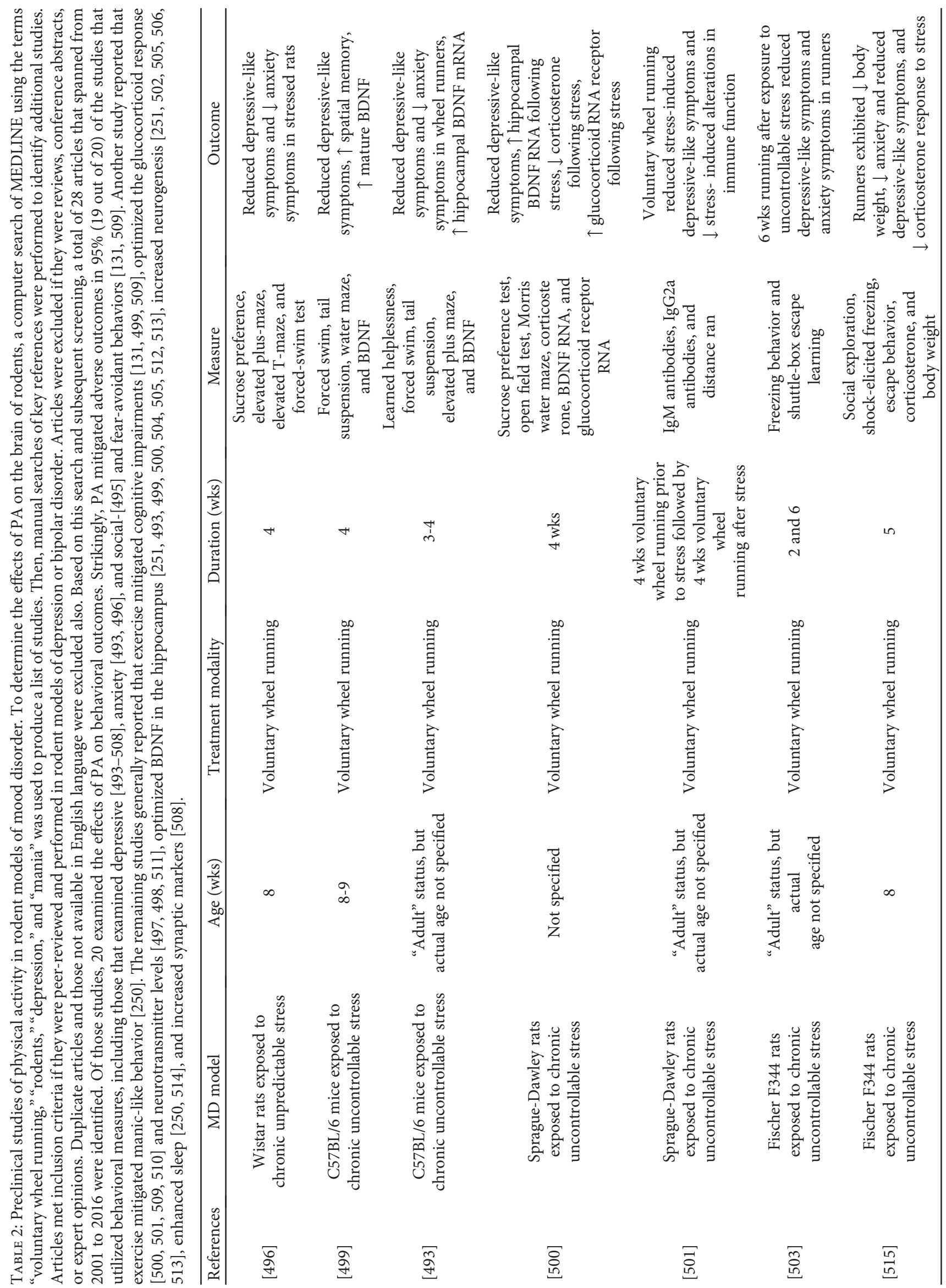




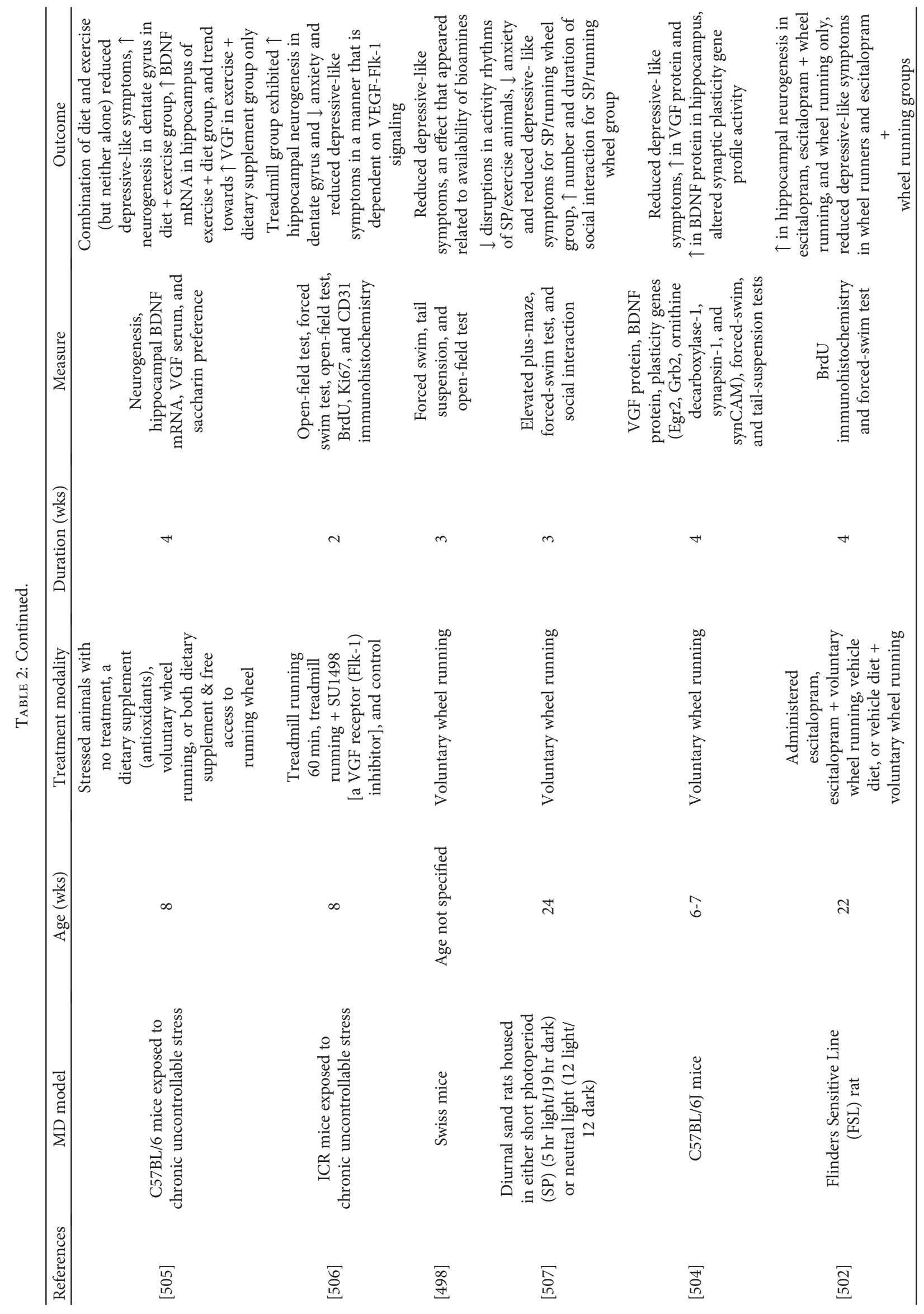




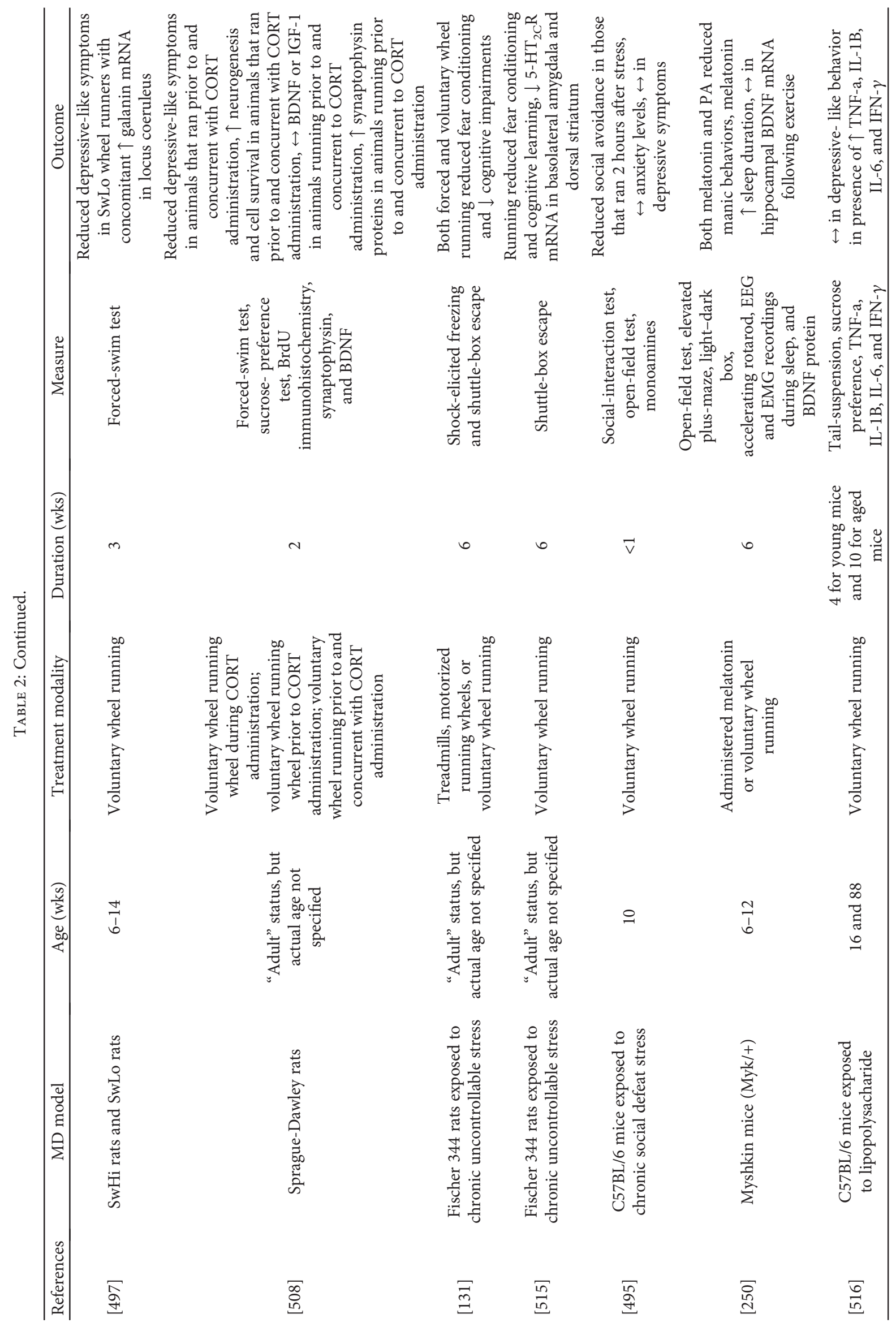




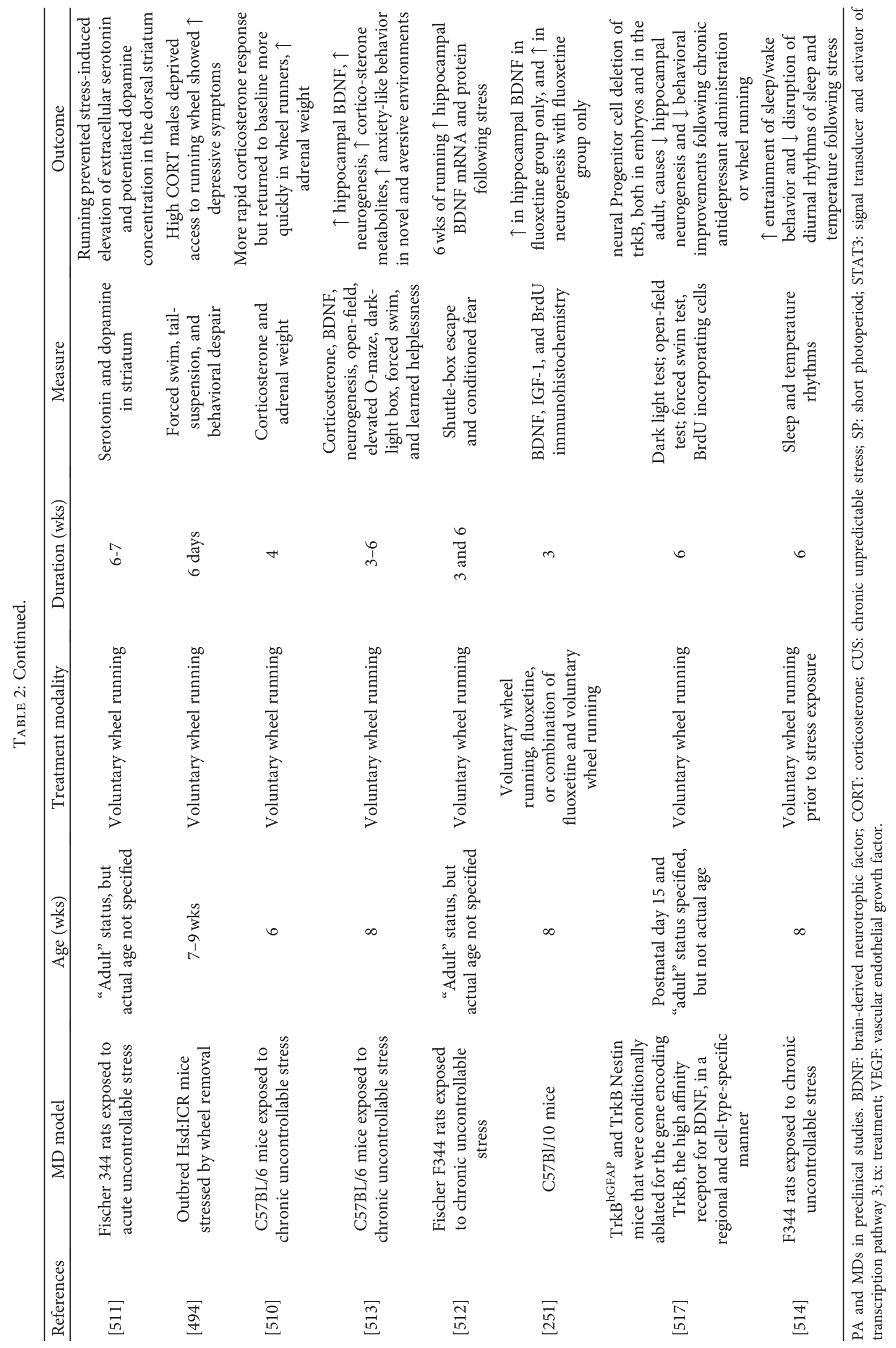


receptors that are associated with neurogenesis and synaptic plasticity $[184,185]$.

Altogether, these studies suggest that PA modulates the underlying pathobiology of MDD [186] and BP [187] by altering the levels of key neurotransmitters that regulate emotional and cognitive health. In turn, the modulation of these neurotransmitters promotes the maintenance, repair, and survival of neurons and induces changes in molecular and cellular plasticity [188-190], effects similar to those exerted by antidepressants and antipsychotics.

\section{Synaptic Number and Function and Physical Activity}

As fundamental sites of communication between a neuron and its partner cell, synapses play an important role in emotion and cognition. Synapses exhibit plasticity, wherein synaptic function and structure are modified in response to activity and factors in the cellular milieu. Long-term potentiation is one form of functional synaptic plasticity, wherein synaptic connections between synapses are strengthened following activity, a process that is fundamental to learning and memory [191]. Long-term depression is another form of functional plasticity, one that is associated with the process of forgetting, where a set of synapses display a reduced capacity to elicit a response in one another [192]. Working in concert, long-term potentiation and long-term depression regulate homeostatic plasticity and the function of neuronal circuits [193]. Structural plasticity refers to changes in the 3-dimensional structure of neurons and their connections.

Convergent evidence suggests that changes in structural and functional plasticity at the synapse are relevant to MDs [194-198] and can adversely affect emotional [199] and cognitive function [200]. Indeed, loss of synapses is a common characteristic of MDD [201, 202], resulting in disconnection and loss of function in key brain regions [80, 203, 204] such as the association cortices and hippocampal region [205]. Rodent models of BP have revealed concentrated levels of ankryin-G at the synapse (which is vital for AMPARmediated synaptic transmission and maintenance of spine morphology), an intriguing finding given that this gene is robustly associated with the disorder [206].

The lack of noninvasive methods for the study of synaptic function precludes direct examination in humans in vivo, prompting the use of proxy measures. Accordingly, neuroimaging studies have revealed smaller hippocampal volume in persons with MDD and BP [194-198, 207]. Moreover, the study of the hippocampus in persons with MDs has revealed that volumes are inversely associated with symptom severity and duration, but positively associated with treatment outcomes [196, 208-210].

Fascinatingly, studies have shown that PA mitigates deficits in synaptic plasticity in the hippocampus. It has been shown that for aging adults, long-term exercise counters agerelated decrements in hippocampus size and protects against memory impairment [211-214]. Another study has demonstrated that healthy people who participated in long-term PA (e.g., aerobic exercise 3 times per week, 30 minutes per session, for 12 weeks) exhibited increased hippocampal volume [214], a finding that could be attributed to an increase in the number of synapses, their projections, or a combination of both. Erickson and colleagues [212] demonstrated that 1 year of aerobic exercise of moderate intensity improved memory and hippocampal volume in healthy older adults, effectively reversing the age-related loss of volume by 1-2 years. Extending these studies, Makizako and colleagues [20] demonstrated that hippocampal volume was the link between moderate PA and memory augmentation in people with mild cognitive impairment and that greater durations of moderate PA resulted in increased hippocampal volume and improved memory. Also, preclinical work has demonstrated that aerobic exercise reverses age-related decrements in long-term potentiation in the dentate gyrus region of the hippocampus $[215,216]$ and increases spine density in the entorhinal cortex and CA1 region [217]. Moreover, voluntary wheel running by rodents for 3 weeks changes the level of several gene transcripts known to be associated with synaptic structure and plasticity, indicating that PA elicits different gene expression profiles relevant for brain function [31]. Together, these studies suggest that PA promotes structural and functional plasticity in key regions of the brain that are adversely affected by MDs and, thereby, may be used to promote functional connectivity in persons with MDs [215, 216, 218].

\section{Neurogenesis and Physical Activity}

Neurogenesis in the adult mammalian brain is a form of experience-dependent plasticity wherein stem cells within distinct regions of the brain give rise to new neurons $[219,220]$ that then migrate to the dentate gyrus of the hippocampus to become integrated into circuits important for learning, memory, and emotional regulation $[5,6,221,222]$. The $20,000,000$ neurons generated over the course of a lifetime replace dead or dying neurons [219] and, in turn, enhance functional capacity to modify neural circuitry in an environmentally dependent manner [223] as both intrinsic and extrinsic factors alter the rate of neurogenesis [223, 224]. Such is relevant for persons with MDD [79] and BP [97] because the elevations in glucocorticoid levels that frequently accompany MDs reduce neurogenesis rates and effectuate volumetric decrements in the hippocampus [225]. Conversely, pharmacological blockade of glucocorticoid receptors [226] blocks decrements in hippocampal size, as can antidepressant [227] or lithium [207] administration.

Also, preclinical and clinical work suggest that rates of neurogenesis can be optimized with exercise. Voluntary wheel running in rodents potently induces neurogenesis in the dentate gyrus, changes that result from increased proliferation and differentiation of neurons [228-230]. The newly born neurons can then integrate into the hippocampal architecture, a process that takes 4-8 weeks [231]. Interestingly, the newly integrated hippocampal neurons exhibit a lower excitability threshold and enhanced neuroplastic capabilities [223]. The latter fact suggests that PA not only mitigates volumetric decrements but also may contribute to neuroplastic changes that enable the reversal of MD-related emotional and cognitive deficits. Indeed, enhanced neurogenesis in 
animal models has been positively correlated with improvements in learning and memory [19, 232]. A clinical study has demonstrated that regular aerobic exercise of moderate intensity (as measured by an accelerometer worn on the hip for 2 weeks) was associated with increased hippocampal volume in older adults, findings positively associated with the encoding of new memories [233]. Thus, PA-induced hippocampal neurogenesis offers considerable hope for exploiting newly born cells and their heightened plasticity to reestablish hippocampal brain circuits that have been damaged as a result of the neuroprogression of MDs [224, 228-230, $234,235]$, particularly when paired with environmental enrichment (e.g., cognitive behavioral therapy).

\section{BDNF and Physical Activity}

Neurotrophins-vital proteins in the brain-contribute to the survival, growth, and maintenance of neurons $[218,236]$ and participate in a variety of learning and memory functions [237]. BDNF, one of the most widely distributed neurotrophins in the brain, plays a vital role in the maintenance of neurons that underlie emotion and cognition, including those adversely affected in MDs $[238,239]$. The neuronal atrophy and dysfunction incurred during the course of MDs effectuate disruptions in neurotrophic support, particularly BDNF. A bevy of BDNF-related abnormalities have been associated with MDs. It has been shown that (1) serum levels of BDNF are reduced in persons with $\mathrm{BP}$ [240, 241] and MDD [242, 243]; (2) reductions of BDNF occur in the hippocampus in MDD and BP [244]; (3) serum levels of BDNF normalize in response to several treatments (e.g., antidepressants in MDD [242, 245], mood stabilizers and antipsychotics in BP [246-248], electroconvulsive therapy in MDD and BP [249], and PA in models of BP [250] and depression [251]); (4) polymorphisms in the BDNF gene are associated with MDD [252, 253] and BP [254, 255]; and (5) mature BDNF plays a critical role in brain plasticity and is intimately involved in cognitive and mood-related behaviors [236]. Accordingly, BDNF is generally regarded as a putative biomarker for BP $[239,256]$ and $\operatorname{MDD}[239,257]$.

Recognition of the aforementioned facts, along with the fact that BDNF is highly inducible by PA, has piqued the interest of multiple laboratories in recent years [6]. Accordingly, it has been shown that PA robustly upregulates the expression of BDNF in the hippocampus of rodents [258-261], changes that endure for days [261]. Moreover, recent work has demonstrated that peroxisome proliferatoractivated gamma receptor coactivator 1-alpha (PGC-1 $\alpha$ ) and FNDC5, muscle-derived proteins that increase following endurance exercise, regulate BDNF expression in the brain in the hippocampus of mice [262]. Such is relevant for stressinduced depression given the interaction with neuroinflammatory and neuroplasticity pathways $[263,264]$ via alterations in tryptophan degradation $[264,265]$ and $5-\mathrm{HT}_{1 \mathrm{~A}}$ receptor activation [266]. Thus, PA may protect against stressinduced depression by altering kynurenine metabolism [18] and, thereby, modulating BDNF levels.

Notably, PA-induced increases in BDNF have been recapitulated in unmedicated patients with MDD [267], elderly persons with remitted depression [268], and women with BP [269]. Moreover, parallel clinical studies in elderly adults have linked acute aerobic PA (until heart rate reached $85 \%$ of max capacity) with alterations in frontal cognitive functions [270], changes that may be particularly beneficial for the domains of attention, processing speed, and memory [271].

Together, these results suggest that PA may effectuate central neuroplastic adaptations via optimization of BDNF levels in persons with MDD and BP. The ability of PA to enhance BDNF release and function in the synapse, promote dendritic spine integrity, and concomitantly activate other cellular pathways $[80,179,203,272]$ is a cornerstone for neuroplastic processes that are necessary to repair and reorganize circuits damaged during the course of MDs.

\section{Inflammation, Immune Function, and Physical Activity}

The dramatic release of inflammatory cytokines following chronic mental or physical stress is a well-known harbinger of MDD [83, 273] and BP $[98,274]$ through mechanisms involving neuroplasticity, cell resilience, and neuronal survival $[275,276]$. It has been shown that persons with MDD exhibit elevated levels of inflammatory cytokines including C-reactive protein (CRP), interleukin- (IL-) 1, IL-6, and tumor necrosis factor- $\alpha$ (TNF- $\alpha$ ) $[277,278]$. Yet, the most robust evidence for the role of inflammation in the causation of MDD derives from evidence that chronic cytokine immunotherapy induces depression in a significant number of patients $[279,280]$. This trend is also seen in BP. Persons who were in the depressive phase exhibited increased IL-2, IL-6, IL-8, CRP, and TNF- $\alpha$ [274, 276]. Persons with $\mathrm{BP}$ in the manic phase exhibited increased proinflammatory markers (CRP, IL-2, IL-4, IL-6, and TNF- $\alpha$ ) $[274,276]$, and mood symptoms have been positively correlated with IL-6 and IL-2 [276]. Fortunately, administration of cyclooxygenase- 2 inhibitors and antagonists of TNF- $\alpha$ inhibits inflammatory markers in persons with MDD and BP [281-284]. Moreover, chronic lithium treatment (over 3 months) in euthymic persons with BP resulted in lower levels of peripheral blood lymphocytes secreting IL-2, IL-6, IL-10, and IFN- $\gamma$ [285]. Another study has demonstrated that inflammatory factors were associated with cognitive performance in euthymic persons with BP. That is, TNF- $\alpha$ was associated with intrusions on the California Verbal Learning Test, IL-8 was associated with repetitions, and IFN- $\gamma$ was negatively correlated with recollection deficits [286]. Whether the relationship of the immune response with MDD and BP is primary or secondary has yet to be determined. Nevertheless, the suggestion that PA may play an anti-inflammatory role and mitigate pathobiology in the brain warrants close consideration.

Notably, clinical studies demonstrate that PA attenuates the inflammatory process and provides a more resilient stress response [21, 22, 287, 288]. A randomized controlled trial (RCT) in healthy aging adults demonstrated that those who participated in progressive aerobic activity (15 minutes increasing to 40 minutes) twice per week for a 6-month duration exhibited a significant improvement in immune system 
function [287]. Similar results were found in a study of elderly women undergoing aerobic exercise (60 minutes per session, 3 times per week, for 16 weeks) [288]. Another study of fitness level (as denoted by heart rate) was associated with IL- 6 and TNF- $\alpha$ response following stress [22], which is important because cytokines may adversely alter glucocorticoid receptor function to contribute to an excessive inflammatory response in MDs [289]. Finally, a study in healthy men demonstrated that PA directed monocytes towards anti-inflammatory pathways [290], a mechanism that likely supports plasticity in the brain [291]. Together, this evidence makes it seem plausible that PA induces an adaptive immune response and mitigates an exaggerated inflammatory response that can be deleterious to brain plasticity.

Admittedly, findings from human studies relating PA and immune function have varied, a situation that likely reflects unaccounted-for influences. Nevertheless, current exercise guidelines issued by the American College of Sports Medicine and the Surgeon General suggest that moderate exercise (150 minutes per week at $40 \%$ to $60 \%$ of aerobic capacity) can be deployed to induce positive immune health [292]. This notion is reaffirmed by a consensus statement drafted by international experts in the field of exercise immunology that states moderate levels of regular exercise optimize immune function [21].

\section{HPA Function and Physical Activity}

The HPA axis is an adaptive mechanism designed to respond to stress. Chronic stress is associated with hyperactivity of the HPA axis and increased levels of glucocorticoids [293, 294], even in the absence of external stressors. Several lines of evidence have implicated stress-related hyperactivity and dysregulation of the HPA axis with $\mathrm{MDD}[295,296]$ and $\mathrm{BP}[62$, 96]. Persons with MDD exhibit excessive HPA activity as measured by increased $\mathrm{CRH}$ in cerebrospinal fluid; increased cortisol in plasma, urine, and cerebrospinal fluid [297]; and increased rates of nonsuppression following administration of the synthetic glucocorticoid, dexamethasone (known as the dexamethasone suppression test) [298-300]. Persons with BP exhibited increased levels of ACTH and cortisol (basal and postdexamethasone), but not of CRH [96]. Euthymic persons with BP exhibited a flatter diurnal slope of cortisol secretion than healthy persons. Moreover, persons with a history of many episodes exhibited higher cortisol levels, reduced cortisol reactivity to daily stress, and a flatter diurnal slope than persons with fewer episodes [301]. Persons with psychotic and nonpsychotic major depression exhibited distinct patterns of HPA axis reactivity-a combination of depressive and psychotic symptoms induced a greater nadir in evening cortisol than depressive symptoms in isolation [302]. Investigation of a rodent model of BP reports stress-induced hypersecretion of glucocorticoids [303]. The relentless dysregulation of glucocorticoids in MDs can effectuate neuronal atrophy secondary to changes in neurochemistry, neuronal excitability, resilience, and plasticity of the hippocampus [196, 304-306]. In turn, these changes contribute to neurotoxicity [294] and can promote neuroprogression in MDD [307] and BP [308]. Also noteworthy is the fact that cytokines disrupt neuroendocrine function (e.g., IL-1, TNF- $\alpha$, and interferon- $\alpha$ ) by inhibiting glucocorticoid receptor signaling $[275,309]$ as reflected by decrements in glucocorticoid translocation and activation of glucocorticoid receptorinducible enzymes [309, 310].

Although acute PA sharply increases levels of cortisol, regular PA mitigates an overactive stress response [23, 311]. Following stimulation, the hypothalamus secretes $\mathrm{CRH}$, which then induces the release of ACTH from the pituitary gland. In turn, ACTH interacts with the adrenal gland to initiate the release of cortisol in humans and corticosterone in some animals (e.g., rodents, amphibians, reptiles, and birds) [312]. Within this context, acute exercise functions as a stressor, but regular exercise initiates neuroprotective effects. Bolstering the latter notion is evidence that long-term training reduces the response to both physical exercise [312] and other forms of stressor challenge [24], effects that may stem from altered density and efficiency of mineralocorticoid receptors, lower levels of circulating cortisol, and inhibition of cortisol synthesis [24, 312]. The ability of PA to attenuate HPA dysregulation is especially important for preventing hippocampal atrophy [313-315] and reversing cognitive deficits in aging populations $[20,212]$ and those with affective disorders [316], as hippocampal neurons persistently exposed to elevated glucocorticoids retract their dendrites and exhibit fewer dendritic spines [317]. Fortunately, the degree of dendritic branching in hippocampal neurons and the overall number of dendritic spines increase when animals are exposed to voluntary wheel running [217, $318,319]$, alterations that enhance neuroplasticity and that mimic antidepressant actions. Translating these findings to humans at the behavioral level, it has been shown that 8 weeks of exercise improved depressive symptoms and levels of 24-hour urinary cortisol [316]. Another study demonstrated that 12 weeks of high-intensity aerobic exercise enhanced mood and optimized responsiveness of the HPA to the dexamethasone responsiveness test in persons experiencing chronic pain [320]. Altogether, these studies suggest that PA may mitigate HPA dysregulation in persons with MDD or BP, a notion that requires a further study.

\section{Antioxidant Defense and Physical Activity}

Oxidative stress is an imbalance between antioxidants and reactive oxygen species (ROS) (e.g., superoxide, hydrogen peroxide, and hydroxyl radical) [321], a problematic situation in the brain given high metabolic demands and low antioxidant capacity [322]. Oxidative stress is particularly germane to the topic of MDs given alterations in cerebral metabolic rates [323], ROS-induced lipid peroxidation, and antioxidant enzyme activity in BP [81, 324, 325] and MDD [99, 326, 327]. Moreover, oxidative changes in the milieu interfere with the stability of genomic DNA in the brain in MDs [328], changes that are correlated with severity of depressive and manic symptoms [329] and frequency of manic episodes [330].

Notably, aerobic exercise appears to increase adaptability to ROS-induced lipid peroxidation and decrease overall levels of ROS $[25,331]$. These mechanisms stem in part from 
the ability of PA to increase antioxidant gene expression (e.g., superoxide dismutases and glutathione peroxidase) and, thereby, antioxidant enzymatic housekeeping activities in the brain $[332,333]$. Together, these studies suggest that long-term exercise may optimize the enzymatic antioxidant system and mitigate oxidative damage. Such is imperative for persons with MDs given that the kinase proteins that induce structural and functional changes in synapses require specific redox environments and that synaptic activity can be modulated via ROS levels [26].

\section{Circadian Rhythmicity and Physical Activity}

Physiological processes such as feeding behavior, motor activity, hormonal secretion, and autonomic nervous function exhibit naturally occurring rhythms that are referred to as circadian rhythmicity [334]. Central to the control of circadian rhythmicity is the suprachiasmatic nucleus (SCN), a structure located in the anterior hypothalamus and composed of neurons that regulate different body functions according to rhythms that vary with the 24-hour night/day light cycle [335]. The SCN's rhythm is endogenously generated but can be synchronized to the environment (in a process referred to as entrainment) by capturing exogenous and endogenous cues that are referred to as zeitgebers. Common zeitgebers include PA, light, temperature, and food. For instance, light exposure decreases the production of melatonin (a hormone that controls sleep and wakefulness). Conversely, darkness effectuates increases in melatonin secretion, particularly two hours prior to bedtime, a change that increases the propensity for sleep [336]. Then, melatonin levels continue to increase, peak in the middle of the night, and finally decline towards the beginning of day [337]. Thereby, melatonin levels signal to the SCN the time of day. In turn, the SCN can interpret the information and use it to regulate other clocks in the brain and periphery.

Another SCN pathway involves cortisol. Cortisol levels typically peak after waking and then wane during the night, a fluctuation that can adjust the peripheral clocks in almost all organs of the body [337]. Importantly, cortisol is unable to reach the SCN. Therefore, abatement of stress provides a critical window for the SCN to resynchronize peripheral clocks [338]. Poststress resynchronization is important because desynchronization is linked to psychiatric illness $[339,340]$. Indeed, reductions in nocturnal melatonin with concomitant increases in nocturnal ACTH and cortisol make it difficult to maintain sleep [341]. In turn, insufficient quantity and quality of sleep engenders disruptions in multiple regulatory systems, particularly the metabolic, immune, and cardiovascular systems [342, 343].

Multiple lines of evidence have implicated circadian disturbances and MDs. Genome-wide association studies have linked polymorphisms in core circadian genes with MDD $[344,345]$ and BP $[345,346]$. Sleep disturbances have been documented in persons with MDD [85] and BP during the manic, depressive, and euthymic states [86, 347]. An estimated $70 \%$ of persons with MDD have reported problems with transitioning to sleep, frequent awakenings, and nonrestorative sleep [348]. For persons with BP, poor sleep quality, nighttime awakenings, and inadequate sleep are predictive factors for conversion [346]. During manic episodes, $69-99 \%$ of patients exhibited a decreased need for sleep, whereas $23-78 \%$ of persons experiencing depression exhibited hypersomnia [349]. Insomnia has been reported during the euthymic phase [349]. Some evidence suggests that persons with BP exhibit lower levels of melatonin during the euthymic, depressed, and manic phases [350]. Additionally, persons with BP exposed to a light source at night exhibit a greater suppression of melatonin synthesis than healthy controls [351], an effect that is mitigated by administration of lithium carbonate and sodium valproate $[352,353]$. Similarly, a decrease in serum melatonin has been reported in persons with MDD [354]. Finally, persons with BP exhibit elevated night cortisol during the manic and depressive episodes $[355,356]$, an effect that can be mitigated therapeutically by administration of cortisol antagonists [357].

Given that SCN disturbances are associated with chronic stress [358] and disease [359], that persons with MDD and BP exhibit sleep disturbances and altered SCN function [360], and that gene expression patterns that regulate neuroplasticity vary with the sleep/wake cycle [361, 362], it is logical to surmise that persons with MDs exhibit circadianrelated deficits in neuroplasticity [363]. Fortunately, evidence suggests that zeitgebers like PA [364], light exposure [365], social contacts, and the scheduling of rest and activity [366] can modulate rhythmic abnormalities by altering body temperature, gene expression, or the activity of several brain regions that project to the SCN (e.g., raphe nuclei and pineal gland) [367].

Supporting this notion is evidence that regular PA induces neurochemical changes that qualitatively and quantitatively improve sleep across patient populations [27-29, 368-372]. One RCT in sedentary adults with insomnia demonstrated that increasing PA to the level recommended in public health guidelines $(\geq 150 \mathrm{~min}$ of moderate- to vigorous-intensity PA per week) improved sleep quality [28], whereas other studies demonstrated that adults who fail to achieve sufficient levels of PA incur sleep problems [372-375]. Other work showed that 3 months of fitness training in the middle of the day improved the consolidation of the sleep/wake cycle in older men [376]. Another study demonstrated that late-afternoon exercise improved measures of cognitive abilities in older adults [29]. Parallel investigations demonstrated that exercise induced phase delays in humans $[377,378]$ and accelerated re-entrainment of an acutely shifted sleep-wake cycle $[379,380]$. Also, it has been demonstrated that PA between noon and evening can phase-advance melatonin rhythms [381]. In patients with nonremitted MDD, a 12-week RCT showed that PA augmentation effectuated improvements in self-reported sleep quality [382]. Later work revealed that PA-induced reductions in hypersomnia were positively correlated with reductions in BDNF and IL- $1 \beta$, a trend that was not present in those with insomnia, suggesting differential biomarker associations for hypersomnia and insomnia [383]. Finally, preclinical work in a rodent model of BP demonstrated that both melatonin and voluntary wheel running were effective at reducing maniarelated behavior [250]. 
While the practical implications of the aforementioned studies have yet to be clarified fully, they suggest that sleep abnormalities in MDs can be reduced with long-term PA [384-386]. Efforts to reduce sleep deficits are warranted given the morbidity associated with insomnia and the deleterious effects of sedatives. Moreover, adequate sleep is essential for plasticity processes: reactivation of regions used during the day must occur at night to consolidate memories and promote cognitive, emotional, and motor recovery [387-389].

\section{Adaptive Epigenetic Signaling and Physical Activity}

Epigenetic mechanisms have been implicated in the neurobiology of MDs [390-396]. Epigenetics refers to functional alterations in chromatin structure (e.g., DNA methylation, histone methylation, and histone acetylation) that induce modifications in gene expression, not changes in DNA sequence per se $[397,398]$. That is, the chromatin structure that is determined by acetylation and methylation patterns can relax the spacing between nucleosomes to permit an increase or decrease in gene transcription, respectively [399]. Neurons utilize dynamic epigenetic modifications to regulate gene expression in an experience-dependent manner [400]. Thus, it has been suggested that neuronal plasticity is controlled in part by chromatin-remodeling processes [401], and emergent evidence has implicated chromatin modification in stress-induced illness, memory impairments, depression, and different phases of BP [402-406]. Basic support for epigenetic mechanisms in the pathobiology of MDD stems from evidence of discordance among monozygotic twins [407] along with evidence that environmental factors (e.g., early adversity) can increase the risk for depression $[408,409]$. Similarly, a study of monozygotic twins discordant for BP revealed that four regions of the genome have significant alterations in methylation patterns, differences that may contribute to altered dopamine transmission and neuroendocrine function [410]. While the means by which these mechanisms impinge on $\mathrm{MD}$ pathobiology are not understood fully, it has become increasingly clear that these adaptations mediate long-lasting changes in vulnerability and resilience, factors relevant for MDs.

Fortunately, endogenous biochemical signals derived from peripheral cues such as PA appear to alter gene expression epigenetically [30, 411, 412] and induce physiological responses throughout the body. Thereby, PA may mitigate stress-induced changes in gene expression in persons with MDD and BP. Recent work in young and aged rats showed that two weeks of treadmill exercise induced age-dependent changes on epigenetic parameters in the hippocampus [413]. Tsankova and colleagues demonstrated that repeated stress increased histone H3K27 methylation in the hippocampus and suppressed the BDNF gene promoter region, an effect that was reversible with imipramine administration [414] or PA [415]. Recently, Januar and colleagues [416] reported similar results. They found that persons with depression at baseline, as well those with chronic late-life depression, demonstrated higher BDNF methylation levels, an effect that was influenced by the presence of three single-nucleotide polymorphisms (rs6265, rs7103411, and rs908867) [416]. Lindholm and colleagues [30] demonstrated that long-term, unilateral exercise (45 minutes, 4 times per week $\times 3$ months) induced more than 5000 methylation changes in regulatory enhancement regions that alter gene expression, providing direct evidence that the regulation and maintenance of exercise-training adaptation is associated with epigenetic changes. In addition to preclinical data demonstrating that a multiplicity of genes that regulate synaptic structure and plasticity are altered by PA [31], the aforementioned studies make it seem plausible that epigenetic changes are responsible for a significant portion of MD-related pathobiological changes and suggest that PA is a strong candidate for reversing symptoms, particularly by promoting stable changes in BDNF gene expression. Moreover, given that chromatin modifications are associated with stress-induced illness, memory impairments, depression, and different phases of BP [393, 394, 402-406, 415, 417, 418], it seems likely that epigenetic profiles in the peripheral blood, particularly in BDNF, could be used as a biomarker for those who are susceptible to MDs, as well as for tracking therapeutic response following PA interventions in persons with MDs [30]. The latter notion is based on evidence that BDNF is robustly upregulated centrally and peripherally [419-422] following acute and long-term exercise $[423,424]$ and that plasma BDNF levels are linked to alterations in brain BDNF levels [270, 425], synaptic plasticity, and learning ability [271].

\section{Telomere Length and Physical Activity}

Recent evidence suggests a correlation between telomere length and MD pathobiology. Telomeres-the tiny, protective caps found on the terminals of DNA strands-protect DNA from damage during the processes of cell division and replication. Telomeres naturally shorten and fray with cellular aging, a hallmark process that is accelerated by adverse health and lifestyle circumstances [426]. Although the specific mechanisms underlying telomere shortening remain unknown, recent evidence has intimated that telomere shortening in MDs may be attributed to oxidative stress and inflammation, processes that can induce telomeric DNA damage and accelerate aging by 10 years [99, 427-429]. Moreover, it has been shown that telomere maintenance is critical for stem cell function in the context of persistent neuronal turnover and that adult stem cells exhibit high levels of telomerase (an enzyme that extends the telomere sequences after cell division) [430-432], making it seem likely that hippocampal neurogenesis depends on telomere dynamics [433].

Shorter telomere length has been reported in persons with remitted MDD and current MDD, findings that correlate with the severity and duration of symptoms [434] and may relate to a person's overall state of resiliency [435]. In postmortem samples, shortened telomere length was observed across brain regions, including the hippocampus in persons with MDD [436]. Also, telomere shortening has been reported in persons with BP [437], and the length was inversely correlated with the number of depressive episodes and response to lithium [438]. Strikingly, recent findings show that lithium increases the expression of the gene that encodes telomerase in human neural progenitor cells [439], intimating that the 
accelerated aging processes that occur in BP may be mitigated through the neuroprotective effects of lithium.

Similarly, recent clinical studies suggest that PA has protective effects on telomeres [32]. In general, persons who report more PA have significantly longer telomere length [440, 441]. Loprinzi and colleagues [33] reported a clear dose-dependent relationship between the degree of PA engagement and shorter leukocyte telomere lengths: persons who participated in a single type of PA were $3 \%$ less likely to have very short telomeres compared to a sedentary individual, whereas persons who reported that they engaged in 4 types of PA were 59\% less likely to have very short telomeres. Werner and colleagues [442] reported that peripheral blood leukocytes from professional endurance athletes exhibited increased telomerase activity and reduced expression of cell-cycle inhibitors compared with those from untrained individuals. Preclinical evidence suggests that PA has a protective effect on telomere length in neurons in brain regions associated with depression $[34,35]$.

Together, this emerging evidence suggests that PA may attenuate MD-related disease and provide a means to protect telomeres from accelerated aging. The fact that telomere maintenance is critical for stem cell function in the context of persistent turnover [430-432] makes it seem likely that hippocampal neurogenesis depends on telomere dynamics and that PA may positively affect these processes, a notion that awaits further investigation.

\section{Implications for Translation, Unresolved Issues, and Future Directions}

Finding an effective treatment for MD-related impairments and symptoms remains an unmet goal. Notwithstanding, the use of animal models and human research have resulted in considerable progress toward understanding common neuroplasticity substrates that are implicated in MDD and $\mathrm{BP}$, along with the identification of new targets and biomarkers for therapeutic intervention. Presented here is a broad assessment of biomedical evidence intimating that PA can optimize neuroplasticity substrates and processes across brain regions so that neuronal networks responsible for emotional and cognitive regulation can reestablish their connectivity to better meet environmental and biological demands in a use-dependent manner [84, 399, 443-445]. Consistent with the delayed effects of PA, this process would take weeks to induce network changes of sufficient magnitude to effectuate downstream changes in mood and behavior. Another key thrust of this notion is that the interplay between these neuroplasticity substrates is important for appropriate network function, not isolated factors per se. Studies of these interrelated processes are imperative given evidence that interventions applied earlier in the course of disease are more likely to achieve disease modification, whereas those applied later may have a significant but more limited effect $[446,447]$.

While the beneficial nature of PA for persons with MDD has been clearly established $[10,448]$, there is a relative dearth of evidence for persons with BP. Cooney and colleagues conducted a meta-analysis of high-quality RCTs published up to March 2013 to determine whether there is enough evidence to support the deployment of PA in clinical populations with depression [10]. Thirty-nine studies with a total of 2326 participants were included in the review. The authors reported that exercise produced effects comparable to treatment with antidepressants or psychotherapy. Another meta-analytic study reported that aerobic exercise moderately reduced the signs of depression, with populations over 60 years of age deriving the greatest effect [448]. A more recent meta-analytic review attempted to determine optimal parameters for using exercise to treat depression (e.g., frequency, intensity, duration, and type of exercise). They noted that all five RCTs meeting inclusion criteria were aerobic in nature (walking on treadmill or outdoors, cycling on a stationary bike, or training on an elliptical machine) [449]. Moreover, positive evidence was found that aerobic exercise of moderate intensity, undertaken 3 times weekly for a minimum of 9 weeks, was successful in treating depression [449]. Separate clinical studies in persons with BP suggest that exercise, in combination with mood stabilizers, improves outcomes [450, 451], and routine exercise is a common wellness strategy practiced by persons with high-functioning $\mathrm{BP}$ [452]. For instance, one preliminary trial noted a trend towards significance for persons with BP in an inpatient psychiatric treatment unit that participated voluntarily in a walking group during their admission [451]. Another preliminary trial in persons with BP found the addition of 100 minutes of weekly exercise to baseline activities, in conjunction with nutrition and wellness activities, effectuated improvements in quality of life, depressive symptoms, and weight loss [453]. A meta-analysis of six studies reported the feasibility and benefit of PA in persons with BP, particularly noting decrements in symptoms of depression, anxiety, and stress [454].

Given that it is generally held that positive, supportive relationships have a beneficial effect on the maintenance of psychological health [455], further consideration of the influence of social interactions during group exercise is warranted, particularly in aging individuals. Group activities such as exercise may help retirees deal more effectively with the loss of social relationships and influence in the workplace by providing an opportunity to meet and socialize with others [456]; disproving stereotypes; and promoting feelings of autonomy, relatedness to others, and competence [457]. In turn, positive social relationships may facilitate the adherence to leisure-time PA. A large prospective cohort study of middle-aged adults found that adults who experienced high levels of emotional support were more likely to adhere to recommended levels of leisure-time PA at follow-up in comparison to those with lower levels of social support [458]. Alternatively, social participation and engagement may reflect an index of behavioral plasticity $[459,460]$ wherein social engagement helps aging persons to compensate for changes in neural systems involved in emotional and cognitive functioning, a notion that awaits future investigation.

Clearly, large-scale, multiple-site clinical investigations that study the relationship between exercise and MDs are needed. The degree to which polymorphisms (common 
variations in gene sequence) determine an individual's response to PA is largely unknown. Future work that combines the study of genetic background (e.g., polymorphisms in BDNF), postexercise serum BDNF, and affective and cognitive measures with neuroimaging studies of $\mathrm{MD}$ related circuits could be used to determine the "dose" of PA requisite to mitigate structural and functional changes in the brain across patient populations. Moreover, strategies for overcoming the core symptoms of depression (e.g., loss of interest, motivation, and energy; low self-worth feelings and self-confidence; psychosomatic complaints; and comorbid health problems) and mania need to be clearly delineated and articulated so that exercise can be personalized.

In summary, the data presented here suggest that moderate $\mathrm{PA}-\mathrm{a}$ target that is practical, well tolerated, and likely to optimize exercise adherence-can be used to improve the neurobiological impairments and behavioral symptoms associated with MDD and BP. Because of this, PA should be advocated to reduce symptoms, prevent relapse, and mitigate residual symptoms vis-a-vis the promotion of good health habits [461]. The success of prevention campaigns will require significant changes in philosophy and approach. Evidence suggests that $50 \%$ or less of mental health professionals recommended exercise for depression, and less than a third of those felt confident in making individualized recommendations [364, 462]. Ultimately, it is hoped that a more consolidated treatment view and research approach will translate into novel therapeutic avenues of preventive and curative value for persons with MDD and BP.

\section{Abbreviations}

$\begin{array}{ll}\text { ACTH: } & \text { Adrenocorticotropic hormone } \\ \text { BDNF: } & \text { Brain-derived neurotrophic factor } \\ \text { BP: } & \text { Bipolar disorder } \\ \text { CRH: } & \text { Corticotropin-releasing hormone } \\ \text { FNDC5: } & \text { Fibronectin type III domain-containing protein } 5 \\ \text { GABA: } & \text { Gamma aminobutyric acid } \\ \text { HPA: } & \text { Hypothalamic-pituitary-adrenal axis } \\ \text { IGF-1: } & \text { Insulin-like growth factor } 1 \\ \text { IL-1: } & \text { Interleukin-1 } \\ \text { IL-6: } & \text { Interleukin-6 } \\ \text { MDD: } & \text { Major depressive disorder } \\ \text { MDs: } & \text { Mood disorders } \\ \text { NMDAR: } & \text { N-Methyl-D-aspartate receptor } \\ \text { PA: } & \text { Physical activity } \\ \text { PGC-1 } \alpha: & \text { Peroxisome proliferator-activated receptor gamma } \\ & \text { coactivator 1-alpha } \\ \text { RCT: } & \text { Randomized controlled trial } \\ \text { ROS: } & \text { Reactive oxygen species } \\ \text { SCN: } & \text { Suprachiasmatic nucleus } \\ \text { TNF- } \alpha: & \text { Tumor necrosis factor- } \alpha \\ \text { VEGF: } & \text { Vascular endothelial growth factor. }\end{array}$

\section{Conflicts of Interest}

The author declares no competing interests.

\section{References}

[1] World Health Organization, Mental Disorders Fact Sheet, 2016.

[2] Association AP, Diagnostic and Statistical Manual of Mental Disorders, American Psychiatric Pub, Washington, DC, USA, 2013.

[3] R. S. Duman, "Neurobiology of stress, depression, and rapid acting antidepressants: remodeling synaptic connections," Depression and Anxiety, vol. 31, no. 4, pp. 291-296, 2014.

[4] D. J. Kupfer, "The increasing medical burden in bipolar disorder," JAMA, vol. 293, no. 20, pp. 2528-2530, 2005.

[5] C. Phillips, M. A. Baktir, D. Das, B. Lin, and A. Salehi, "The link between physical activity and cognitive dysfunction in Alzheimer disease," Physical Therapy, vol. 95, no. 7, pp. 1046-1060, 2015.

[6] C. Phillips, M. A. Baktir, M. Srivatsan, and A. Salehi, "Neuroprotective effects of physical activity on the brain: a closer look at trophic factor signaling," Frontiers in Cellular Neuroscience, vol. 8, p. 170, 2014.

[7] S. Kvam, C. L. Kleppe, I. H. Nordhus, and A. Hovland, "Exercise as a treatment for depression: a meta-analysis," Journal of Affective Disorders, vol. 202, pp. 67-86, 2016.

[8] F. B. Schuch, D. Vancampfort, S. Rosenbaum, J. Richards, P. B. Ward, and B. Stubbs, "Exercise improves physical and psychological quality of life in people with depression: a meta-analysis including the evaluation of control group response," Psychiatry Research, vol. 241, pp. 47-54, 2016.

[9] R. Stanton, B. Happell, M. Hayman, and P. Reaburn, "Exercise interventions for the treatment of affective disorders - research to practice," Frontiers in Psychiatry, vol. 5, p. 46, 2014.

[10] G. M. Cooney, K. Dwan, C. A. Greig et al., "Exercise for depression," Cochrane Database of Systematic Reviews, no. 9, article CD004366, 2013.

[11] M. C. Melo, E. F. Daher, S. G. Albuquerque, and V. M. de Bruin, "Exercise in bipolar patients: a systematic review," Journal of Affective Disorders, vol. 198, pp. 32-38, 2016.

[12] L. Bherer, K. I. Erickson, and T. Liu-Ambrose, "Physical exercise and brain functions in older adults," Journal of Aging Research, vol. 2013, Article ID 197326, p. 2, 2013.

[13] B. Winter, C. Breitenstein, F. C. Mooren et al., "High impact running improves learning," Neurobiology of Learning and Memory, vol. 87, no. 4, pp. 597-609, 2007.

[14] A. A. Russo-Neustadt, H. Alejandre, C. Garcia, A. S. Ivy, and M. J. Chen, "Hippocampal brain-derived neurotrophic factor expression following treatment with reboxetine, citalopram, and physical exercise," Neuropsychopharmacology, vol. 29, no. 12, pp. 2189-2199, 2004.

[15] L. Schwarz and W. Kindermann, "Beta-endorphin, catecholamines, and cortisol during exhaustive endurance exercise," International Journal of Sports Medicine, vol. 10, no. 5, pp. 324-328, 1989.

[16] T. Traustadottir, P. R. Bosch, T. Cantu, and K. S. Matt, "Hypothalamic-pituitary-adrenal axis response and recovery from high-intensity exercise in women: effects of aging and fitness," The Journal of Clinical Endocrinology and Metabolism, vol. 89, no. 7, pp. 3248-3254, 2004.

[17] G. Mastorakos, M. Pavlatou, E. Diamanti-Kandarakis, and G. P. Chrousos, "Exercise and the stress system," Hormones (Athens, Greece), vol. 4, no. 2, pp. 73-89, 2005. 
[18] L. Z. Agudelo, T. Femenia, F. Orhan et al., "Skeletal muscle PGC-1alpha1 modulates kynurenine metabolism and mediates resilience to stress-induced depression," Cell, vol. 159, no. 1, pp. 33-45, 2014.

[19] M. L. Mustroph, S. Chen, S. C. Desai, E. B. Cay, E. K. DeYoung, and J. S. Rhodes, "Aerobic exercise is the critical variable in an enriched environment that increases hippocampal neurogenesis and water maze learning in male C57BL/6J mice," Neuroscience, vol. 219, pp. 62-71, 2012.

[20] H. Makizako, T. Liu-Ambrose, H. Shimada et al., "Moderateintensity physical activity, hippocampal volume, and memory in older adults with mild cognitive impairment," The Journals of Gerontology Series A, Biological Sciences and Medical Sciences, vol. 70, no. 4, pp. 480-486, 2015.

[21] N. P. Walsh, M. Gleeson, D. B. Pyne et al., "Position statement. Part two: maintaining immune health," Exercise Immunology Review, vol. 17, pp. 64-103, 2011.

[22] M. Hamer and A. Steptoe, "Association between physical fitness, parasympathetic control, and proinflammatory responses to mental stress," Psychosomatic Medicine, vol. 69, no. 7, pp. 660-666, 2007.

[23] B. K. Pedersen and B. Saltin, "Evidence for prescribing exercise as therapy in chronic disease," Scandinavian Journal of Medicine \& Science in Sports, vol. 16, Supplement 1, pp. 363, 2006.

[24] H. E. Webb, D. S. Rosalky, S. E. Tangsilsat, K. A. McLeod, E. O. Acevedo, and B. Wax, "Aerobic fitness affects cortisol responses to concurrent challenges," Medicine and Science in Sports and Exercise, vol. 45, no. 2, pp. 379-386, 2013.

[25] Z. Radak, H. Y. Chung, and S. Goto, "Exercise and hormesis: oxidative stress-related adaptation for successful aging," Biogerontology, vol. 6, no. 1, pp. 71-75, 2005.

[26] T. F. Beckhauser, J. Francis-Oliveira, and R. De Pasquale, "Reactive oxygen species: physiological and physiopathological effects on synaptic plasticity," Journal of Experimental Neuroscience, vol. 10, no. Supplement 1, pp. 23-48, 2016.

[27] H. M. Chen, Y. C. Wu, C. M. Tsai, J. I. Tzeng, and C. C. Lin, "Relationships of circadian rhythms and physical activity with objective sleep parameters in lung cancer patients," Cancer Nursing, vol. 38, no. 3, pp. 215-223, 2015.

[28] N. A. Singh, K. M. Clements, and M. A. Fiatarone, "A randomized controlled trial of the effect of exercise on sleep," Sleep, vol. 20, no. 2, pp. 95-101, 1997.

[29] S. Benloucif, L. Orbeta, R. Ortiz et al., "Morning or evening activity improves neuropsychological performance and subjective sleep quality in older adults," Sleep, vol. 27, no. 8, pp. 1542-1551, 2004.

[30] M. E. Lindholm, F. Marabita, D. Gomez-Cabrero et al., "An integrative analysis reveals coordinated reprogramming of the epigenome and the transcriptome in human skeletal muscle after training," Epigenetics, vol. 9, no. 12, pp. 15571569,2014

[31] L. Tong, H. Shen, V. M. Perreau, R. Balazs, and C. W. Cotman, "Effects of exercise on gene-expression profile in the rat hippocampus," Neurobiology of Disease, vol. 8, no. 6, pp. 1046-1056, 2001.

[32] R. J. Simpson, C. Cosgrove, M. M. Chee et al., "Senescent phenotypes and telomere lengths of peripheral blood T-cells mobilized by acute exercise in humans," Exercise Immunology Review, vol. 16, pp. 40-55, 2010.
[33] P. D. Loprinzi, J. P. Loenneke, and E. H. Blackburn, "Movement-based behaviors and leukocyte telomere length among US adults," Medicine and Science in Sports and Exercise, vol. 47, no. 11, pp. 2347-2352, 2015.

[34] S. A. Wolf, A. Melnik, and G. Kempermann, "Physical exercise increases adult neurogenesis and telomerase activity, and improves behavioral deficits in a mouse model of schizophrenia," Brain, Behavior, and Immunity, vol. 25, no. 5, pp. 971-980, 2011.

[35] M. Botha, L. Grace, K. Bugarith et al., "The impact of voluntary exercise on relative telomere length in a rat model of developmental stress," BMC Research Notes, vol. 5, no. 1, p. 697, 2012.

[36] L. M. Haarasilta, M. J. Marttunen, J. A. Kaprio, and H. M. Aro, "Correlates of depression in a representative nationwide sample of adolescents (15-19 years) and young adults (20-24 years)," European Journal of Public Health, vol. 14, no. 3, pp. 280-285, 2004.

[37] K. Abu-Omar, A. Rutten, and V. Lehtinen, "Mental health and physical activity in the European Union," Sozial- und Präventivmedizin, vol. 49, no. 5, pp. 301-309, 2004.

[38] R. W. Motl, A. S. Birnbaum, M. Y. Kubik, and R. K. Dishman, "Naturally occurring changes in physical activity are inversely related to depressive symptoms during early adolescence," Psychosomatic Medicine, vol. 66, no. 3, pp. 336-342, 2004.

[39] R. Pemberton and M. D. Fuller Tyszkiewicz, "Factors contributing to depressive mood states in everyday life: a systematic review," Journal of Affective Disorders, vol. 200, pp. 103-110, 2016.

[40] B. M. Hoffman, M. A. Babyak, W. E. Craighead et al., "Exercise and pharmacotherapy in patients with major depression: one-year follow-up of the SMILE study," Psychosomatic Medicine, vol. 73, no. 2, pp. 127-133, 2011.

[41] M. Babyak, J. A. Blumenthal, S. Herman et al., "Exercise treatment for major depression: maintenance of therapeutic benefit at 10 months," Psychosomatic Medicine, vol. 62, no. 5, pp. 633-638, 2000.

[42] G. Christofoletti, M. M. Oliani, L. T. Bucken-Gobbi, S. Gobbi, F. Beinotti, and F. Stella, "Physical activity attenuates neuropsychiatric disturbances and caregiver burden in patients with dementia," Clinics (São Paulo, Brazil), vol. 66, no. 4, pp. 613-618, 2011.

[43] K. A. Barbour, T. M. Edenfield, and J. A. Blumenthal, "Exercise as a treatment for depression and other psychiatric disorders: a review," Journal of Cardiopulmonary Rehabilitation and Prevention, vol. 27, no. 6, pp. 359-367, 2007.

[44] A. J. Gelenberg, M. P. Freeman, J. C. Markowitz et al., "Practice guidelines for the treatment of patients with major depressive disorder," in National Guideline Clearinghouse, Psychiatrists TRANZCo, Ed., 3rd edition, American Psychological Association, Washington, DC, 2010.

[45] E. Ranjbar, A. H. Memari, S. Hafizi, M. Shayestehfar, F. S. Mirfazeli, and M. A. Eshghi, "Depression and exercise: a clinical review and management guideline," Asian Journal of Sports Medicine, vol. 6, no. 2, article e24055, 2015.

[46] B. A. Fischer, "A review of American psychiatry through its diagnoses: the history and development of the Diagnostic and Statistical Manual of Mental Disorders," The Journal of Nervous and Mental Disease, vol. 200, no. 12, pp. 10221030, 2012. 
[47] R. L. Spitzer, J. Endicott, and E. Robins, "Research diagnostic criteria: rationale and reliability," Archives of General Psychiatry, vol. 35, no. 6, pp. 773-782, 1978.

[48] Cross-Disorder Group of the Psychiatric Genomics C, "Identification of risk loci with shared effects on five major psychiatric disorders: a genome-wide analysis," Lancet, vol. 381, no. 9875, pp. 1371-1379, 2013.

[49] A. K. Wittenborn, H. Rahmandad, J. Rick, and N. Hosseinichimeh, "Depression as a systemic syndrome: mapping the feedback loops of major depressive disorder," Psychological Medicine, vol. 46, no. 3, pp. 551-562, 2016.

[50] M. Goodkind, S. B. Eickhoff, D. J. Oathes et al., "Identification of a common neurobiological substrate for mental illness," JAMA Psychiatry, vol. 72, no. 4, pp. 305-315, 2015.

[51] J. Du, J. A. Quiroz, N. A. Gray, S. T. Szabo, C. A. Zarate Jr., and H. K. Manji, "Regulation of cellular plasticity and resilience by mood stabilizers: the role of AMPA receptor trafficking," Dialogues in Clinical Neuroscience, vol. 6, no. 2, pp. 143-155, 2004.

[52] C. A. Zarate Jr., J. Du, J. Quiroz et al., "Regulation of cellular plasticity cascades in the pathophysiology and treatment of mood disorders: role of the glutamatergic system," Annals of the New York Academy of Sciences, vol. 1003, no. 1, pp. 273-291, 2003.

[53] A. Sale, N. Berardi, and L. Maffei, "Environment and brain plasticity: towards an endogenous pharmacotherapy," Physiological Reviews, vol. 94, no. 1, pp. 189-234, 2014.

[54] H. K. Manji, G. J. Moore, G. Rajkowska, and G. Chen, "Neuroplasticity and cellular resilience in mood disorders," Molecular Psychiatry, vol. 5, no. 6, pp. 578-593, 2000.

[55] R. M. Hirschfeld, "History and evolution of the monoamine hypothesis of depression," The Journal of Clinical Psychiatry, vol. 61, Supplement 6, pp. 4-6, 2000.

[56] B. Weintraub, Molecular Endocrinology: Basic Concepts and Clinical Correlations, Raven Press, New York, NY, USA, 1995.

[57] A. K. Cuellar, S. L. Johnson, and R. Winters, "Distinctions between bipolar and unipolar depression," Clinical Psychology Review, vol. 25, no. 3, pp. 307-339, 2005.

[58] S. L. Weisenbach and A. Kumar, "Current understanding of the neurobiology and longitudinal course of geriatric depression," Current Psychiatry Reports, vol. 16, no. 9, p. 463, 2014.

[59] R. Villanueva, "Neurobiology of major depressive disorder," Neural Plasticity, vol. 2013, Article ID 873278, p. 7, 2013.

[60] A. L. Chirita, V. Gheorman, D. Bondari, and I. Rogoveanu, "Current understanding of the neurobiology of major depressive disorder," Romanian Journal of Morphology and Embryology, vol. 56, Supplement 2, pp. 651-658, 2015.

[61] P. J. Harrison, "Molecular neurobiological clues to the pathogenesis of bipolar disorder," Current Opinion in Neurobiology, vol. 36, pp. 1-6, 2016.

[62] A. Muneer, "The neurobiology of bipolar disorder: an integrated approach," Chonnam Medical Journal, vol. 52, no. 1, pp. 18-37, 2016.

[63] V. Maletic and C. Raison, "Integrated neurobiology of bipolar disorder," Frontiers in Psychiatry, vol. 5, p. 98, 2014.

[64] H. K. Manji, J. A. Quiroz, J. L. Payne et al., "The underlying neurobiology of bipolar disorder," World Psychiatry, vol. 2, no. 3, pp. 136-146, 2003.

[65] J. C. Masdeu, "Neuroimaging in psychiatric disorders," Neurotherapeutics, vol. 8, no. 1, pp. 93-102, 2011.
[66] J. L. Price and W. C. Drevets, "Neural circuits underlying the pathophysiology of mood disorders," Trends in Cognitive Sciences, vol. 16, no. 1, pp. 61-71, 2012.

[67] Y. Nagafusa, N. Okamoto, K. Sakamoto et al., "Assessment of cerebral blood flow findings using $99 \mathrm{mTc}-\mathrm{ECD}$ singlephoton emission computed tomography in patients diagnosed with major depressive disorder," Journal of Affective Disorders, vol. 140, no. 3, pp. 296-299, 2012.

[68] S. Kito, T. Hasegawa, and Y. Koga, "Cerebral blood flow ratio of the dorsolateral prefrontal cortex to the ventromedial prefrontal cortex as a potential predictor of treatment response to transcranial magnetic stimulation in depression," Brain Stimulation, vol. 5, no. 4, pp. 547-553, 2012.

[69] K. Willeumier, D. V. Taylor, and D. G. Amen, "Decreased cerebral blood flow in the limbic and prefrontal cortex using SPECT imaging in a cohort of completed suicides," Translational Psychiatry, vol. 1, no. 8, article e28, 2011.

[70] W. C. Drevets, J. Savitz, and M. Trimble, "The subgenual anterior cingulate cortex in mood disorders," CNS Spectrums, vol. 13, no. 8, pp. 663-681, 2008.

[71] K. S. Kendler, M. Gatz, C. O. Gardner, and N. L. Pedersen, "A Swedish national twin study of lifetime major depression," The American Journal of Psychiatry, vol. 163, no. 1, pp. 109-114, 2006.

[72] I. C. Weaver, N. Cervoni, F. A. Champagne et al., "Epigenetic programming by maternal behavior," Nature Neuroscience, vol. 7, no. 8, pp. 847-854, 2004.

[73] R. Massart, R. Mongeau, and L. Lanfumey, "Beyond the monoaminergic hypothesis: neuroplasticity and epigenetic changes in a transgenic mouse model of depression," Philosophical Transactions of the Royal Society of London. Series B, Biological Sciences, vol. 367, no. 1601, pp. 2485-2494, 2012.

[74] A. Baudry, S. Mouillet-Richard, B. Schneider, J. M. Launay, and O. Kellermann, "miR-16 targets the serotonin transporter: a new facet for adaptive responses to antidepressants," Science, vol. 329, no. 5998, pp. 1537-1541, 2010.

[75] P. L. Delgado, "Depression: the case for a monoamine deficiency," The Journal of Clinical Psychiatry, vol. 61, Supplement 6, pp. 7-11, 2000.

[76] R. M. Salomon, H. L. Miller, J. H. Krystal, G. R. Heninger, and D. S. Charney, "Lack of behavioral effects of monoamine depletion in healthy subjects," Biological Psychiatry, vol. 41, no. 1, pp. 58-64, 1997.

[77] P. L. Delgado, L. H. Price, H. L. Miller et al., "Serotonin and the neurobiology of depression. Effects of tryptophan depletion in drug-free depressed patients," Archives of General Psychiatry, vol. 51, no. 11, pp. 865-874, 1994.

[78] R. M. Berman, G. Sanacora, A. Anand et al., "Monoamine depletion in unmedicated depressed subjects," Biological Psychiatry, vol. 51, no. 6, pp. 469-473, 2002.

[79] T. F. Yuan, F. Paes, O. Arias-Carrion, N. B. Ferreira Rocha, A. S. de Sa Filho, and S. Machado, "Neural mechanisms of exercise: anti-depression, neurogenesis, and serotonin signaling," CNS \& Neurological Disorders Drug Targets, vol. 14, no. 10, pp. 1307-1311, 2015.

[80] R. S. Duman and L. M. Monteggia, "A neurotrophic model for stress-related mood disorders," Biological Psychiatry, vol. 59, no. 12, pp. 1116-1127, 2006.

[81] N. C. Brown, A. C. Andreazza, and L. T. Young, "An updated meta-analysis of oxidative stress markers in bipolar disorder," Psychiatry Research, vol. 218, no. 1-2, pp. 61-68, 2014. 
[82] C. M. Pariante and S. L. Lightman, "The HPA axis in major depression: classical theories and new developments," Trends in Neurosciences, vol. 31, no. 9, pp. 464-468, 2008.

[83] A. M. Hashmi, Z. Butt, and M. Umair, "Is depression an inflammatory condition? A review of available evidence," The Journal of the Pakistan Medical Association, vol. 63, no. 7, pp. 899-906, 2013.

[84] E. Castren, "Is mood chemistry?" Nature Reviews. Neuroscience, vol. 6, no. 3, pp. 241-246, 2005.

[85] N. Tsuno, A. Besset, and K. Ritchie, "Sleep and depression," The Journal of Clinical Psychiatry, vol. 66, no. 10, pp. 12541269,2005

[86] V. Milhiet, C. Boudebesse, F. Bellivier et al., "Circadian abnormalities as markers of susceptibility in bipolar disorders," Frontiers in Bioscience (Scholar Edition), vol. 6, pp. 120-137, 2014.

[87] M. T. Treadway and D. A. Pizzagalli, "Imaging the pathophysiology of major depressive disorder - from localist models to circuit-based analysis," Biology of Mood \& Anxiety Disorders, vol. 4, no. 1, p. 5, 2014.

[88] R. M. Post, D. R. Rubinow, and J. C. Ballenger, "Conditioning and sensitisation in the longitudinal course of affective illness," The British Journal of Psychiatry, vol. 149, no. 2, pp. 191-201, 1986.

[89] K. S. Kendler, L. M. Thornton, and C. O. Gardner, "Stressful life events and previous episodes in the etiology of major depression in women: an evaluation of the "kindling" hypothesis," The American Journal of Psychiatry, vol. 157, no. 8, pp. 1243-1251, 2000.

[90] P. Pregelj, "Gene environment interactions in bipolar disorder," Psychiatria Danubina, vol. 23, Supplement 1, pp. S91-S93, 2011.

[91] C. L. Bowden, "Towards an integrated biological model of bipolar disorder," in Bipolar Disorder: Biological Bodels and Their Clinical Application, L. T. Young and R. T. Joffe, Eds., pp. 235-254, Dekker, New York, NY, USA, 1997.

[92] N. Craddock and P. Sklar, "Genetics of bipolar disorder," Lancet, vol. 381, no. 9878, pp. 1654-1662, 2013.

[93] F. J. McMahon, N. Akula, T. G. Schulze et al., "Meta-analysis of genome-wide association data identifies a risk locus for major mood disorders on 3p21.1," Nature Genetics, vol. 42, no. 2, pp. 128-131, 2010.

[94] N. Horesh and I. Iancu, "A comparison of life events in patients with unipolar disorder or bipolar disorder and controls," Comprehensive Psychiatry, vol. 51, no. 2, pp. 157-164, 2010.

[95] S. L. Johnson, "Life events in bipolar disorder: towards more specific models," Clinical Psychology Review, vol. 25, no. 8, pp. 1008-1027, 2005.

[96] M. Belvederi Murri, D. Prestia, V. Mondelli et al., “The HPA axis in bipolar disorder: systematic review and meta-analysis," Psychoneuroendocrinology, vol. 63, pp. 327-342, 2016.

[97] L. G. Sylvia, R. M. Ametrano, and A. A. Nierenberg, "Exercise treatment for bipolar disorder: potential mechanisms of action mediated through increased neurogenesis and decreased allostatic load," Psychotherapy and Psychosomatics, vol. 79, no. 2, pp. 87-96, 2010

[98] M. Berk, F. Kapczinski, A. C. Andreazza et al., "Pathways underlying neuroprogression in bipolar disorder: focus on inflammation, oxidative stress and neurotrophic factors," Neuroscience and Biobehavioral Reviews, vol. 35, no. 3, pp. 804-817, 2011.
[99] G. Scapagnini, S. Davinelli, F. Drago, A. De Lorenzo, and G. Oriani, "Antioxidants as antidepressants: fact or fiction?" CNS Drugs, vol. 26, no. 6, pp. 477-490, 2012.

[100] R. C. Malenka, E. J. Nestler, and S. E. Hyman, Molecular Neuropharmacology: A Foundation for Clinical Neuroscience, McGraw-Hill Medical, New York, NY, USA, 2nd edition, 2009.

[101] R. J. Schloesser, G. Chen, and H. K. Manji, "Neurogenesis and neuroenhancement in the pathophysiology and treatment of bipolar disorder," International Review of Neurobiology, vol. 77, pp. 143-178, 2007.

[102] R. J. Nudo, "Recovery after damage to motor cortical areas," Current Opinion in Neurobiology, vol. 9, no. 6, pp. 740-747, 1999.

[103] H. Pantazopoulos and S. Berretta, "In sickness and in health: perineuronal nets and synaptic plasticity in psychiatric disorders," Neural Plasticity, vol. 2016, Article ID 9847696, p. 23, 2016.

[104] J. H. Krystal, D. F. Tolin, G. Sanacora et al., "Neuroplasticity as a target for the pharmacotherapy of anxiety disorders, mood disorders, and schizophrenia," Drug Discovery Today, vol. 14, no. 13-14, pp. 690-697, 2009.

[105] L. G. Cohen, P. Celnik, A. Pascual-Leone et al., "Functional relevance of cross-modal plasticity in blind humans," Nature, vol. 389, no. 6647, pp. 180-183, 1997.

[106] G. Kempermann, K. Fabel, D. Ehninger et al., "Why and how physical activity promotes experience-induced brain plasticity," Frontiers in Neuroscience, vol. 4, p. 189, 2010.

[107] T. Garland Jr., H. Schutz, M. A. Chappell et al., "The biological control of voluntary exercise, spontaneous physical activity and daily energy expenditure in relation to obesity: human and rodent perspectives," The Journal of Experimental Biology, vol. 214, Part 2, pp. 206-229, 2011.

[108] K. R. Westerterp, “Assessment of physical activity: a critical appraisal," European Journal of Applied Physiology, vol. 105, no. 6, pp. 823-828, 2009.

[109] K. Kowalski, R. Rhodes, P. J. Naylor, H. Tuokko, and S. MacDonald, "Direct and indirect measurement of physical activity in older adults: a systematic review of the literature," International Journal of Behavioral Nutrition and Physical Activity, vol. 9, no. 1, p. 148, 2012.

[110] R. K. Dishman, "Gene-physical activity interactions in the etiology of obesity: behavioral considerations," Obesity (Silver Spring), vol. 16, Supplement 3, pp. S60-S65, 2008.

[111] R. J. Shephard, "Limits to the measurement of habitual physical activity by questionnaires," British Journal of Sports Medicine, vol. 37, no. 3, pp. 197-206, 2003, discussion 06.

[112] D. M. de Vilhena e Santos, P. T. Katzmarzyk, A. F. Seabra, and J. A. Maia, "Genetics of physical activity and physical inactivity in humans," Behavior Genetics, vol. 42, no. 4, pp. 559-578, 2012.

[113] S. Wilcox and B. E. Ainsworth, "The measurement of physical activity," in The Handbook of Health Behavior Change, S. A. Shumaker, J. Ockene and K. A. Riekert, Eds., pp. 327346, Springer Publishing Company, LLC, New York, NY, USA, 2009.

[114] M. K. Dinger, R. F. Oman, E. L. Taylor, S. K. Vesely, and J. Able, "Stability and convergent validity of the Physical Activity Scale for the Elderly (PASE)," The Journal of Sports Medicine and Physical Fitness, vol. 44, no. 2, pp. 186-192, 2004. 
[115] S. A. Prince, K. B. Adamo, M. E. Hamel, J. Hardt, S. Connor Gorber, and M. Tremblay, "A comparison of direct versus self-report measures for assessing physical activity in adults: a systematic review," International Journal of Behavioral Nutrition and Physical Activity, vol. 5, no. 1, p. 56, 2008.

[116] K. B. Adamo, S. A. Prince, A. C. Tricco, S. Connor-Gorber, and M. Tremblay, "A comparison of indirect versus direct measures for assessing physical activity in the pediatric population: a systematic review," International Journal of Pediatric Obesity, vol. 4, no. 1, pp. 2-27, 2009.

[117] A. M. Joosen, M. Gielen, R. Vlietinck, and K. R. Westerterp, "Genetic analysis of physical activity in twins," The American Journal of Clinical Nutrition, vol. 82, no. 6, pp. 1253-1259, 2005.

[118] E. L. Rezende, F. R. Gomes, M. A. Chappell, and T. Garland Jr, "Running behavior and its energy cost in mice selectively bred for high voluntary locomotor activity," Physiological and Biochemical Zoology, vol. 82, no. 6, pp. 662-679, 2009.

[119] S. A. Kelly and D. Pomp, "Genetic determinants of voluntary exercise," Trends in Genetics, vol. 29, no. 6, pp. 348-357, 2013.

[120] C. M. Novak, P. R. Burghardt, and J. A. Levine, "The use of a running wheel to measure activity in rodents: relationship to energy balance, general activity, and reward," Neuroscience and Biobehavioral Reviews, vol. 36, no. 3, pp. 1001-1014, 2012.

[121] S. Brene, A. Bjornebekk, E. Aberg, A. A. Mathe, L. Olson, and M. Werme, "Running is rewarding and antidepressive," Physiology \& Behavior, vol. 92, no. 1-2, pp. 136-140, 2007.

[122] B. T. Lett, V. L. Grant, M. J. Byrne, and M. T. Koh, "Pairings of a distinctive chamber with the aftereffect of wheel running produce conditioned place preference," Appetite, vol. 34, no. 1, pp. 87-94, 2000.

[123] T. W. Belke and T. Garland Jr., "A brief opportunity to run does not function as a reinforcer for mice selected for high daily wheel-running rates," Journal of the Experimental Analysis of Behavior, vol. 88, no. 2, pp. 199-213, 2007.

[124] J. F. Sallis, "Age-related decline in physical activity: a synthesis of human and animal studies," Medicine and Science in Sports and Exercise, vol. 32, no. 9, pp. 1598-1600, 2000.

[125] A. M. Bronikowski, T. J. Morgan, T. Garland Jr., and P. A. Carter, "The evolution of aging and age-related physical decline in mice selectively bred for high voluntary exercise," Evolution, vol. 60, no. 7, pp. 1494-1508, 2006.

[126] F. W. Booth, M. V. Chakravarthy, S. E. Gordon, and E. E. Spangenburg, "Waging war on physical inactivity: using modern molecular ammunition against an ancient enemy," Journal of Applied Physiology (1985), vol. 93, no. 1, pp. 3-30, 2002.

[127] R. Clubb and G. Mason, "Animal welfare: captivity effects on wide-ranging carnivores," Nature, vol. 425, no. 6957, pp. 473-474, 2003.

[128] S. Chiba, T. Numakawa, M. Ninomiya, M. C. Richards, C. Wakabayashi, and H. Kunugi, "Chronic restraint stress causes anxiety- and depression-like behaviors, downregulates glucocorticoid receptor expression, and attenuates glutamate release induced by brain-derived neurotrophic factor in the prefrontal cortex," Progress in NeuroPsychopharmacology \& Biological Psychiatry, vol. 39, no. 1, pp. 112-119, 2012.

[129] M. W. Sullivan and M. Lewis, "Contextual determinants of anger and other negative expressions in young infants," Developmental Psychology, vol. 39, no. 4, pp. 693-705, 2003.
[130] L. A. Leotti, S. S. Iyengar, and K. N. Ochsner, "Born to choose: the origins and value of the need for control," Trends in Cognitive Sciences, vol. 14, no. 10, pp. 457-463, 2010.

[131] B. N. Greenwood, K. G. Spence, D. M. Crevling, P. J. Clark, W. C. Craig, and M. Fleshner, "Exercise-induced stress resistance is independent of exercise controllability and the medial prefrontal cortex," The European Journal of Neuroscience, vol. 37, no. 3, pp. 469-478, 2013.

[132] R. M. Arida, C. A. Scorza, A. V. da Silva, F. A. Scorza, and E. A. Cavalheiro, "Differential effects of spontaneous versus forced exercise in rats on the staining of parvalbuminpositive neurons in the hippocampal formation," Neuroscience Letters, vol. 364, no. 3, pp. 135-138, 2004.

[133] P. V. Holmes, "Rodent models of depression: reexamining validity without anthropomorphic inference," Critical Reviews in Neurobiology, vol. 15, no. 2, pp. 143-174, 2003.

[134] J. L. Kays, R. A. Hurley, and K. H. Taber, "The dynamic brain: neuroplasticity and mental health," The Journal of Neuropsychiatry and Clinical Neurosciences, vol. 24, no. 2, pp. 118-124, 2012.

[135] S. C. Cramer, M. Sur, B. H. Dobkin et al., "Harnessing neuroplasticity for clinical applications," Brain, vol. 134, Part 6, pp. 1591-1609, 2011.

[136] C. Knochel, V. Oertel-Knochel, L. O'Dwyer et al., "Cognitive and behavioural effects of physical exercise in psychiatric patients," Progress in Neurobiology, vol. 96, no. 1, pp. 46-68, 2012.

[137] M. Ghasemi, C. Phillips, L. Trillo, Z. De Miguel, D. Das, and A. Salehi, "The role of NMDA receptors in the pathophysiology and treatment of mood disorders," Neuroscience and Biobehavioral Reviews, vol. 47, pp. 336-358, 2014.

[138] M. M. Jukic, T. Carrillo-Roa, M. Bar et al., "Abnormal development of monoaminergic neurons is implicated in mood fluctuations and bipolar disorder," Neuropsychopharmacology, vol. 40, no. 4, pp. 839-848, 2015.

[139] L. Coque, S. Mukherjee, J. L. Cao et al., "Specific role of VTA dopamine neuronal firing rates and morphology in the reversal of anxiety-related, but not depression-related behavior in the ClockDelta19 mouse model of mania," Neuropsychopharmacology, vol. 36, no. 7, pp. 1478-1488, 2011.

[140] J. D. Barchus and M. Altemus, Monoamine Hypotheses of Mood Disorders, Lippincott-Raven, Philadelphia, PA, 6th edition, 1999.

[141] T. W. Robbins and A. F. Arnsten, "The neuropsychopharmacology of fronto-executive function: monoaminergic modulation," Annual Review of Neuroscience, vol. 32, pp. 267-287, 2009.

[142] A. L. Dunn and R. K. Dishman, "Exercise and the neurobiology of depression," Exercise and Sport Sciences Reviews, vol. 19, no. 1, pp. 41-98, 1991.

[143] R. Meeusen and K. De Meirleir, "Exercise and brain neurotransmission,” Sports Medicine, vol. 20, no. 3, pp. 160-188, 1995.

[144] B. N. Greenwood, T. E. Foley, H. E. Day et al., "Freewheel running prevents learned helplessness/behavioral depression: role of dorsal raphe serotonergic neurons," The Journal of Neuroscience, vol. 23, no. 7, pp. 28892898, 2003.

[145] B. N. Greenwood and M. Fleshner, "Exercise, learned helplessness, and the stress-resistant brain," Neuromolecular Medicine, vol. 10, no. 2, pp. 81-98, 2008. 
[146] F. Chaouloff, J. L. Elghozi, Y. Guezennec, and D. Laude, "Effects of conditioned running on plasma, liver and brain tryptophan and on brain 5-hydroxytryptamine metabolism of the rat," British Journal of Pharmacology, vol. 86, no. 1, pp. 33-41, 1985.

[147] A. L. Dunn, T. G. Reigle, S. D. Youngstedt, R. B. Armstrong, and R. K. Dishman, "Brain norepinephrine and metabolites after treadmill training and wheel running in rats," Medicine and Science in Sports and Exercise, vol. 28, no. 2, pp. 204-209, 1996.

[148] R. K. Dishman, "Brain monoamines, exercise, and behavioral stress: animal models," Medicine and Science in Sports and Exercise, vol. 29, no. 1, pp. 63-74, 1997.

[149] F. Chaouloff, D. Laude, Y. Guezennec, and J. L. Elghozi, "Motor activity increases tryptophan, 5-hydroxyindoleacetic acid, and homovanillic acid in ventricular cerebrospinal fluid of the conscious rat," Journal of Neurochemistry, vol. 46, no. 4, pp. 1313-1316, 1986.

[150] E. L. Bliss and J. Ailion, "Relationship of stress and activity to brain dopamine and homovanillic acid," Life Sciences, vol. 10, no. 20, pp. 1161-1169, 1971.

[151] E. A. Herbst and G. P. Holloway, "Exercise increases mitochondrial glutamate oxidation in the mouse cerebral cortex," Applied Physiology, Nutrition, and Metabolism, vol. 41, no. 7, pp. 799-801, 2016.

[152] R. J. Maddock, G. A. Casazza, D. H. Fernandez, and M. I. Maddock, "Acute modulation of cortical glutamate and GABA content by physical activity," The Journal of Neuroscience, vol. 36, no. 8, pp. 2449-2457, 2016.

[153] W. J. Lynch, A. B. Peterson, V. Sanchez, J. Abel, and M. A. Smith, "Exercise as a novel treatment for drug addiction: a neurobiological and stage-dependent hypothesis," Neuroscience and Biobehavioral Reviews, vol. 37, no. 8, pp. 1622$1644,2013$.

[154] S. Dey, R. H. Singh, and P. K. Dey, "Exercise training: significance of regional alterations in serotonin metabolism of rat brain in relation to antidepressant effect of exercise," Physiology \& Behavior, vol. 52, no. 6, pp. 1095-1099, 1992.

[155] F. Chaouloff, "Physical exercise and brain monoamines: a review," Acta Physiologica Scandinavica, vol. 137, no. 1, pp. 1-13, 1989.

[156] R. P. Patrick and B. N. Ames, "Vitamin D and the omega-3 fatty acids control serotonin synthesis and action, part 2: relevance for ADHD, bipolar disorder, schizophrenia, and impulsive behavior," The FASEB Journal, vol. 29, no. 6, pp. 2207-2222, 2015.

[157] F. Chaouloff, D. Laude, D. Merino, B. Serrurrier, Y. Guezennec, and J. L. Elghozi, "Amphetamine and alpha-methyl-ptyrosine affect the exercise-induced imbalance between the availability of tryptophan and synthesis of serotonin in the brain of the rat," Neuropharmacology, vol. 26, no. 8, pp. 1099-1106, 1987.

[158] F. Chaoloff, "The serotonin hypothesis," in Physical Activity and Mental Health, W. P. Morgan, Ed., Washington, D.C., Talyor \& Francis, 2013.

[159] C. Kiank, J. P. Zeden, S. Drude et al., "Psychological stressinduced, IDO1-dependent tryptophan catabolism: implications on immunosuppression in mice and humans," PLoS One, vol. 5, no. 7, article e11825, 2010.

[160] Y. Ito, R. Yonekura, K. Maruta et al., “Tryptophan metabolism was accelerated by exercise in rat," Advances in
Experimental Medicine and Biology, vol. 527, pp. 531535, 2003.

[161] V. A. Pieribone, Z. Q. Xu, X. Zhang, S. Grillner, T. Bartfai, and T. Hokfelt, "Galanin induces a hyperpolarization of norepinephrine-containing locus coeruleus neurons in the brainstem slice," Neuroscience, vol. 64, no. 4, pp. 861-874, 1995.

[162] V. Seutin, P. Verbanck, L. Massotte, and A. Dresse, "Galanin decreases the activity of locus coeruleus neurons in vitro," European Journal of Pharmacology, vol. 164, no. 2, pp. 373376, 1989.

[163] P. S. Murray, J. L. Groves, B. J. Pettett et al., "Locus coeruleus galanin expression is enhanced after exercise in rats selectively bred for high capacity for aerobic activity," Peptides, vol. 31, no. 12, pp. 2264-2268, 2010.

[164] J. I. Reiss, R. K. Dishman, H. E. Boyd, J. K. Robinson, and P. V. Holmes, "Chronic activity wheel running reduces the severity of kainic acid-induced seizures in the rat: possible role of galanin," Brain Research, vol. 1266, pp. 54-63, 2009.

[165] C. Gouarne, C. Groussard, A. Gratas-Delamarche, P. Delamarche, and M. Duclos, "Overnight urinary cortisol and cortisone add new insights into adaptation to training," Medicine and Science in Sports and Exercise, vol. 37, no. 7, pp. 1157-1167, 2005.

[166] T. Traustadottir, P. R. Bosch, and K. S. Matt, “The HPA axis response to stress in women: effects of aging and fitness," Psychoneuroendocrinology, vol. 30, no. 4, pp. 392-402, 2005.

[167] U. Rimmele, R. Seiler, B. Marti, P. H. Wirtz, U. Ehlert, and M. Heinrichs, "The level of physical activity affects adrenal and cardiovascular reactivity to psychosocial stress," Psychoneuroendocrinology, vol. 34, no. 2, pp. 190-198, 2009.

[168] B. von Haaren, J. Ottenbacher, J. Muenz, R. Neumann, K. Boes, and U. Ebner-Priemer, "Does a 20-week aerobic exercise training programme increase our capabilities to buffer real-life stressors? A randomized, controlled trial using ambulatory assessment," European Journal of Applied Physiology, vol. 116, no. 2, pp. 383-394, 2016.

[169] J. M. de Castro and G. Duncan, "Operantly conditioned running: effects on brain catecholamine concentrations and receptor densities in the rat," Pharmacology, Biochemistry, and Behavior, vol. 23, no. 4, pp. 495-500, 1985.

[170] B. N. Greenwood, T. E. Foley, T. V. Le et al., "Long-term voluntary wheel running is rewarding and produces plasticity in the mesolimbic reward pathway," Behavioural Brain Research, vol. 217, no. 2, pp. 354-362, 2011.

[171] W. F. Mathes, D. L. Nehrenberg, R. Gordon, K. Hua, T. Garland Jr., and D. Pomp, "Dopaminergic dysregulation in mice selectively bred for excessive exercise or obesity," Behavioural Brain Research, vol. 210, no. 2, pp. 155-163, 2010.

[172] G. Morris and M. Berk, "The many roads to mitochondrial dysfunction in neuroimmune and neuropsychiatric disorders," BMC Medicine, vol. 13, no. 1, p. 68, 2015.

[173] Y. Goffer, D. Xu, S. E. Eberle et al., "Calcium-permeable AMPA receptors in the nucleus accumbens regulate depression-like behaviors in the chronic neuropathic pain state," The Journal of Neuroscience, vol. 33, no. 48, pp. 19034-19044, 2013.

[174] S. Lammel, B. K. Lim, and R. C. Malenka, "Reward and aversion in a heterogeneous midbrain dopamine system," Neuropharmacology, vol. 76, Part B, pp. 351-359, 2014. 
[175] H. C. Fibiger, "Dopaminergic-cholinergic interactions in the striatum," The Japanese Journal of Psychiatry and Neurology, vol. 45, no. 2, p. 512, 1991.

[176] P. Willner, R. Muscat, and G. Phillips, "The role of dopamine in rewarded behavior: ability, insight, drive or incentive?" Polish Journal of Pharmacology and Pharmacy, vol. 43, no. 4, pp. 291-300, 1991.

[177] G. L. Collingridge and T. V. Bliss, "Memories of NMDA receptors and LTP," Trends in Neurosciences, vol. 18, no. 2, pp. 54-56, 1995.

[178] A. Holtmaat and K. Svoboda, "Experience-dependent structural synaptic plasticity in the mammalian brain," Nature Reviews Neuroscience, vol. 10, no. 9, pp. 647-658, 2009.

[179] H. W. Kessels and R. Malinow, "Synaptic AMPA receptor plasticity and behavior," Neuron, vol. 61, no. 3, pp. 340350, 2009.

[180] A. Yildiz-Yesiloglu and D. P. Ankerst, "Review of $1 \mathrm{H}$ magnetic resonance spectroscopy findings in major depressive disorder: a meta-analysis," Psychiatry Research, vol. 147, no. 1, pp. 1-25, 2006.

[181] J. Jia, Y. S. Hu, Y. Wu et al., "Pre-ischemic treadmill training affects glutamate and gamma aminobutyric acid levels in the striatal dialysate of a rat model of cerebral ischemia," Life Sciences, vol. 84, no. 15-16, pp. 505-511, 2009.

[182] D. E. Sutoo and K. Akiyama, "The mechanism by which exercise modifies brain function," Physiology \& Behavior, vol. 60, no. 1, pp. 177-181, 1996.

[183] L. Canevari, G. Richter-Levin, and T. V. Bliss, "LTP in the dentate gyrus is associated with a persistent NMDA receptordependent enhancement of synaptosomal glutamate release," Brain Research, vol. 667, no. 1, pp. 115-117, 1994.

[184] S. J.Lou, J. Y.Liu, H. Chang, and P. J. Chen, "Hippocampal neurogenesis and gene expression depend on exercise intensity in juvenile rats," Brain Research, vol. 1210, pp. 48-55, 2008.

[185] C. Vasuta, C. Caunt, R. James et al., "Effects of exercise on NMDA receptor subunit contributions to bidirectional synaptic plasticity in the mouse dentate gyrus," Hippocampus, vol. 17, no. 12, pp. 1201-1208, 2007.

[186] H. Pareja-Galeano, S. Mayero, M. Perales et al., "Biological rationale for regular physical exercise as an effective intervention for the prevention and treatment of depressive disorders," Current Pharmaceutical Design, vol. 22, no. 24, pp. 3764-3775, 2016.

[187] M. T. Alsuwaidan, A. Kucyi, C. W. Law, and R. S. McIntyre, "Exercise and bipolar disorder: a review of neurobiological mediators," Neuromolecular Medicine, vol. 11, no. 4, pp. 328-336, 2009.

[188] C. Garcia, M. J. Chen, A. A. Garza, C. W. Cotman, and A. Russo-Neustadt, "The influence of specific noradrenergic and serotonergic lesions on the expression of hippocampal brain-derived neurotrophic factor transcripts following voluntary physical activity," Neuroscience, vol. 119, no. 3, pp. 721-732, 2003.

[189] M. P. Mattson, S. Maudsley, and B. Martin, "BDNF and 5HT: a dynamic duo in age-related neuronal plasticity and neurodegenerative disorders," Trends in Neurosciences, vol. 27, no. 10, pp. 589-594, 2004.

[190] M. J. Chen, T. V. Nguyen, C. J. Pike, and A. A. Russo-Neustadt, "Norepinephrine induces BDNF and activates the PI-3K and MAPK cascades in embryonic hippocampal neurons," Cellular Signalling, vol. 19, no. 1, pp. 114-128, 2007.
[191] T. V. Bliss and G. L. Collingridge, "A synaptic model of memory: long-term potentiation in the hippocampus," Nature, vol. 361, no. 6407, pp. 31-39, 1993.

[192] M. F. Bear and W. C. Abraham, "Long-term depression in hippocampus," Annual Review of Neuroscience, vol. 19, no. 1, pp. 437-462, 1996.

[193] G. G. Turrigiano, K. R. Leslie, N. S. Desai, L. C. Rutherford, and S. B. Nelson, "Activity-dependent scaling of quantal amplitude in neocortical neurons," Nature, vol. 391, no. 6670 , pp. 892-896, 1998.

[194] M. C. McKinnon, K. Yucel, A. Nazarov, and G. M. MacQueen, "A meta-analysis examining clinical predictors of hippocampal volume in patients with major depressive disorder," Journal of Psychiatry \& Neuroscience, vol. 34, no. 1, pp. 41-54, 2009.

[195] M. J. Kempton, Z. Salvador, M. R. Munafo et al., "Structural neuroimaging studies in major depressive disorder. Metaanalysis and comparison with bipolar disorder," Archives of General Psychiatry, vol. 68, no. 7, pp. 675-690, 2011.

[196] M. Otten and M. Meeter, "Hippocampal structure and function in individuals with bipolar disorder: a systematic review," Journal of Affective Disorders, vol. 174, pp. 113125, 2015.

[197] S. M. Strakowski, D. E. Fleck, J. Welge et al., "fMRI brain activation changes following treatment of a first bipolar manic episode," Bipolar Disorders, vol. 18, no. 6, pp. 490-501, 2016.

[198] D. M. Hafeman, K. D. Chang, A. S. Garrett, E. M. Sanders, and M. L. Phillips, "Effects of medication on neuroimaging findings in bipolar disorder: an updated review," Bipolar Disorders, vol. 14, no. 4, pp. 375-410, 2012.

[199] M. L. Phillips, W. C. Drevets, S. L. Rauch, and R. Lane, "Neurobiology of emotion perception I: the neural basis of normal emotion perception," Biological Psychiatry, vol. 54, no. 5, pp. 504-514, 2003.

[200] L. E. Jarrard, "On the role of the hippocampus in learning and memory in the rat," Behavioral and Neural Biology, vol. 60, no. 1, pp. 9-26, 1993.

[201] M. R. Bennett, “The prefrontal-limbic network in depression: a core pathology of synapse regression," Progress in Neurobiology, vol. 93, no. 4, pp. 457-467, 2011.

[202] B. Czeh and P. J. Lucassen, "What causes the hippocampal volume decrease in depression? Are neurogenesis, glial changes and apoptosis implicated?" European Archives of Psychiatry and Clinical Neuroscience, vol. 257, no. 5, pp. 250-260, 2007.

[203] V. Krishnan and E. J. Nestler, "The molecular neurobiology of depression," Nature, vol. 455, no. 7215, pp. 894-902, 2008.

[204] J. Savitz and W. C. Drevets, "Bipolar and major depressive disorder: neuroimaging the developmental-degenerative divide," Neuroscience and Biobehavioral Reviews, vol. 33, no. 5, pp. 699-771, 2009.

[205] S. Campbell, M. Marriott, C. Nahmias, and G. M. MacQueen, "Lower hippocampal volume in patients suffering from depression: a meta-analysis," The American Journal of Psychiatry, vol. 161, no. 4, pp. 598-607, 2004.

[206] K. R. Smith, K. J. Kopeikina, J. M. Fawcett-Patel et al., "Psychiatric risk factor ANK3/ankyrin-G nanodomains regulate the structure and function of glutamatergic synapses," Neuron, vol. 84, no. 2, pp. 399-415, 2014.

[207] T. Hajek, M. Kopecek, C. Hoschl, and M. Alda, "Smaller hippocampal volumes in patients with bipolar disorder 
are masked by exposure to lithium: a meta-analysis," Journal of Psychiatry \& Neuroscience, vol. 37, no. 5, pp. 333343, 2012.

[208] T. Frodl, M. Jager, I. Smajstrlova et al., "Effect of hippocampal and amygdala volumes on clinical outcomes in major depression: a 3-year prospective magnetic resonance imaging study," Journal of Psychiatry \& Neuroscience, vol. 33, no. 5, pp. 423-430, 2008.

[209] N. V. Malykhin, R. Carter, P. Seres, and N. J. Coupland, "Structural changes in the hippocampus in major depressive disorder: contributions of disease and treatment," Journal of Psychiatry \& Neuroscience, vol. 35, no. 5, pp. 337-343, 2010.

[210] A. Simonetti, G. Sani, C. Dacquino et al., "Hippocampal subfield volumes in short- and long-term lithium-treated patients with bipolar I disorder," Bipolar Disorders, vol. 18, no. 4, pp. 352-362, 2016.

[211] K. I. Erickson, R. S. Prakash, M. W. Voss et al., “Aerobic fitness is associated with hippocampal volume in elderly humans," Hippocampus, vol. 19, no. 10, pp. 1030-1039, 2009.

[212] K. I. Erickson, M. W. Voss, R. S. Prakash et al., "Exercise training increases size of hippocampus and improves memory," Proceedings of the National Academy of Sciences of the United States of America, vol. 108, no. 7, pp. 3017-3022, 2011.

[213] A. C. Pereira, D. E. Huddleston, A. M. Brickman et al., “An in vivo correlate of exercise-induced neurogenesis in the adult dentate gyrus," Proceedings of the National Academy of Sciences of the United States of America, vol. 104, no. 13, pp. 5638-5643, 2007.

[214] F. G. Pajonk, T. Wobrock, O. Gruber et al., "Hippocampal plasticity in response to exercise in schizophrenia," Archives of General Psychiatry, vol. 67, no. 2, pp. 133-143, 2010.

[215] M. W. Voss, C. Vivar, A. F. Kramer, and H. van Praag, "Bridging animal and human models of exercise-induced brain plasticity," Trends in Cognitive Sciences, vol. 17, no. 10, pp. 525-544, 2013.

[216] B. R. Christie, B. D. Eadie, T. S. Kannangara, J. M. Robillard, J. Shin, and A. K. Titterness, "Exercising our brains: how physical activity impacts synaptic plasticity in the dentate gyrus," Neuromolecular Medicine, vol. 10, no. 2, pp. 47-58, 2008.

[217] A. M. Stranahan, D. Khalil, and E. Gould, "Running induces widespread structural alterations in the hippocampus and entorhinal cortex," Hippocampus, vol. 17, no. 11, pp. 10171022, 2007.

[218] C. W. Cotman and N. C. Berchtold, "Physical activity and the maintenance of cognition: learning from animal models," Alzheimers Dement, vol. 3, Supplement 2, pp. S30-S37, 2007.

[219] F. Nottebohm, "Why are some neurons replaced in adult brain?" The Journal of Neuroscience, vol. 22, no. 3, pp. 624628, 2002.

[220] F. Nottebohm, "Neuronal replacement in adult brain," Brain Research Bulletin, vol. 57, no. 6, pp. 737-749, 2002.

[221] K. M. Christian, H. Song, and G. L. Ming, "Functions and dysfunctions of adult hippocampal neurogenesis," Annual Review of Neuroscience, vol. 37, pp. 243-262, 2014.

[222] H. Suh, W. Deng, and F. H. Gage, "Signaling in adult neurogenesis," Annual Review of Cell and Developmental Biology, vol. 25, pp. 253-275, 2009.

[223] C. Schmidt-Hieber, P. Jonas, and J. Bischofberger, "Enhanced synaptic plasticity in newly generated granule cells of the adult hippocampus," Nature, vol. 429, no. 6988, pp. 184187, 2004.
[224] A. Sahay and R. Hen, "Adult hippocampal neurogenesis in depression," Nature Neuroscience, vol. 10, no. 9, pp. 1110$1115,2007$.

[225] J. Herbert and P. J. Lucassen, "Depression as a risk factor for Alzheimer's disease: genes, steroids, cytokines and neurogenesis - what do we need to know?" Frontiers in Neuroendocrinology, vol. 41, pp. 153-171, 2016.

[226] I. Zalachoras, R. Houtman, E. Atucha et al., "Differential targeting of brain stress circuits with a selective glucocorticoid receptor modulator," Proceedings of the National Academy of Sciences of the United States of America, vol. 110, no. 19, pp. 7910-7915, 2013.

[227] Y. I. Sheline, M. H. Gado, and H. C. Kraemer, "Untreated depression and hippocampal volume loss," The American Journal of Psychiatry, vol. 160, no. 8, pp. 1516-1518, 2003.

[228] H. van Praag, G. Kempermann, and F. H. Gage, "Running increases cell proliferation and neurogenesis in the adult mouse dentate gyrus," Nature Neuroscience, vol. 2, no. 3, pp. 266-270, 1999.

[229] H. van Praag, T. Shubert, C. Zhao, and F. H. Gage, "Exercise enhances learning and hippocampal neurogenesis in aged mice," The Journal of Neuroscience, vol. 25, no. 38, pp. 8680-8685, 2005.

[230] M. Uda, M. Ishido, K. Kami, and M. Masuhara, "Effects of chronic treadmill running on neurogenesis in the dentate gyrus of the hippocampus of adult rat," Brain Research, vol. 1104, no. 1, pp. 64-72, 2006.

[231] C. Zhao, E. M. Teng, R. G. Summers Jr., G. L. Ming, and F. H. Gage, "Distinct morphological stages of dentate granule neuron maturation in the adult mouse hippocampus," The Journal of Neuroscience, vol. 26, no. 1, pp. 3-11, 2006.

[232] D. J. Creer, C. Romberg, L. M. Saksida, H. van Praag, and T. J. Bussey, "Running enhances spatial pattern separation in mice," Proceedings of the National Academy of Sciences of the United States of America, vol. 107, no. 5, pp. 23672372, 2010.

[233] R. Coras, F. A. Siebzehnrubl, E. Pauli et al., "Low proliferation and differentiation capacities of adult hippocampal stem cells correlate with memory dysfunction in humans," Brain, vol. 133, no. 11, pp. 3359-3372, 2010.

[234] M. R. Drew and R. Hen, "Adult hippocampal neurogenesis as target for the treatment of depression," CNS \& Neurological Disorders Drug Targets, vol. 6, no. 3, pp. 205-218, 2007.

[235] A. J. Eisch and D. Petrik, "Depression and hippocampal neurogenesis: a road to remission?" Science, vol. 338, no. 6103, pp. 72-75, 2012.

[236] K. K. Cowansage, J. E. LeDoux, and M. H. Monfils, "Brainderived neurotrophic factor: a dynamic gatekeeper of neural plasticity," Current Molecular Pharmacology, vol. 3, no. 1, pp. 12-29, 2010.

[237] J. E. Ahlskog, Y. E. Geda, N. R. Graff-Radford, and R. C. Petersen, "Physical exercise as a preventive or diseasemodifying treatment of dementia and brain aging," Mayo Clinic Proceedings, vol. 86, no. 9, pp. 876-884, 2011.

[238] A. E. Autry and L. M. Monteggia, "Brain-derived neurotrophic factor and neuropsychiatric disorders," Pharmacological Reviews, vol. 64, no. 2, pp. 238-258, 2012.

[239] B. S. Fernandes, M. Berk, C. W. Turck, J. Steiner, and C. A. Goncalves, "Decreased peripheral brain-derived neurotrophic factor levels are a biomarker of disease activity in 
major psychiatric disorders: a comparative meta-analysis," Molecular Psychiatry, vol. 19, no. 7, pp. 750-751, 2014.

[240] B. S. Fernandes, M. L. Molendijk, C. A. Kohler et al., "Peripheral brain-derived neurotrophic factor (BDNF) as a biomarker in bipolar disorder: a meta-analysis of 52 studies," BMC Medicine, vol. 13, no. 1, p. 289, 2015.

[241] A. T. Soares, A. C. Andreazza, S. Rej et al., "Decreased brainderived neurotrophic factor in older adults with bipolar disorder," The American Journal of Geriatric Psychiatry, vol. 24, no. 8, pp. 596-601, 2016.

[242] F. Matrisciano, S. Bonaccorso, A. Ricciardi et al., "Changes in BDNF serum levels in patients with major depression disorder (MDD) after 6 months treatment with sertraline, escitalopram, or venlafaxine," Journal of Psychiatric Research, vol. 43, no. 3, pp. 247-254, 2009.

[243] A. R. Brunoni, M. Lopes, and F. Fregni, "A systematic review and meta-analysis of clinical studies on major depression and BDNF levels: implications for the role of neuroplasticity in depression," The International Journal of Neuropsychopharmacology, vol. 11, no. 8, pp. 1169-1180, 2008.

[244] J. S. Dunham, J. F. Deakin, F. Miyajima, A. Payton, and C. T. Toro, "Expression of hippocampal brain-derived neurotrophic factor and its receptors in Stanley consortium brains," Journal of Psychiatric Research, vol. 43, no. 14, pp. 11751184, 2009.

[245] S. Sen, R. Duman, and G. Sanacora, "Serum brain-derived neurotrophic factor, depression, and antidepressant medications: meta-analyses and implications," Biological Psychiatry, vol. 64, no. 6, pp. 527-532, 2008.

[246] Y. C. Chang, S. I. Rapoport, and J. S. Rao, "Chronic administration of mood stabilizers upregulates BDNF and bcl-2 expression levels in rat frontal cortex," Neurochemical Research, vol. 34, no. 3, pp. 536-541, 2009.

[247] S. Yasuda, M. H. Liang, Z. Marinova, A. Yahyavi, and D. M. Chuang, "The mood stabilizers lithium and valproate selectively activate the promoter IV of brain-derived neurotrophic factor in neurons," Molecular Psychiatry, vol. 14, no. 1, pp. 51-59, 2009.

[248] I. Grande, F. Kapczinski, L. Stertz et al., "Peripheral brainderived neurotrophic factor changes along treatment with extended release quetiapine during acute mood episodes: an open-label trial in drug-free patients with bipolar disorder," Journal of Psychiatric Research, vol. 46, no. 11, pp. 15111514, 2012.

[249] A. R. Brunoni, C. Baeken, R. Machado-Vieira, W. F. Gattaz, and M. A. Vanderhasselt, "BDNF blood levels after electroconvulsive therapy in patients with mood disorders: a systematic review and meta-analysis," The World Journal of Biological Psychiatry, vol. 15, no. 5, pp. 411-418, 2014.

[250] G. S. Kirshenbaum, C. R. Burgess, N. Dery, M. Fahnestock, J. H. Peever, and J. C. Roder, "Attenuation of mania-like behavior in $\mathrm{Na}(+), \mathrm{K}(+)$-ATPase alpha3 mutant mice by prospective therapies for bipolar disorder: melatonin and exercise," Neuroscience, vol. 260, pp. 195-204, 2014.

[251] C. Engesser-Cesar, A. J. Anderson, and C. W. Cotman, "Wheel running and fluoxetine antidepressant treatment have differential effects in the hippocampus and the spinal cord," Neuroscience, vol. 144, no. 3, pp. 1033-1044, 2007.

[252] R. M. Legge, S. Sendi, J. H. Cole et al., "Modulatory effects of brain-derived neurotrophic factor Val66Met polymorphism on prefrontal regions in major depressive disorder," The British Journal of Psychiatry, vol. 206, no. 5, pp. 379-384, 2015.
[253] M. Verhagen, A. van der Meij, P. A. van Deurzen et al., "Meta-analysis of the BDNF Val66Met polymorphism in major depressive disorder: effects of gender and ethnicity," Molecular Psychiatry, vol. 15, no. 3, pp. 260-271, 2010.

[254] M. Neves-Pereira, E. Mundo, P. Muglia, N. King, F. Macciardi, and J. L. Kennedy, "The brain-derived neurotrophic factor gene confers susceptibility to bipolar disorder: evidence from a family-based association study," American Journal of Human Genetics, vol. 71, no. 3, pp. 651-655, 2002.

[255] K. Matsuo, C. Walss-Bass, F. G. Nery et al., "Neuronal correlates of brain-derived neurotrophic factor Val66Met polymorphism and morphometric abnormalities in bipolar disorder," Neuropsychopharmacology, vol. 34, no. 8, pp. 1904-1913, 2009.

[256] B. N. Frey, A. C. Andreazza, J. Houenou et al., "Biomarkers in bipolar disorder: a positional paper from the International Society for Bipolar Disorders Biomarkers Task Force," The Australian and New Zealand Journal of Psychiatry, vol. 47, no. 4, pp. 321-332, 2013.

[257] G. Zhao, C. Zhang, J. Chen et al., "Ratio of mBDNF to proBDNF for differential diagnosis of major depressive disorder and bipolar depression," Molecular Neurobiology, pp. 1-10, 2016.

[258] E. E. Noble, V. Mavanji, M. R. Little, C. J. Billington, C. M. Kotz, and C. Wang, "Exercise reduces diet-induced cognitive decline and increases hippocampal brain-derived neurotrophic factor in CA3 neurons," Neurobiology of Learning and Memory, vol. 114, pp. 40-50, 2014.

[259] Q. Ding, Z. Ying, and F. Gomez-Pinilla, "Exercise influences hippocampal plasticity by modulating brain-derived neurotrophic factor processing," Neuroscience, vol. 192, pp. 773780, 2011.

[260] A. Russo-Neustadt, T. Ha, R. Ramirez, and J. P. Kesslak, "Physical activity-antidepressant treatment combination: impact on brain-derived neurotrophic factor and behavior in an animal model," Behavioural Brain Research, vol. 120, no. 1, pp. 87-95, 2001.

[261] N. C. Berchtold, G. Chinn, M. Chou, J. P. Kesslak, and C. W. Cotman, "Exercise primes a molecular memory for brainderived neurotrophic factor protein induction in the rat hippocampus," Neuroscience, vol. 133, no. 3, pp. 853-861, 2005.

[262] C. D. Wrann, J. P. White, J. Salogiannnis et al., "Exercise induces hippocampal BDNF through a PGC-1alpha/FNDC5 pathway," Cell Metabolism, vol. 18, no. 5, pp. 649-659, 2013.

[263] E. Y. Yuen, J. Wei, W. Liu, P. Zhong, X. Li, and Z. Yan, "Repeated stress causes cognitive impairment by suppressing glutamate receptor expression and function in prefrontal cortex," Neuron, vol. 73, no. 5, pp. 962-977, 2012.

[264] W. Liu, H. Sheng, Y. Xu, Y. Liu, J. Lu, and X. Ni, "Swimming exercise ameliorates depression-like behavior in chronically stressed rats: relevant to proinflammatory cytokines and IDO activation," Behavioural Brain Research, vol. 242, pp. 110-116, 2013.

[265] S. M. Gibney, B. McGuinness, C. Prendergast, A. Harkin, and T. J. Connor, "Poly I:C-induced activation of the immune response is accompanied by depression and anxiety-like behaviours, kynurenine pathway activation and reduced BDNF expression," Brain, Behavior, and Immunity, vol. 28, pp. 170-181, 2013.

[266] Y. Yoshimura, C. Ishikawa, H. Kasegai, T. Masuda, M. Yoshikawa, and T. Shiga, "Roles of 5-HT1A receptor in the expression of AMPA receptor and BDNF in developing 
mouse cortical neurons," Neuroscience Research, vol. 115, pp. 13-20, 2016.

[267] G. Gustafsson, C. M. Lira, J. Johansson et al., "The acute response of plasma brain-derived neurotrophic factor as a result of exercise in major depressive disorder," Psychiatry Research, vol. 169, no. 3, pp. 244-248, 2009.

[268] C. Laske, S. Banschbach, E. Stransky et al., "Exercise-induced normalization of decreased BDNF serum concentration in elderly women with remitted major depression," The International Journal of Neuropsychopharmacology, vol. 13, no. 5, pp. 595-602, 2010.

[269] F. B. Schuch, L. E. da Silveira, T. C. de Zeni et al., "Effects of a single bout of maximal aerobic exercise on BDNF in bipolar disorder: a gender-based response," Psychiatry Research, vol. 229, no. 1-2, pp. 57-62, 2015.

[270] F. G. Coelho, L. P. Andrade, R. V. Pedroso et al., "Multimodal exercise intervention improves frontal cognitive functions and gait in Alzheimer's disease: a controlled trial," Geriatrics \& Gerontology International, vol. 13, no. 1, pp. 198-203, 2013.

[271] S. Vaynman and F. Gomez-Pinilla, "Revenge of the "sit": how lifestyle impacts neuronal and cognitive health through molecular systems that interface energy metabolism with neuronal plasticity," Journal of Neuroscience Research, vol. 84, no. 4, pp. 699-715, 2006.

[272] Y. Lu, K. Christian, and B. Lu, "BDNF: a key regulator for protein synthesis-dependent LTP and long-term memory?" Neurobiology of Learning and Memory, vol. 89, no. 3, pp. 312-323, 2008.

[273] H. Anisman and S. Hayley, "Inflammatory factors contribute to depression and its comorbid conditions," Science Signaling, vol. 5, no. 244, article pe45, 2012.

[274] B. I. Goldstein, D. E. Kemp, J. K. Soczynska, and R. S. McIntyre, "Inflammation and the phenomenology, pathophysiology, comorbidity, and treatment of bipolar disorder: a systematic review of the literature," The Journal of Clinical Psychiatry, vol. 70, no. 8, pp. 1078-1090, 2009.

[275] C. L. Raison, L. Capuron, and A. H. Miller, "Cytokines sing the blues: inflammation and the pathogenesis of depression," Trends in Immunology, vol. 27, no. 1, pp. 24-31, 2006.

[276] E. Brietzke, M. Kauer-Sant'Anna, A. L. Teixeira, and F. Kapczinski, "Abnormalities in serum chemokine levels in euthymic patients with bipolar disorder," Brain, Behavior, and Immunity, vol. 23, no. 8, pp. 1079-1082, 2009.

[277] Y. Dowlati, N. Herrmann, W. Swardfager et al., "A metaanalysis of cytokines in major depression," Biological Psychiatry, vol. 67, no. 5, pp. 446-457, 2010.

[278] M. B. Howren, D. M. Lamkin, and J. Suls, "Associations of depression with C-reactive protein, IL-1, and IL-6: a metaanalysis," Psychosomatic Medicine, vol. 71, no. 2, pp. 171186, 2009.

[279] G. M. Asnis and R. De La Garza 2nd, "Interferon-induced depression in chronic hepatitis C: a review of its prevalence, risk factors, biology, and treatment approaches," Journal of Clinical Gastroenterology, vol. 40, no. 4, pp. 322-335, 2006.

[280] E. Dieperink, M. Willenbring, and S. B. Ho, "Neuropsychiatric symptoms associated with hepatitis $\mathrm{C}$ and interferon alpha: a review," The American Journal of Psychiatry, vol. 157, no. 6, pp. 867-876, 2000.

[281] K. S. Na, K. J. Lee, J. S. Lee, Y. S. Cho, and H. Y. Jung, "Efficacy of adjunctive celecoxib treatment for patients with major depressive disorder: a meta-analysis," Progress in NeuroPsychopharmacology \& Biological Psychiatry, vol. 48, pp. 79-85, 2014.

[282] J. K. Soczynska, S. H. Kennedy, B. I. Goldstein, A. Lachowski, H. O. Woldeyohannes, and R. S. McIntyre, "The effect of tumor necrosis factor antagonists on mood and mental health-associated quality of life: novel hypothesis-driven treatments for bipolar depression?" Neurotoxicology, vol. 30, no. 4, pp. 497-521, 2009.

[283] A. Menter, M. Augustin, J. Signorovitch et al., "The effect of adalimumab on reducing depression symptoms in patients with moderate to severe psoriasis: a randomized clinical trial," Journal of the American Academy of Dermatology, vol. 62, no. 5, pp. 812-818, 2010.

[284] N. Muller, M. J. Schwarz, S. Dehning et al., "The cyclooxygenase- 2 inhibitor celecoxib has therapeutic effects in major depression: results of a double-blind, randomized, placebo controlled, add-on pilot study to reboxetine," Molecular Psychiatry, vol. 11, no. 7, pp. 680-684, 2006.

[285] F. Boufidou, C. Nikolaou, B. Alevizos, I. A. Liappas, and G. N. Christodoulou, "Cytokine production in bipolar affective disorder patients under lithium treatment," Journal of Affective Disorders, vol. 82, no. 2, pp. 309-313, 2004.

[286] R. S. McIntyre, D. J. Muzina, D. E. Kemp et al., "Bipolar disorder and suicide: research synthesis and clinical translation," Current Psychiatry Reports, vol. 10, no. 1, pp. 6672, 2008.

[287] J. A. Woods, M. A. Ceddia, B. W. Wolters, J. K. Evans, Q. Lu, and E. McAuley, "Effects of 6 months of moderate aerobic exercise training on immune function in the elderly," Mechanisms of Ageing and Development, vol. 109, no. 1, pp. 1-19, 1999.

[288] D. M. Crist, L. T. Mackinnon, R. F. Thompson, H. A. Atterbom, and P. A. Egan, "Physical exercise increases natural cellularmediated tumor cytotoxicity in elderly women," Gerontology, vol. 35, no. 2-3, pp. 66-71, 1989.

[289] T. W. Pace, F. Hu, and A. H. Miller, "Cytokine-effects on glucocorticoid receptor function: relevance to glucocorticoid resistance and the pathophysiology and treatment of major depression," Brain, Behavior, and Immunity, vol. 21, no. 1, pp. 9-19, 2007.

[290] S. Radom-Aizik, F. P. Zaldivar Jr., F. Haddad, and D. M. Cooper, "Impact of brief exercise on circulating monocyte gene and microRNA expression: implications for atherosclerotic vascular disease," Brain, Behavior, and Immunity, vol. 39, pp. 121-129, 2014.

[291] C. T. Ekdahl, J. H. Claasen, S. Bonde, Z. Kokaia, and O. Lindvall, "Inflammation is detrimental for neurogenesis in adult brain," Proceedings of the National Academy of Sciences of the United States of America, vol. 100, no. 23, pp. 13632-13637, 2003.

[292] General OoS, The Surgeon General's Vision for a Healthy and Fit Nation, Service UPH, Rockville, MD, USA, 2010.

[293] S. J. Lupien, C. Buss, T. E. Schramek, F. Maheu, and J. Pruessner, "Hormetic influence of glucocorticoids on human memory," Nonlinearity in Biology, Toxicology, Medicine, vol. 3, no. 1, pp. 23-56, 2005.

[294] R. M. Sapolsky, H. Uno, C. S. Rebert, and C. E. Finch, "Hippocampal damage associated with prolonged glucocorticoid exposure in primates," The Journal of Neuroscience, vol. 10, no. 9, pp. 2897-2902, 1990. 
[295] F. Holsboer, "The corticosteroid receptor hypothesis of depression," Neuropsychopharmacology, vol. 23, no. 5, pp. 477-501, 2000.

[296] T. Steckler, F. Holsboer, and J. M. Reul, "Glucocorticoids and depression," Baillière's Best Practice \& Research. Clinical Endocrinology \& Metabolism, vol. 13, no. 4, pp. 597-614, 1999.

[297] C. M. Pariante and A. H. Miller, "Glucocorticoid receptors in major depression: relevance to pathophysiology and treatment," Biological Psychiatry, vol. 49, no. 5, pp. 391404, 2001.

[298] M. Ising, H. E. Kunzel, E. B. Binder, T. Nickel, S. Modell, and F. Holsboer, "The combined dexamethasone/CRH test as a potential surrogate marker in depression," Progress in Neuro-Psychopharmacology \& Biological Psychiatry, vol. 29, no. 6, pp. 1085-1093, 2005.

[299] I. Heuser, A. Yassouridis, and F. Holsboer, "The combined dexamethasone/CRH test: a refined laboratory test for psychiatric disorders," Journal of Psychiatric Research, vol. 28, no. 4, pp. 341-356, 1994.

[300] C. B. Nemeroff, E. Widerlov, G. Bissette et al., "Elevated concentrations of CSF corticotropin-releasing factor-like immunoreactivity in depressed patients," Science, vol. 226, no. 4680, pp. 1342-1344, 1984.

[301] R. Havermans, N. A. Nicolson, J. Berkhof, and M. W. deVries, "Patterns of salivary cortisol secretion and responses to daily events in patients with remitted bipolar disorder," Psychoneuroendocrinology, vol. 36, no. 2, pp. 258-265, 2011.

[302] J. Keller, B. Flores, R. G. Gomez et al., "Cortisol circadian rhythm alterations in psychotic major depression," Biological Psychiatry, vol. 60, no. 3, pp. 275-281, 2006.

[303] R. Zhou, Y. Lu, Y. Han et al., "Mice heterozygous for cathepsin D deficiency exhibit mania-related behavior and stress-induced depression," Progress in Neuro-Psychopharmacology \& Biological Psychiatry, vol. 63, pp. 110-118, 2015.

[304] W. R. Marchand, D. D. Valentina, and C. R. Jensen, "Neurobiology of mood disorders," Hospital Physician, vol. 43, pp. 17-26, 2005.

[305] H. K. Manji, J. A. Quiroz, J. Sporn et al., "Enhancing neuronal plasticity and cellular resilience to develop novel, improved therapeutics for difficult-to-treat depression," Biological Psychiatry, vol. 53, no. 8, pp. 707-742, 2003.

[306] J. D. Bremner, M. Narayan, E. R. Anderson, L. H. Staib, H. L. Miller, and D. S. Charney, "Hippocampal volume reduction in major depression," The American Journal of Psychiatry, vol. 157, no. 1, pp. 115-118, 2000.

[307] K. Dedovic and J. Ngiam, “The cortisol awakening response and major depression: examining the evidence," Neuropsychiatric Disease and Treatment, vol. 11, pp. 1181-1189, 2015.

[308] I. G. Barbosa, M. E. Bauer, R. Machado-Vieira, and A. L. Teixeira, "Cytokines in bipolar disorder: paving the way for neuroprogression," Neural Plasticity, vol. 2014, Article ID 360481, p. 9, 2014.

[309] A. H. Miller, C. M. Pariante, and B. D. Pearce, "Effects of cytokines on glucocorticoid receptor expression and function. Glucocorticoid resistance and relevance to depression," Advances in Experimental Medicine and Biology, vol. 461, pp. 107-116, 1999.

[310] A. H. Miller, B. D. Pearce, M. C. Ruzek, and C. A. Biron, Interactions between the Hypothalamic-Pituitary-Adrenal
Axis and Immune System during Viral Infection: Pathways for Environmental Effects of Disease Expression, Oxford University Press, New York, NY, USA, 2001.

[311] H. E. Ploeger, T. Takken, M. H. de Greef, and B. W. Timmons, "The effects of acute and chronic exercise on inflammatory markers in children and adults with a chronic inflammatory disease: a systematic review," Exercise Immunology Review, vol. 15, no. 1, pp. 6-41, 2009.

[312] A. M. Stranahan, K. Lee, and M. P. Mattson, "Central mechanisms of HPA axis regulation by voluntary exercise," Neuromolecular Medicine, vol. 10, no. 2, pp. 118-127, 2008.

[313] S. J. Lupien, M. de Leon, S. de Santi et al., "Cortisol levels during human aging predict hippocampal atrophy and memory deficits," Nature Neuroscience, vol. 1, no. 1, pp. 69-73, 1998.

[314] L. G. Apostolova, R. A. Dutton, I. D. Dinov et al., "Conversion of mild cognitive impairment to Alzheimer disease predicted by hippocampal atrophy maps," Archives of Neurology, vol. 63, no. 5, pp. 693-699, 2006.

[315] D. P. Devanand, G. Pradhaban, X. Liu et al., "Hippocampal and entorhinal atrophy in mild cognitive impairment: prediction of Alzheimer disease," Neurology, vol. 68, no. 11, pp. 828-836, 2007.

[316] C. Nabkasorn, N. Miyai, A. Sootmongkol et al., "Effects of physical exercise on depression, neuroendocrine stress hormones and physiological fitness in adolescent females with depressive symptoms," European Journal of Public Health, vol. 16, no. 2, pp. 179-184, 2006.

[317] C. S. Woolley, E. Gould, and B. S. McEwen, "Exposure to excess glucocorticoids alters dendritic morphology of adult hippocampal pyramidal neurons," Brain Research, vol. 531, no. 1-2, pp. 225-231, 1990.

[318] B. D. Eadie, V. A. Redila, and B. R. Christie, "Voluntary exercise alters the cytoarchitecture of the adult dentate gyrus by increasing cellular proliferation, dendritic complexity, and spine density," The Journal of Comparative Neurology, vol. 486, no. 1, pp. 39-47, 2005.

[319] V. A. Redila and B. R. Christie, "Exercise-induced changes in dendritic structure and complexity in the adult hippocampal dentate gyrus," Neuroscience, vol. 137, no. 4, pp. 1299-1307, 2006.

[320] D. Chatzitheodorou, S. Mavromoustakos, and S. Milioti, "The effect of exercise on adrenocortical responsiveness of patients with chronic low back pain, controlled for psychological strain," Clinical Rehabilitation, vol. 22, no. 4, pp. 319-328, 2008.

[321] H. Sies, "Oxidative stress: a concept in redox biology and medicine," Redox Biology, vol. 4, pp. 180-183, 2015.

[322] R. A. Floyd, "Antioxidants, oxidative stress, and degenerative neurological disorders," Proceedings of the Society for Experimental Biology and Medicine, vol. 222, no. 3, pp. 236-245, 1999.

[323] L. R. Baxter Jr., M. E. Phelps, J. C. Mazziotta et al., "Cerebral metabolic rates for glucose in mood disorders. Studies with positron emission tomography and fluorodeoxyglucose $\mathrm{F}$ 18," Archives of General Psychiatry, vol. 42, no. 5, pp. 441447, 1985.

[324] M. Kuloglu, B. Ustundag, M. Atmaca, H. Canatan, A. E. Tezcan, and N. Cinkilinc, "Lipid peroxidation and antioxidant enzyme levels in patients with schizophrenia and bipolar disorder," Cell Biochemistry and Function, vol. 20, no. 2, pp. 171-175, 2002. 
[325] A. C. Andreazza, M. Kauer-Sant'anna, B. N. Frey et al., "Oxidative stress markers in bipolar disorder: a meta-analysis," Journal of Affective Disorders, vol. 111, no. 2-3, pp. 135-144, 2008.

[326] A. L. Lopresti, G. L. Maker, S. D. Hood, and P. D. Drummond, "A review of peripheral biomarkers in major depression: the potential of inflammatory and oxidative stress biomarkers," Progress in Neuro-Psychopharmacology \& Biological Psychiatry, vol. 48, pp. 102-111, 2014.

[327] M. Maes, P. Galecki, Y. S. Chang, and M. Berk, "A review on the oxidative and nitrosative stress (O\&NS) pathways in major depression and their possible contribution to the (neuro) degenerative processes in that illness," Progress in Neuro-Psychopharmacology \& Biological Psychiatry, vol. 35, no. 3, pp. 676-692, 2011.

[328] M. U. Raza, T. Tufan, Y. Wang, C. Hill, and M. Y. Zhu, "DNA damage in major psychiatric diseases," Neurotoxicity Research, vol. 30, no. 2, pp. 251-267, 2016.

[329] A. C. Andreazza, B. N. Frey, B. Erdtmann et al., "DNA damage in bipolar disorder," Psychiatry Research, vol. 153, no. 1, pp. 27-32, 2007.

[330] M. G. Soeiro-de-Souza, A. C. Andreazza, A. F. Carvalho, R. Machado-Vieira, L. T. Young, and R. A. Moreno, "Number of manic episodes is associated with elevated DNA oxidation in bipolar I disorder," The International Journal of Neuropsychopharmacology, vol. 16, no. 7, pp. 1505-1512, 2013.

[331] P. G. Friedland, R. P. Petot, G. J. Nunomura, R. J. Castellani, and Z. Kubat, "Alzheimer as a disease of metabolic demand: benefits of physical and brain exercise," in Exercise and Diseases, Z. Radak, Ed., pp. 7-16, Meyer Sport, Oxford, 2005.

[332] C. Leeuwenburgh and J. W. Heinecke, "Oxidative stress and antioxidants in exercise," Current Medicinal Chemistry, vol. 8, no. 7, pp. 829-838, 2001.

[333] Z. Radak, H. Y. Chung, and S. Goto, "Systemic adaptation to oxidative challenge induced by regular exercise," Free Radical Biology \& Medicine, vol. 44, no. 2, pp. 153-159, 2008.

[334] W. Teo, M. J. Newton, and M. R. McGuigan, "Circadian rhythms in exercise performance: implications for hormonal and muscular adaptation," Journal of Sports Science and Medicine, vol. 10, no. 4, pp. 600-606, 2011.

[335] D. C. Klein and R. Y. Moore, "Pineal N-acetyltransferase and hydroxyindole-O-methyltransferase: control by the retinohypothalamic tract and the suprachiasmatic nucleus," Brain Research, vol. 174, no. 2, pp. 245-262, 1979.

[336] G. Murray and A. Harvey, "Circadian rhythms and sleep in bipolar disorder," Bipolar Disorders, vol. 12, no. 5, pp. 459472, 2010.

[337] A. Kalsbeek, S. Perreau-Lenz, and R. M. Buijs, "A network of (autonomic) clock outputs," Chronobiology International, vol. 23, no. 3, pp. 521-535, 2006.

[338] N. Nader, G. P. Chrousos, and T. Kino, "Interactions of the circadian CLOCK system and the HPA axis," Trends in Endocrinology and Metabolism, vol. 21, no. 5, pp. 277-286, 2010.

[339] H. A. Mansour, J. Wood, K. V. Chowdari et al., "Circadian phase variation in bipolar I disorder," Chronobiology International, vol. 22, no. 3, pp. 571-584, 2005.

[340] A. Wirz-Justice, "Chronobiology and mood disorders," Dialogues in Clinical Neuroscience, vol. 5, no. 4, pp. 315-325, 2003.

[341] N. Kronfeld-Schor and H. Einat, "Circadian rhythms and depression: human psychopathology and animal models," Neuropharmacology, vol. 62, no. 1, pp. 101-114, 2012.
[342] B. S. McEwen, "Sleep deprivation as a neurobiologic and physiologic stressor: allostasis and allostatic load," Metabolism, vol. 55, no. 10, Supplement 2, pp. S20-S23, 2006.

[343] S. Redline and J. Foody, "Sleep disturbances: time to join the top 10 potentially modifiable cardiovascular risk factors?" Circulation, vol. 124, no. 19, pp. 2049-2051, 2011.

[344] P. Hua, W. Liu, D. Chen et al., "Cryl and Tef gene polymorphisms are associated with major depressive disorder in the Chinese population," Journal of Affective Disorders, vol. 157, pp. 100-103, 2014.

[345] V. Soria, E. Martinez-Amoros, G. Escaramis et al., "Differential association of circadian genes with mood disorders: CRY1 and NPAS2 are associated with unipolar major depression and CLOCK and VIP with bipolar disorder," Neuropsychopharmacology, vol. 35, no. 6, pp. 1279-1289, 2010.

[346] M. C. Melo, R. F. Garcia, V. B. Linhares Neto et al., "Sleep and circadian alterations in people at risk for bipolar disorder: a systematic review," Journal of Psychiatric Research, vol. 83, pp. 211-219, 2016.

[347] V. Milhiet, B. Etain, C. Boudebesse, and F. Bellivier, "Circadian biomarkers, circadian genes and bipolar disorders," Journal of Physiology, Paris, vol. 105, no. 4-6, pp. 183-189, 2011.

[348] A. B. Medina, D. A. Lechuga, O. S. Escandon, and J. V. Moctezuma, "Update of sleep alterations in depression," Sleep Science, vol. 7, no. 3, pp. 165-169, 2014.

[349] A. G. Harvey, "Sleep and circadian rhythms in bipolar disorder: seeking synchrony, harmony, and regulation," The American Journal of Psychiatry, vol. 165, no. 7, pp. 820-829, 2008.

[350] J. I. Nurnberger Jr., S. Adkins, D. K. Lahiri et al., "Melatonin suppression by light in euthymic bipolar and unipolar patients," Archives of General Psychiatry, vol. 57, no. 6, pp. 572-579, 2000.

[351] A. J. Lewy, J. I. Nurnberger Jr., T. A. Wehr et al., "Supersensitivity to light: possible trait marker for manic-depressive illness," The American Journal of Psychiatry, vol. 142, no. 6, pp. 725-727, 1985.

[352] K. T. Hallam, J. S. Olver, and T. R. Norman, "Effect of sodium valproate on nocturnal melatonin sensitivity to light in healthy volunteers," Neuropsychopharmacology, vol. 30, no. 7, pp. 1400-1404, 2005.

[353] K. T. Hallam, J. S. Olver, J. E. Horgan, C. McGrath, and T. R. Norman, "Low doses of lithium carbonate reduce melatonin light sensitivity in healthy volunteers," The International Journal of Neuropsychopharmacology, vol. 8, no. 2, pp. 255259, 2005.

[354] J. M. Bumb, F. Enning, J. K. Mueller et al., "Differential melatonin alterations in cerebrospinal fluid and serum of patients with major depressive disorder and bipolar disorder," Comprehensive Psychiatry, vol. 68, pp. 34-39, 2016.

[355] P. Gallagher, S. Watson, M. S. Smith, A. H. Young, and I. N. Ferrier, "Plasma cortisol-dehydroepiandrosterone (DHEA) ratios in schizophrenia and bipolar disorder," Schizophrenia Research, vol. 90, no. 1-3, pp. 258-265, 2007.

[356] P. Linkowski, M. Kerkhofs, A. Van Onderbergen et al., "The 24-hour profiles of cortisol, prolactin, and growth hormone secretion in mania," Archives of General Psychiatry, vol. 51, no. 8, pp. 616-624, 1994.

[357] A. H. Young, "Antiglucocoticoid treatments for depression," The Australian and New Zealand Journal of Psychiatry, vol. 40, no. 5, pp. 402-405, 2006. 
[358] G. P. Chrousos, "Stress and disorders of the stress system," Nature Reviews Endocrinology, vol. 5, no. 7, pp. 374-381, 2009.

[359] M. C. Antle, V. M. Smith, R. Sterniczuk, G. R. Yamakawa, and B. D. Rakai, "Physiological responses of the circadian clock to acute light exposure at night," Reviews in Endocrine \& Metabolic Disorders, vol. 10, no. 4, pp. 279-291, 2009.

[360] M. J. McCarthy and D. K. Welsh, "Cellular circadian clocks in mood disorders," Journal of Biological Rhythms, vol. 27, no. 5, pp. 339-352, 2012.

[361] R. Zhang, N. F. Lahens, H. I. Ballance, M. E. Hughes, and J. B. Hogenesch, "A circadian gene expression atlas in mammals: implications for biology and medicine," Proceedings of the National Academy of Sciences of the United States of America, vol. 111, no. 45, pp. 16219-16224, 2014.

[362] C. Cirelli and G. Tononi, "Gene expression in the brain across the sleep-waking cycle," Brain Research, vol. 885, no. 2, pp. 303-321, 2000.

[363] R. Iyer, T. A. Wang, and M. U. Gillette, "Circadian gating of neuronal functionality: a basis for iterative metaplasticity," Frontiers in Systems Neuroscience, vol. 8, p. 164, 2014.

[364] N. W. Burton, K. I. Pakenham, and W. J. Brown, "Are psychologists willing and able to promote physical activity as part of psychological treatment?" International Journal of Behavioral Medicine, vol. 17, no. 4, pp. 287-297, 2010.

[365] S. J. Kim, S. Benloucif, K. J. Reid et al., "Phase-shifting response to light in older adults," The Journal of Physiology, vol. 592, no. 1, pp. 189-202, 2014.

[366] G. Escames, G. Ozturk, B. Bano-Otalora et al., "Exercise and melatonin in humans: reciprocal benefits," Journal of Pineal Research, vol. 52, no. 1, pp. 1-11, 2012.

[367] D. F. Swaab, "Suprachiasmatic nucleus (SCN) and pineal gland," in Handbook of Clinical Neurology, M. B. Aminoff and D. F. Swaab, Eds., pp. 63-123, Amsterdam, Netherlands, 2003.

[368] E. Naylor, P. D. Penev, L. Orbeta et al., "Daily social and physical activity increases slow-wave sleep and daytime neuropsychological performance in the elderly," Sleep, vol. 23, no. 1, pp. 87-95, 2000.

[369] K. A. Kubitz, D. M. Landers, S. J. Petruzzello, and M. Han, "The effects of acute and chronic exercise on sleep. a metaanalytic review," Sports Medicine, vol. 21, no. 4, pp. 277291, 1996.

[370] J. N. Ablin, D. J. Clauw, A. K. Lyden et al., "Effects of sleep restriction and exercise deprivation on somatic symptoms and mood in healthy adults," Clinical and Experimental Rheumatology, vol. 31, no. 6, Supplement 79, pp. S53-S59, 2013.

[371] K. G. Baron, K. J. Reid, and P. C. Zee, "Exercise to improve sleep in insomnia: exploration of the bidirectional effects," Journal of Clinical Sleep Medicine, vol. 9, no. 8, pp. 819-824, 2013.

[372] H. Tanaka, K. Taira, M. Arakawa et al., "Effects of short nap and exercise on elderly people having difficulty in sleeping," Psychiatry and Clinical Neurosciences, vol. 55, no. 3, pp. 173-174, 2001.

[373] H. Tanaka, K. Taira, M. Arakawa et al., "Short naps and exercise improve sleep quality and mental health in the elderly," Psychiatry and Clinical Neurosciences, vol. 56, no. 3, pp. 233-234, 2002.
[374] E. Uezu, K. Taira, H. Tanaka et al., "Survey of sleep-health and lifestyle of the elderly in Okinawa," Psychiatry and Clinical Neurosciences, vol. 54, no. 3, pp. 311-3, 2000.

[375] D. Foley, S. Ancoli-Israel, P. Britz, and J. Walsh, "Sleep disturbances and chronic disease in older adults: results of the 2003 National Sleep Foundation Sleep in America Survey," Journal of Psychosomatic Research, vol. 56, no. 5, pp. 497502, 2004.

[376] E. J. Van Someren, C. Lijzenga, M. Mirmiran, and D. F. Swaab, "Long-term fitness training improves the circadian rest-activity rhythm in healthy elderly males," Journal of Biological Rhythms, vol. 12, no. 2, pp. 146-156, 1997.

[377] O. M. Buxton, S. A. Frank, M. L'Hermite-Baleriaux, R. Leproult, F. W. Turek, and E. Van Cauter, "Roles of intensity and duration of nocturnal exercise in causing phase delays of human circadian rhythms," The American Journal of Physiology, vol. 273, no. 3, Part 1, pp. E536-E542, 1997.

[378] E. K. Baehr, C. I. Eastman, W. Revelle, S. H. Olson, L. F. Wolfe, and P. C. Zee, "Circadian phase-shifting effects of nocturnal exercise in older compared with young adults," American Journal of Physiology. Regulatory, Integrative and Comparative Physiology, vol. 284, no. 6, pp. R1542R1550, 2003.

[379] Y. Yamanaka, S. Hashimoto, Y. Tanahashi, S. Y. Nishide, S. Honma, and K. Honma, "Physical exercise accelerates reentrainment of human sleep-wake cycle but not of plasma melatonin rhythm to 8-h phase-advanced sleep schedule," American Journal of Physiology Regulatory, Integrative and Comparative Physiology, vol. 298, no. 3, pp. R681-R691, 2010.

[380] T. Miyazaki, S. Hashimoto, S. Masubuchi, S. Honma, and K. I. Honma, "Phase-advance shifts of human circadian pacemaker are accelerated by daytime physical exercise," American Journal of Physiology Regulatory, Integrative and Comparative Physiology, vol. 281, no. 1, pp. R197R205, 2001.

[381] O. M. Buxton, C. W. Lee, M. L'Hermite-Baleriaux, F. W. Turek, and E. Van Cauter, "Exercise elicits phase shifts and acute alterations of melatonin that vary with circadian phase," American Journal of Physiology Regulatory, Integrative and Comparative Physiology, vol. 284, no. 3, pp. R714R724, 2003.

[382] C. D. Rethorst, P. Sunderajan, T. L. Greer et al., "Does exercise improve self-reported sleep quality in non-remitted major depressive disorder?" Psychological Medicine, vol. 43, no. 4, pp. 699-709, 2013.

[383] C. D. Rethorst, T. L. Greer, M. S. Toups, I. Bernstein, T. J. Carmody, and M. H. Trivedi, "IL-1beta and BDNF are associated with improvement in hypersomnia but not insomnia following exercise in major depressive disorder," Translational Psychiatry, vol. 5, no. 8, article e611, 2015.

[384] E. L. McGlinchey, A. Gershon, P. Eidelman, K. A. Kaplan, and A. G. Harvey, "Physical activity and sleep: day-to-day associations among individuals with and without bipolar disorder," Mental Health and Physical Activity, vol. 7, no. 3, pp. 183-190, 2014.

[385] M. Suto, G. Murray, S. Hale, E. Amari, and E. E. Michalak, "What works for people with bipolar disorder? Tips from the experts," Journal of Affective Disorders, vol. 124, no. 1-2, pp. 76-84, 2010.

[386] J. Proudfoot, A. Whitton, G. Parker, J. Doran, V. Manicavasagar, and K. Delmas, "Triggers of mania and depression in young 
adults with bipolar disorder," Journal of Affective Disorders, vol. 143, no. 1-3, pp. 196-202, 2012.

[387] J. G. Klinzing, B. Rasch, J. Born, and S. Diekelmann, "Sleep's role in the reconsolidation of declarative memories," Neurobiology of Learning and Memory, vol. 136, pp. 166-173, 2016.

[388] M. P. Walker and R. Stickgold, "Sleep, memory, and plasticity,” Annual Review of Psychology, vol. 57, pp. 139-166, 2006.

[389] G. Tononi and C. Cirelli, "Sleep and the price of plasticity: from synaptic and cellular homeostasis to memory consolidation and integration," Neuron, vol. 81, no. 1, pp. 12-34, 2014.

[390] S. Sabunciyan, M. J. Aryee, R. A. Irizarry et al., "Genomewide DNA methylation scan in major depressive disorder," PLoS One, vol. 7, no. 4, article e34451, 2012.

[391] S. Numata, K. Ishii, A. Tajima et al., "Blood diagnostic biomarkers for major depressive disorder using multiplex DNA methylation profiles: discovery and validation," Epigenetics, vol. 10, no. 2, pp. 135-141, 2015.

[392] J. S. Rao, V. L. Keleshian, S. Klein, and S. I. Rapoport, "Epigenetic modifications in frontal cortex from Alzheimer's disease and bipolar disorder patients," Translational Psychiatry, vol. 2, no. 7, article e132, 2012.

[393] M. G. Banigan, P. F. Kao, J. A. Kozubek et al., "Differential expression of exosomal microRNAs in prefrontal cortices of schizophrenia and bipolar disorder patients," PLoS One, vol. 8, no. 1, article e48814, 2013.

[394] E. R. Gamazon, J. A. Badner, L. Cheng et al., "Enrichment of cis-regulatory gene expression SNPs and methylation quantitative trait loci among bipolar disorder susceptibility variants," Molecular Psychiatry, vol. 18, no. 3, pp. 340-346, 2013.

[395] E. L. Dempster, R. Pidsley, L. C. Schalkwyk et al., "Diseaseassociated epigenetic changes in monozygotic twins discordant for schizophrenia and bipolar disorder," Human Molecular Genetics, vol. 20, no. 24, pp. 4786-4796, 2011.

[396] T. Ikegame, M. Bundo, Y. Murata, K. Kasai, T. Kato, and K. Iwamoto, "DNA methylation of the BDNF gene and its relevance to psychiatric disorders," Journal of Human Genetics, vol. 58, no. 7, pp. 434-438, 2013.

[397] K. J. Dudley, X. Li, M. S. Kobor, T. E. Kippin, and T. W. Bredy, "Epigenetic mechanisms mediating vulnerability and resilience to psychiatric disorders," Neuroscience and Biobehavioral Reviews, vol. 35, no. 7, pp. 1544-1551, 2011.

[398] V. Vialou, J. Feng, A. J. Robison, and E. J. Nestler, "Epigenetic mechanisms of depression and antidepressant action," Annual Review of Pharmacology and Toxicology, vol. 53, pp. 59-87, 2013.

[399] R. S. Duman, G. K. Aghajanian, G. Sanacora, and J. H. Krystal, "Synaptic plasticity and depression: new insights from stress and rapid-acting antidepressants," Nature Medicine, vol. 22, no. 3, pp. 238-249, 2016.

[400] D. K. Ma, M. H. Jang, J. U. Guo et al., "Neuronal activityinduced Gadd45b promotes epigenetic DNA demethylation and adult neurogenesis," Science, vol. 323, no. 5917, pp. 1074-1077, 2009.

[401] E. Borrelli, E. J. Nestler, C. D. Allis, and P. Sassone-Corsi, "Decoding the epigenetic language of neuronal plasticity," Neuron, vol. 60, no. 6, pp. 961-974, 2008.

[402] E. J. Nestler, "Epigenetic mechanisms in psychiatry," Biological Psychiatry, vol. 65, no. 3, pp. 189-190, 2009.
[403] T. Hobara, S. Uchida, K. Otsuki et al., "Altered gene expression of histone deacetylases in mood disorder patients," Journal of Psychiatric Research, vol. 44, no. 5, pp. 263-270, 2010.

[404] K. Munkholm, M. Vinberg, M. Berk, and L. V. Kessing, "State-related alterations of gene expression in bipolar disorder: a systematic review," Bipolar Disorders, vol. 14, no. 7, pp. 684-696, 2012.

[405] J. D. Sweatt, "Experience-dependent epigenetic modifications in the central nervous system," Biological Psychiatry, vol. 65, no. 3, pp. 191-197, 2009.

[406] J. M. Reul and Y. Chandramohan, "Epigenetic mechanisms in stress-related memory formation," Psychoneuroendocrinology, vol. 32, Supplement 1, pp. S21-S25, 2007.

[407] J.Zhao, J. Goldberg, J. D. Bremner, and V. Vaccarino, “Association between promoter methylation of serotonin transporter gene and depressive symptoms: a monozygotic twin study," Psychosomatic Medicine, vol. 75, no. 6, pp. 523-529, 2013.

[408] C. Hammen, "Stress and depression," Annual Review of Clinical Psychology, vol. 1, pp. 293-319, 2005.

[409] C. Anacker, K. J. O'Donnell, and M. J. Meaney, "Early life adversity and the epigenetic programming of hypothalamicpituitary-adrenal function," Dialogues in Clinical Neuroscience, vol. 16, no. 3, pp. 321-333, 2014.

[410] G. Kuratomi, K. Iwamoto, M. Bundo et al., "Aberrant DNA methylation associated with bipolar disorder identified from discordant monozygotic twins," Molecular Psychiatry, vol. 13, no. 4, pp. 429-441, 2008.

[411] R. Barres, J. Yan, B. Egan et al., "Acute exercise remodels promoter methylation in human skeletal muscle," Cell Metabolism, vol. 15, no. 3, pp. 405-411, 2012.

[412] S. L. McGee and M. Hargreaves, "Histone modifications and exercise adaptations," Journal of Applied Physiology (1985), vol. 110, no. 1, pp. 258-263, 2011.

[413] V. R. Elsner, G. A. Lovatel, F. Moyses et al., "Exercise induces age-dependent changes on epigenetic parameters in rat hippocampus: a preliminary study," Experimental Gerontology, vol. 48, no. 2, pp. 136-139, 2013.

[414] N. M. Tsankova, O. Berton, W. Renthal, A. Kumar, R. L. Neve, and E. J. Nestler, "Sustained hippocampal chromatin regulation in a mouse model of depression and antidepressant action," Nature Neuroscience, vol. 9, no. 4, pp. 519525, 2006.

[415] F. Gomez-Pinilla, Y. Zhuang, J. Feng, Z. Ying, and G. Fan, "Exercise impacts brain-derived neurotrophic factor plasticity by engaging mechanisms of epigenetic regulation," The European Journal of Neuroscience, vol. 33, no. 3, pp. 383390, 2011.

[416] V. Januar, M. L. Ancelin, K. Ritchie, R. Saffery, and J. Ryan, "BDNF promoter methylation and genetic variation in latelife depression," Translational Psychiatry, vol. 5, no. 8, article e619, 2015.

[417] F. Sanchis-Gomar, J. L. Garcia-Gimenez, C. Perez-Quilis, M. C. Gomez-Cabrera, F. V. Pallardo, and G. Lippi, "Physical exercise as an epigenetic modulator: eustress, the "positive stress" as an effector of gene expression," Journal of Strength and Conditioning Research, vol. 26, no. 12, pp. 3469-3472, 2012.

[418] A. B. Niculescu, "Convergent functional genomics of psychiatric disorders," American Journal of Medical Genetics Part B, Neuropsychiatric Genetics, vol. 162B, no. 7, pp. 587594, 2013. 
[419] S. A. Neeper, F. Gomez-Pinilla, J. Choi, and C. Cotman, "Exercise and brain neurotrophins," Nature, vol. 373, no. 6510, p. 109, 1995.

[420] S. W. Tang, E. Chu, T. Hui, D. Helmeste, and C. Law, "Influence of exercise on serum brain-derived neurotrophic factor concentrations in healthy human subjects," Neuroscience Letters, vol. 431, no. 1, pp. 62-65, 2008.

[421] T. Seifert, P. Brassard, M. Wissenberg et al., "Endurance training enhances BDNF release from the human brain," American Journal of Physiology Regulatory, Integrative and Comparative Physiology, vol. 298, no. 2, pp. R372-R377, 2010.

[422] P. Rasmussen, P. Brassard, H. Adser et al., "Evidence for a release of brain-derived neurotrophic factor from the brain during exercise," Experimental Physiology, vol. 94, no. 10, pp. 1062-1069, 2009.

[423] J. L. Abel and E. F. Rissman, "Running-induced epigenetic and gene expression changes in the adolescent brain," International Journal of Developmental Neuroscience, vol. 31, no. 6, pp. 382-390, 2013.

[424] M. W. Marlatt, M. C. Potter, P. J. Lucassen, and H. van Praag, "Running throughout middle-age improves memory function, hippocampal neurogenesis, and BDNF levels in female C57BL/6J mice," Developmental Neurobiology, vol. 72, no. 6 , pp. 943-952, 2012.

[425] A. M. Stranahan, K. Lee, and M. P. Mattson, "Contributions of impaired hippocampal plasticity and neurodegeneration to age-related deficits in hormonal pulsatility," Ageing Research Reviews, vol. 7, no. 3, pp. 164-176, 2008.

[426] A. Muezzinler, A. K. Zaineddin, and H. Brenner, "A systematic review of leukocyte telomere length and age in adults," Ageing Research Reviews, vol. 12, no. 2, pp. 509-519, 2013.

[427] I. Hovatta, J. Juhila, and J. Donner, "Oxidative stress in anxiety and comorbid disorders," Neuroscience Research, vol. 68, no. 4, pp. 261-275, 2010.

[428] N. M. Simon, J. W. Smoller, K. L. McNamara et al., “Telomere shortening and mood disorders: preliminary support for a chronic stress model of accelerated aging," Biological Psychiatry, vol. 60, no. 5, pp. 432-5, 2006.

[429] O. M. Wolkowitz, S. H. Mellon, E. S. Epel et al., "Leukocyte telomere length in major depression: correlations with chronicity, inflammation and oxidative stress-preliminary findings," PLoS One, vol. 6, no. 3, article e17837, 2011.

[430] G. L. Caporaso, D. A. Lim, A. Alvarez-Buylla, and M. V. Chao, "Telomerase activity in the subventricular zone of adult mice," Molecular and Cellular Neurosciences, vol. 23, no. 4, pp. 693-702, 2003.

[431] I. Flores, R. Benetti, and M. A. Blasco, "Telomerase regulation and stem cell behaviour," Current Opinion in Cell Biology, vol. 18, no. 3, pp. 254-260, 2006.

[432] I. Flores, A. Canela, E. Vera, A. Tejera, G. Cotsarelis, and M. A. Blasco, "The longest telomeres: a general signature of adult stem cell compartments," Genes \& Development, vol. 22, no. 5 , pp. $654-667,2008$.

[433] S. Ferron, H. Mira, S. Franco et al., "Telomere shortening and chromosomal instability abrogates proliferation of adult but not embryonic neural stem cells," Development, vol. 131, no. 16, pp. 4059-4070, 2004.

[434] J. E. Verhoeven, D. Revesz, E. S. Epel, J. Lin, O. M. Wolkowitz, and B. W. Penninx, "Major depressive disorder and accelerated cellular aging: results from a large psychiatric cohort study," Molecular Psychiatry, vol. 19, no. 8, pp. 895-901, 2014.
[435] E. Puterman, E. S. Epel, J. Lin et al., "Multisystem resiliency moderates the major depression-telomere length association: findings from the Heart and Soul Study," Brain, Behavior, and Immunity, vol. 33, pp. 65-73, 2013.

[436] F. Mamdani, B. Rollins, L. Morgan et al., "Variable telomere length across post-mortem human brain regions and specific reduction in the hippocampus of major depressive disorder," Translational Psychiatry, vol. 5, no. 9, article e636, 2015.

[437] I. M. Lima, A. Barros, D. V. Rosa et al., "Analysis of telomere attrition in bipolar disorder," Journal of Affective Disorders, vol. 172, pp. 43-47, 2015.

[438] L. Martinsson, Y. Wei, D. Xu et al., "Long-term lithium treatment in bipolar disorder is associated with longer leukocyte telomeres," Translational Psychiatry, vol. 3, no. 5, article e261, 2013.

[439] A. Squassina, C. Pisanu, N. Corbett, and M. Alda, "Telomere length in bipolar disorder and lithium response," European Neuropsychopharmacology, 2015.

[440] L. F. Cherkas, J. L. Hunkin, B. S. Kato et al., "The association between physical activity in leisure time and leukocyte telomere length," Archives of Internal Medicine, vol. 168, no. 2, pp. 154-158, 2008.

[441] M. Du, J. Prescott, P. Kraft et al., "Physical activity, sedentary behavior, and leukocyte telomere length in women," American Journal of Epidemiology, vol. 175, no. 5, pp. 414-422, 2012.

[442] C. Werner, T. Furster, T. Widmann et al., "Physical exercise prevents cellular senescence in circulating leukocytes and in the vessel wall," Circulation, vol. 120, no. 24, pp. $2438-$ 2447, 2009.

[443] K. J. Ressler and H. S. Mayberg, "Targeting abnormal neural circuits in mood and anxiety disorders: from the laboratory to the clinic," Nature Neuroscience, vol. 10, no. 9, pp. 11161124, 2007.

[444] E. Castren, "Neuronal network plasticity and recovery from depression," JAMA Psychiatry, vol. 70, no. 9, pp. 983-9, 2013.

[445] J. L. Price and W. C. Drevets, "Neurocircuitry of mood disorders," Neuropsychopharmacology, vol. 35, no. 1, pp. 192-216, 2010.

[446] M. Vavakova, Z. Durackova, and J. Trebaticka, "Markers of oxidative stress and neuroprogression in depression disorder," Oxidative Medicine and Cellular Longevity, vol. 2015, Article ID 898393, p. 12, 2015.

[447] N. S. Kapczinski, B. Mwangi, R. M. Cassidy et al., "Neuroprogression and illness trajectories in bipolar disorder," Expert Review of Neurotherapeutics, vol. 17, no. 3, pp. 277-285, 2017.

[448] H. Silveira, H. Moraes, N. Oliveira, E. S. Coutinho, J. Laks, and A. Deslandes, "Physical exercise and clinically depressed patients: a systematic review and meta-analysis," Neuropsychobiology, vol. 67, no. 2, pp. 61-68, 2013.

[449] R. Stanton and P. Reaburn, "Exercise and the treatment of depression: a review of the exercise program variables," Journal of Science and Medicine in Sport, vol. 17, no. 2, pp. 177182, 2014.

[450] A. Kucyi, M. T. Alsuwaidan, S. S. Liauw, and R. S. McIntyre, "Aerobic physical exercise as a possible treatment for neurocognitive dysfunction in bipolar disorder," Postgraduate Medicine, vol. 122, no. 6, pp. 107-116, 2010.

[451] F. Ng, S. Dodd, and M. Berk, "The effects of physical activity in the acute treatment of bipolar disorder: a pilot study," Journal of Affective Disorders, vol. 101, no. 1-3, pp. 259-262, 2007. 
[452] G. Murray, M. Suto, R. Hole, S. Hale, E. Amari, and E. E. Michalak, "Self-management strategies used by 'high functioning' individuals with bipolar disorder: from research to clinical practice," Clinical Psychology \& Psychotherapy, vol. 18, no. 2, pp. 95-109, 2011.

[453] L. G. Sylvia, A. A. Nierenberg, J. P. Stange, A. D. Peckham, and T. Deckersbach, "Development of an integrated psychosocial treatment to address the medical burden associated with bipolar disorder," Journal of Psychiatric Practice, vol. 17, no. 3, pp. 224-232, 2011.

[454] K. A. Wright, E. S. Everson-Hock, and A. H. Taylor, "The effects of physical activity on physical and mental health among individuals with bipolar disorder: a systematic review," Mental Health and Physical Activity, vol. 2, no. 2, pp. 86-94, 2009.

[455] M. S. Ibarra-Rovillard and N. A. Kuiper, "Social support and social negativity findings in depression: perceived responsiveness to basic psychological needs," Clinical Psychology Review, vol. 31, no. 3, pp. 342-352, 2011.

[456] R. J. Shepard, Aging, Physical Activity, and Health, Human Kinetics, Champaign, IL, 1997.

[457] E. L. Deci and R. M. Ryan, "The "what" and "why" of goal pursuits: human needs and self-determination of behavior," Psychological Inquiry, vol. 11, no. 4, pp. 227-268, 2000.

[458] A. Kouvonen, R. De Vogli, M. Stafford et al., "Social support and the likelihood of maintaining and improving levels of physical activity: the Whitehall II Study," European Journal of Public Health, vol. 22, no. 4, pp. 514-518, 2012.

[459] Y. Stern, "What is cognitive reserve? Theory and research application of the reserve concept," Journal of the International Neuropsychological Society, vol. 8, no. 3, pp. 448-460, 2002.

[460] R. Katzman, R. Terry, R. DeTeresa et al., "Clinical, pathological, and neurochemical changes in dementia: a subgroup with preserved mental status and numerous neocortical plaques," Annals of Neurology, vol. 23, no. 2, pp. 138-144, 1988.

[461] M. H. Trivedi, T. L. Greer, B. D. Grannemann, H. O. Chambliss, and A. N. Jordan, "Exercise as an augmentation strategy for treatment of major depression," Journal of Psychiatric Practice, vol. 12, no. 4, pp. 205-213, 2006.

[462] P. Phongsavan, D. Merom, A. Bauman, and R. Wagner, "Mental illness and physical activity: therapists' beliefs and practices," The Australian and New Zealand Journal of Psychiatry, vol. 41, no. 5, pp. 458-459, 2007.

[463] M. Belvederi Murri, M. Amore, M. Menchetti et al., "Physical exercise for late-life major depression," The British Journal of Psychiatry, vol. 207, no. 3, pp. 235-242, 2015.

[464] J. A. Blumenthal, M. A. Babyak, K. A. Moore et al., "Effects of exercise training on older patients with major depression," Archives of Internal Medicine, vol. 159, no. 19, pp. 23492356, 1999.

[465] M. A. Brown, J. Goldstein-Shirley, J. Robinson, and S. Casey, "The effects of a multi-modal intervention trial of light, exercise, and vitamins on women's mood," Women \& Health, vol. 34, no. 3, pp. 93-112, 2001.

[466] L. Danielsson, I. Papoulias, E. L. Petersson, J. Carlsson, and M. Waern, "Exercise or basic body awareness therapy as add-on treatment for major depression: a controlled study," Journal of Affective Disorders, vol. 168, pp. 98106, 2014.
[467] P. de la Cerda, E. Cervello, A. Cocca, and J. Viciana, "Effect of an aerobic training program as complementary therapy in patients with moderate depression," Perceptual and Motor Skills, vol. 112, no. 3, pp. 761-769, 2011.

[468] E. J. Doyne, D. J. Ossip-Klein, E. D. Bowman, K. M. Osborn, I. B. McDougall-Wilson, and R. A. Neimeyer, "Running versus weight lifting in the treatment of depression," Journal of Consulting and Clinical Psychology, vol. 55, no. 5, pp. 748754, 1987.

[469] A. L. Dunn, M. H. Trivedi, J. B. Kampert, C. G. Clark, and H. O. Chambliss, "Exercise treatment for depression: efficacy and dose response," American Journal of Preventive Medicine, vol. 28, no. 1, pp. 1-8, 2005.

[470] F. Euteneuer, M. J. Schwarz, R. Schmidmaier et al., "Blunted exercise-induced mobilization of monocytes in somatization syndromes and major depression," Journal of Affective Disorders, vol. 166, pp. 156-164, 2014.

[471] T. L. Greer, B. D. Grannemann, M. Chansard, A. I. Karim, and M. H. Trivedi, "Dose-dependent changes in cognitive function with exercise augmentation for major depression: results from the TREAD study," European Neuropsychopharmacology, vol. 25, no. 2, pp. 248-256, 2015.

[472] N. Gusi, M. C. Reyes, J. L. Gonzalez-Guerrero, E. Herrera, and J. M. Garcia, "Cost-utility of a walking programme for moderately depressed, obese, or overweight elderly women in primary care: a randomised controlled trial," BMC Public Health, vol. 8, no. 1, p. 231, 2008.

[473] B. M. Hoffman, J. A. Blumenthal, M. A. Babyak et al., "Exercise fails to improve neurocognition in depressed middleaged and older adults," Medicine and Science in Sports and Exercise, vol. 40, no. 7, pp. 1344-1352, 2008.

[474] A. Kerling, U. Tegtbur, E. Gutzlaff et al., "Effects of adjunctive exercise on physiological and psychological parameters in depression: a randomized pilot trial," Journal of Affective Disorders, vol. 177, pp. 1-6, 2015.

[475] N. Kerse, K. J. Hayman, S. A. Moyes et al., "Home-based activity program for older people with depressive symptoms: DeLLITE - a randomized controlled trial," Annals of Family Medicine, vol. 8, no. 3, pp. 214-223, 2010.

[476] F. Legrand and J. P. Heuze, “Antidepressant effects associated with different exercise conditions in participants with depression: a pilot study," Journal of Sport \& Exercise Psychology, vol. 29, no. 3, pp. 348-364, 2007.

[477] S. Leppamaki, T. Partonen, and J. Lonnqvist, "Bright-light exposure combined with physical exercise elevates mood," Journal of Affective Disorders, vol. 72, no. 2, pp. 139-144, 2002.

[478] S. J. Leppamaki, T. T. Partonen, J. Hurme, J. K. Haukka, and J. K. Lonnqvist, "Randomized trial of the efficacy of bright-light exposure and aerobic exercise on depressive symptoms and serum lipids," The Journal of Clinical Psychiatry, vol. 63, no. 4, pp. 316-321, 2002.

[479] K. Martiny, E. Refsgaard, V. Lund et al., "Maintained superiority of chronotherapeutics vs. exercise in a 20-week randomized follow-up trial in major depression," Acta Psychiatrica Scandinavica, vol. 131, no. 6, pp. 446-457, 2015.

[480] A. S. Mather, C. Rodriguez, M. F. Guthrie, A. M. McHarg, I. C. Reid, and M. E. McMurdo, "Effects of exercise on depressive symptoms in older adults with poorly responsive depressive disorder: randomised controlled trial," The British Journal of Psychiatry, vol. 180, no. 5, pp. 411-415, 2002. 
[481] B. W. Penninx, W. J. Rejeski, J. Pandya et al., "Exercise and depressive symptoms: a comparison of aerobic and resistance exercise effects on emotional and physical function in older persons with high and low depressive symptomatology," The Journals of Gerontology Series B, Psychological Sciences and Social Sciences, vol. 57, no. 2, pp. P124-P132, 2002.

[482] F. B. Schuch, M. P. Vasconcelos-Moreno, C. Borowsky, and M. P. Fleck, "Exercise and severe depression: preliminary results of an add-on study," Journal of Affective Disorders, vol. 133, no. 3, pp. 615-618, 2011.

[483] F. B. Schuch, M. P. Vasconcelos-Moreno, C. Borowsky, A. B. Zimmermann, N. S. Rocha, and M. P. Fleck, "Exercise and severe major depression: effect on symptom severity and quality of life at discharge in an inpatient cohort," Journal of Psychiatric Research, vol. 61, pp. 25-32, 2015.

[484] N. A. Singh, K. M. Clements, and M. A. Singh, "The efficacy of exercise as a long-term antidepressant in elderly subjects: a randomized, controlled trial," The Journals of Gerontology Series A, Biological Sciences and Medical Sciences, vol. 56, no. 8, pp. M497-M504, 2001.

[485] E. W. Martinsen, A. Hoffart, and O. Solberg, "Comparing aerobic with nonaerobic forms of exercise in the treatment of clinical depression: a randomized trial," Comprehensive Psychiatry, vol. 30, no. 4, pp. 324-331, 1989.

[486] J. J. Pfaff, H. Alfonso, R. U. Newton, M. Sim, L. Flicker, and O. P. Almeida, "ACTIVEDEP: a randomised, controlled trial of a home-based exercise intervention to alleviate depression in middle-aged and older adults," British Journal of Sports Medicine, vol. 48, no. 3, pp. 226-232, 2014.

[487] D. S. Pereira, B. Z. de Queiroz, A. S. Miranda et al., "Effects of physical exercise on plasma levels of brain-derived neurotrophic factor and depressive symptoms in elderly women-a randomized clinical trial," Archives of Physical Medicine and Rehabilitation, vol. 94, no. 8, pp. 1443-1450, 2013.

[488] C. C. Siqueira, L. L. Valiengo, A. F. Carvalho et al., "Antidepressant efficacy of adjunctive aerobic activity and associated biomarkers in major depression: a 4-week, randomized, single-blind, controlled clinical trial," PLoS One, vol. 11, no. 5, article e0154195, 2016.

[489] N. Sarubin, C. Nothdurfter, C. Schule et al., "The influence of hatha yoga as an add-on treatment in major depression on hypothalamic-pituitary-adrenal-axis activity: a randomized trial," Journal of Psychiatric Research, vol. 53, pp. 76-83, 2014.

[490] J. Krogh, E. Rostrup, C. Thomsen, B. Elfving, P. Videbech, and M. Nordentoft, "The effect of exercise on hippocampal volume and neurotrophines in patients with major depression-a randomized clinical trial," Journal of Affective Disorders, vol. 165, pp. 24-30, 2014.

[491] J. Krogh, J. P. Gotze, M. B. Jorgensen, L. O. Kristensen, C. Kistorp, and M. Nordentoft, "Copeptin during rest and exercise in major depression," Journal of Affective Disorders, vol. 151, no. 1, pp. 284-290, 2013.

[492] J. Krogh, B. Saltin, C. Gluud, and M. Nordentoft, "The DEMO trial: a randomized, parallel-group, observer-blinded clinical trial of strength versus aerobic versus relaxation training for patients with mild to moderate depression," The Journal of Clinical Psychiatry, vol. 70, no. 6, pp. 790-800, 2009.

[493] C. H. Duman, L. Schlesinger, D. S. Russell, and R. S. Duman, "Voluntary exercise produces antidepressant and anxiolytic behavioral effects in mice," Brain Research, vol. 1199, pp. 148-158, 2008.
[494] J. L. Malisch, C. W. Breuner, E. M. Kolb et al., "Behavioral despair and home-cage activity in mice with chronically elevated baseline corticosterone concentrations," Behavior Genetics, vol. 39, no. 2, pp. 192-201, 2009.

[495] A. Otsuka, T. Shiuchi, S. Chikahisa, N. Shimizu, and H. Sei, "Voluntary exercise and increased food intake after mild chronic stress improve social avoidance behavior in mice," Physiology \& Behavior, vol. 151, pp. 264-271, 2015.

[496] S. Lapmanee, J. Charoenphandhu, and N. Charoenphandhu, "Beneficial effects of fluoxetine, reboxetine, venlafaxine, and voluntary running exercise in stressed male rats with anxietyand depression-like behaviors," Behavioural Brain Research, vol. 250, pp. 316-325, 2013.

[497] S. A. Epps, A. B. Kahn, P. V. Holmes, K. A. Boss-Williams, J. M. Weiss, and D. Weinshenker, "Antidepressant and anticonvulsant effects of exercise in a rat model of epilepsy and depression comorbidity," Epilepsy \& Behavior, vol. 29, no. 1, pp. 47-52, 2013.

[498] M. P. Cunha, A. Oliveira, F. L. Pazini et al., "The antidepressant-like effect of physical activity on a voluntary running wheel," Medicine and Science in Sports and Exercise, vol. 45, no. 5, pp. 851-859, 2013.

[499] C. R. Sartori, A. S. Vieira, E. M. Ferrari, F. Langone, E. Tongiorgi, and C. A. Parada, "The antidepressive effect of the physical exercise correlates with increased levels of mature BDNF, and proBDNF proteolytic cleavage-related genes, p11 and tPA," Neuroscience, vol. 180, pp. 9-18, 2011.

[500] H. Zheng, Y. Liu, W. Li et al., "Beneficial effects of exercise and its molecular mechanisms on depression in rats," Behavioural Brain Research, vol. 168, no. 1, pp. 47-55, 2006.

[501] A. Moraska and M. Fleshner, "Voluntary physical activity prevents stress-induced behavioral depression and antiKLH antibody suppression," American Journal of Physiology. Regulatory, Integrative and Comparative Physiology, vol. 281, no. 2, pp. R484-R489, 2001.

[502] A. Bjornebekk, A. A. Mathe, and S. Brene, "The antidepressant effects of running and escitalopram are associated with levels of hippocampal NPY and Y1 receptor but not cell proliferation in a rat model of depression," Hippocampus, vol. 20, no. 7, pp. 820-828, 2010.

[503] B. N. Greenwood, P. V. Strong, A. A. Dorey, and M. Fleshner, "Therapeutic effects of exercise: wheel running reverses stress-induced interference with shuttle box escape," Behavioral Neuroscience, vol. 121, no. 5, pp. 992-1000, 2007.

[504] J. G. Hunsberger, S. S. Newton, A. H. Bennett et al., “Antidepressant actions of the exercise-regulated gene VGF," Nature Medicine, vol. 13, no. 12, pp. 1476-1482, 2007.

[505] C. P. Hutton, N. Dery, E. Rosa et al., "Synergistic effects of diet and exercise on hippocampal function in chronically stressed mice," Neuroscience, vol. 308, pp. 180-193, 2015.

[506] T. Kiuchi, H. Lee, and T. Mikami, "Regular exercise cures depression-like behavior via VEGF-Flk-1 signaling in chronically stressed mice," Neuroscience, vol. 207, pp. 208-217, 2012.

[507] K. Tal-Krivisky, N. Kronfeld-Schor, and H. Einat, "Voluntary exercise enhances activity rhythms and ameliorates anxietyand depression-like behaviors in the sand rat model of circadian rhythm-related mood changes," Physiology \& Behavior, vol. 151, pp. 441-447, 2015.

[508] S. Y. Yau, A. Li, E. D. Zhang et al., "Sustained running in rats administered corticosterone prevents the development of 
depressive behaviors and enhances hippocampal neurogenesis and synaptic plasticity without increasing neurotrophic factor levels," Cell Transplantation, vol. 23, no. 4-5, pp. 481-492, 2014.

[509] B. N. Greenwood, A. B. Loughridge, N. Sadaoui, J. P. Christianson, and M. Fleshner, "The protective effects of voluntary exercise against the behavioral consequences of uncontrollable stress persist despite an increase in anxiety following forced cessation of exercise," Behavioural Brain Research, vol. 233, no. 2, pp. 314-321, 2012.

[510] B. D. Hare, J. A. Beierle, D. J. Toufexis, S. E. Hammack, and W. A. Falls, "Exercise-associated changes in the corticosterone response to acute restraint stress: evidence for increased adrenal sensitivity and reduced corticosterone response duration," Neuropsychopharmacology, vol. 39, no. 5, pp. 1262-1269, 2014.

[511] P. J. Clark, J. Amat, S. O. McConnell et al., "Running reduces uncontrollable stress-evoked serotonin and potentiates stress-evoked dopamine concentrations in the rat dorsal striatum," PLoS One, vol. 10, no. 11, article e0141898, 2015.

[512] B. N. Greenwood, P. V. Strong, T. E. Foley, R. S. Thompson, and M. Fleshner, "Learned helplessness is independent of levels of brain-derived neurotrophic factor in the hippocampus," Neuroscience, vol. 144, no. 4, pp. 1193-1208, 2007.

[513] J. Fuss, N. M. Ben Abdallah, M. A. Vogt et al., "Voluntary exercise induces anxiety-like behavior in adult C57BL/6J mice correlating with hippocampal neurogenesis," Hippocampus, vol. 20, no. 3, pp. 364-376, 2010.

[514] R. S. Thompson, R. Roller, B. N. Greenwood, and M. Fleshner, "Wheel running improves REM sleep and attenuates stressinduced flattening of diurnal rhythms in F344 rats," Stress, vol. 19, no. 3, pp. 312-324, 2016.

[515] B. N. Greenwood, P. V. Strong, A. B. Loughridge et al., "5HT2C receptors in the basolateral amygdala and dorsal striatum are a novel target for the anxiolytic and antidepressant effects of exercise," PLoS One, vol. 7, no. 9, article e46118, 2012.

[516] S. A. Martin, R. Dantzer, K. W. Kelley, and J. A. Woods, "Voluntary wheel running does not affect lipopolysaccharideinduced depressive-like behavior in young adult and aged mice," Neuroimmunomodulation, vol. 21, no. 1, pp. 52-63, 2014.

[517] Y. Li, B. W. Luikart, S. Birnbaum et al., “TrkB regulates hippocampal neurogenesis and governs sensitivity to antidepressive treatment," Neuron, vol. 59, no. 3, pp. 399-412, 2008. 

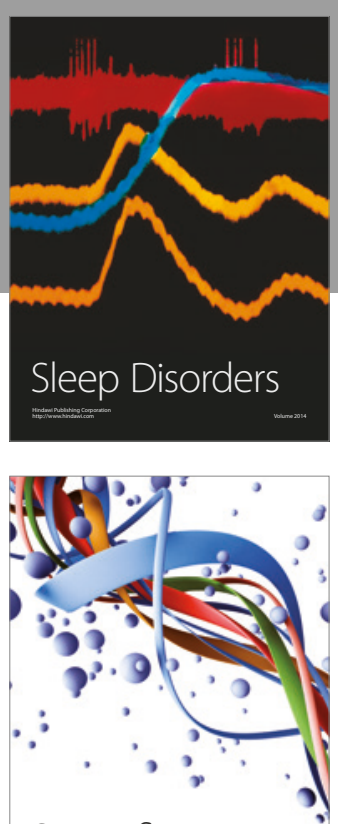

Scientifica
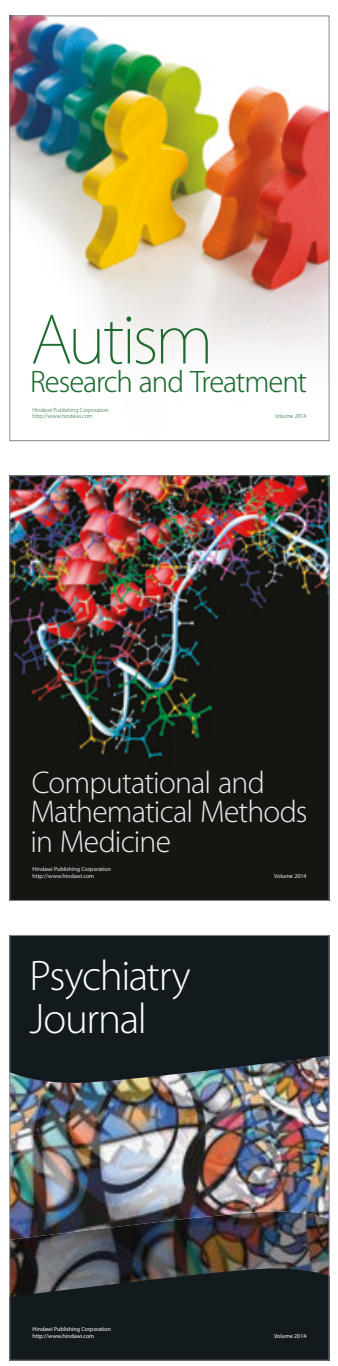
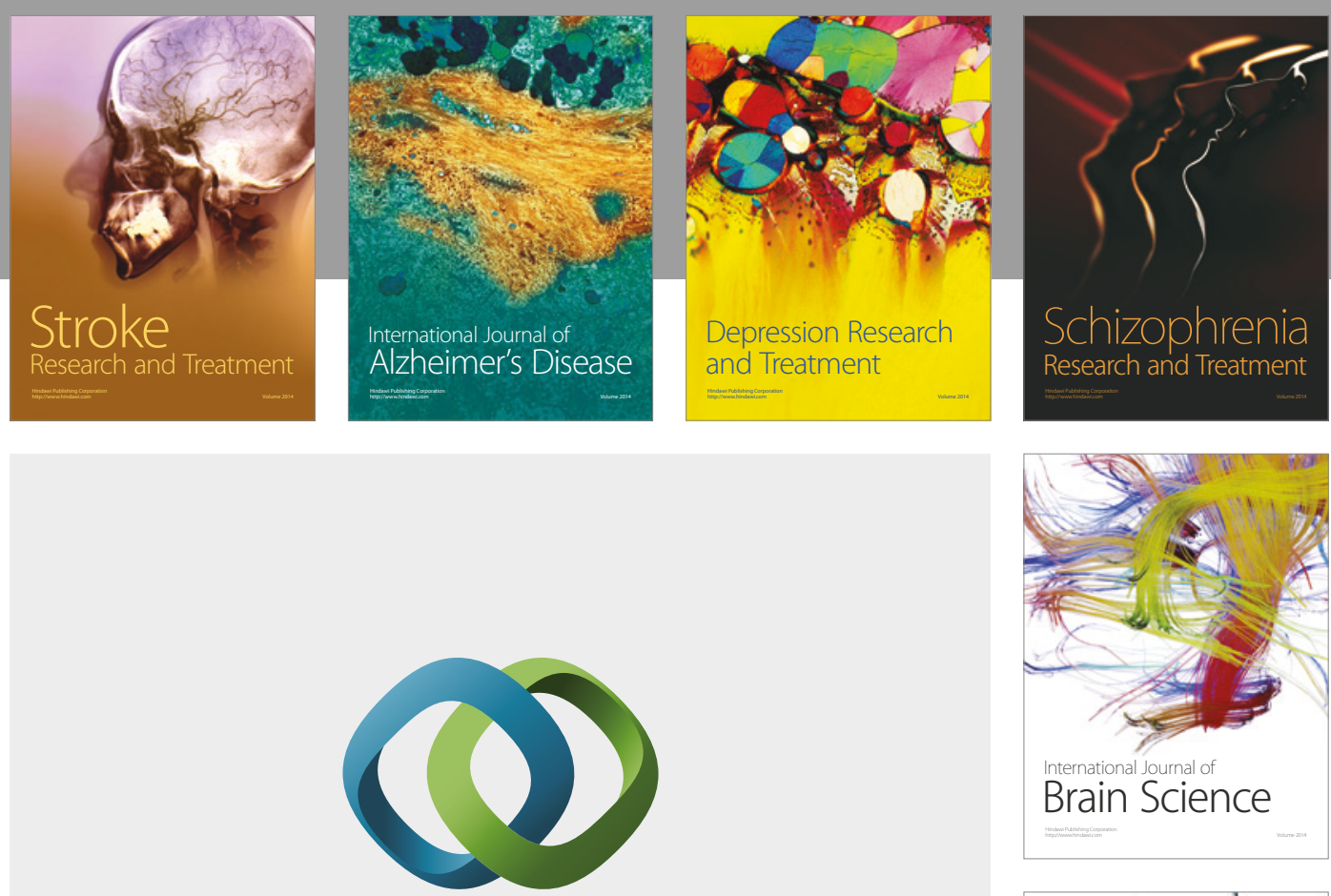

\section{Hindawi}

Submit your manuscripts at

https://www.hindawi.com
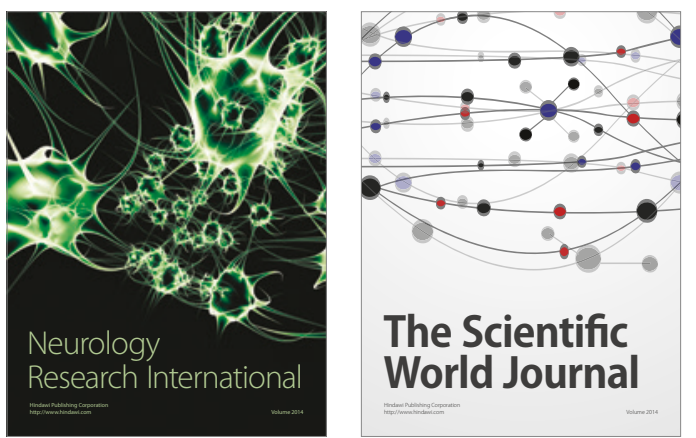

The Scientific World Journal

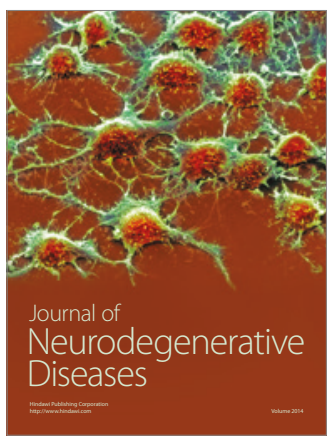

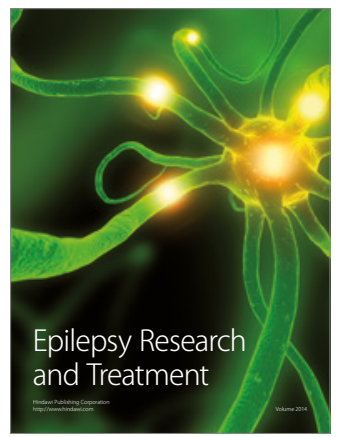

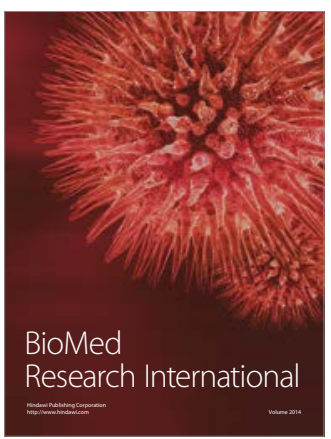

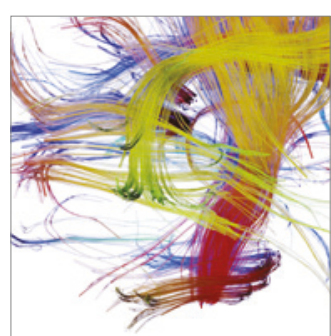

Brain Science

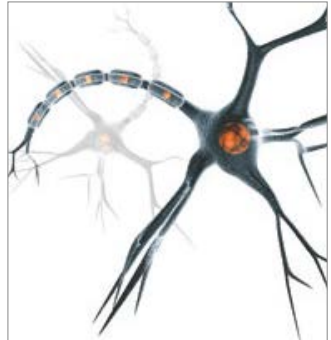

Neural Plasticity
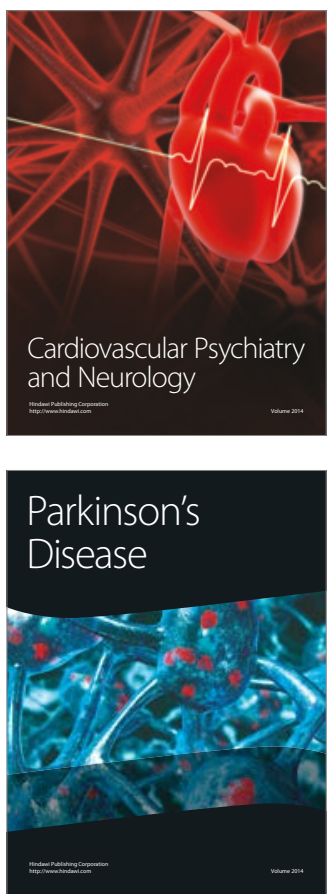